\title{
FORÇA MUSCULAR DO ASSOALHO PÉLVICO DE PRIMÍPARAS SEGUNDO O TIPO DE PARTO: ESTUDO DE COORTE
}

\author{
Versão corrigida da Dissertação \\ apresentada ao Programa Pós- \\ Graduação em Enfermagem da Escola \\ de Enfermagem da Universidade de São \\ Paulo para obtenção do título de Mestre \\ em Ciências.
}

Área de concentração: Cuidado em Saúde

Orientadora: $\operatorname{Prof}^{\mathrm{a}}$. $\operatorname{Dr}^{\mathrm{a}}$. Sonia M. Junqueira Vasconcellos de Oliveira

\section{VERSÃO CORRIGIDA}

A versão original encontra-se disponível na Biblioteca da Escola de Enfermagem da Universidade de São Paulo e na Biblioteca Digital de Teses e Dissertações da Universidade de São Paulo.

\section{SÃO PAULO}


AUTORIZO A REPRODUÇÃO E DIVULGAÇÃO TOTAL OU PARCIAL DESTE TRABALHO, POR QUALQUER MEIO CONVENCIONAL OU ELETRÔNICO, PARA FINS DE ESTUDO E PESQUISA, DESDE QUE CITADA A FONTE.

Assinatura:

Data:

Oliveira, Sheyla Guimarães

Força muscular do assoalho pélvico de primíparas segundo o tipo de parto: estudo de Coorte / Sheyla Guimarães Oliveira. São Paulo, 2017.

$124 \mathrm{p}$.

Dissertação (Mestrado) - Escola de Enfermagem da Universidade de São Paulo.

Orientadora: Prof. ${ }^{a}$ Dr. ${ }^{a}$ Sonia Maria Junqueira Vasconcellos de Oliveira

Área de concentração: Cuidado em Saúde

1. Força muscular. 2. Períneo. 3. Parto. 4. Assoalho pélvico. 5. Enfermagem obstétrica. I. Título. 


\section{Nome: Sheyla Guimarães Oliveira}

Título: Força muscular do assoalho pélvico de primíparas segundo o tipo de parto: estudo de coorte

Dissertação apresentada ao Programa de Pós-Graduação em Enfermagem da Escola de Enfermagem da Universidade de São Paulo para a obtenção do título de Mestre em Ciências.

Aprovada em:

\section{Banca Examinadora}

Prof. Dr. Instituição:

Julgamento: Assinatura:

Prof. Dr. Instituição:

Julgamento: Assinatura:

Prof. Dr. Instituição:

Julgamento: Assinatura: 
Dedico este trabalho aos meus amados familiares 


\section{Agradecimentos}

ao bondoso Deus por me conduzir nessa jornada, carregar meus fardos e por colocar em minha vida as pessoas aqui citadas | à minha orientadora sonia junqueira por me receber como aluna, ensinando com muita paciência e dedicação. Em especial à professora adriana caroci que me incentivou a trilhar este caminho e me acompanhou nas lutas e desafios $\mid$ ao meu marido robson pela compreensão, apoio nas horas difíceis $\mid$ aos meus filhos gustavo e gabriela por entenderem minhas ausências, pelo carinho e amor demonstrado | aos meus pais josé paulo e cleyde, que sempre me animaram com palavras positivas e encorajamento | ao meu irmão aguinaldo pelo exemplo de força, determinação e por me ajudar em algumas traduções | minha cunhada marziani pela amizade, carinho e atenção | aos meus sobrinhos yuri e natasha pelas demonstrações de carinho e também ajuda nas traduções | amiga da EEUSP edilaine que se tornou uma amiga para toda vida, por compartilhar conhecimento, experiência e amizade | aos funcionários da maternidade zoraide e das unidades básicas de saúde de itapecerica da serra que me receberam e me ajudaram durante a coleta de dados, possibilitaram a realização deste trabalho e a grande pessoa e amiga maísa que sempre me acalmou com palavras engraçadas que não posso citar aqui | ao douglas que sempre se prontificou a me ajudar com as digitações | à minha chefe silvia que incondicionalmente me ajudou liberando no horário de trabalho e me incentivando a crescer nos estudos, sem ela eu não teria conseguido | aos estatísticos luís e bernardo pela ajuda fundamental | às puérperas que aceitaram participar voluntariamente e a outras pessoas não citadas, que contribuíram de forma direta ou indireta para que esse estudo fosse realizado.

\section{Sheyla Guimarães Oliveira}


Combati o bom combate, completei a carreira, guardei a fé.

2 Timóteo 4:7 
Oliveira SG. Força muscular do assoalho pélvico de primíparas segundo o tipo de parto: estudo de coorte [dissertação]. São Paulo: Escola de Enfermagem, Universidade de São Paulo; 2017.

\section{RESUMO}

Introdução: $O$ parto pode influenciar a força muscular do assoalho pélvico (FMAP), com possíveis morbidades do trato gênito-urinário e anal de forma transitória ou permanente. Objetivos: 1. Investigar a prevalência de infecção do trato urinário, incontinência urinária, incontinência anal e dispareunia, em primíparas com 50 a 70 ( 2 meses) e 170 a 190 dias (6 meses) após o parto. 2. Analisar a variação FMAP, mediante perineometria em primíparas de acordo com o tipo de parto, idade materna, escolaridade, cor da pele, situação conjugal, ocupação, índice de massa corpórea (IMC), infecção do trato urinário (ITU), incontinência urinária (IU) e anal (IA), exercícios perineais, dispareunia, intervenções e condições do períneo no parto e do recém-nascido (RN), com 50 a 70 e 170 a 190 dias após o parto. Método: Coorte prospectiva com 99 primíparas recrutadas em maternidade pública de Itapecerica da Serra, São Paulo. Colheramse os dados em três etapas: a $1^{\mathrm{a}}$, na internação hospitalar, até o momento da alta; a $2^{\mathrm{a}}$ e $3^{\mathrm{a}}, 50-70$ dias e 170-190 dias após o parto, respectivamente, nas quais foi mensurada a FMAP. O trabalho foi aprovado pelo Comitê de Ética e Pesquisa da Escola de Enfermagem da Universidade de São Paulo (CAAE:13545113.5.0000.5392). Resultados: Considerando o período anterior à gestação houve um aumento de 13,1 pontos percentuais (p.p.) na prevalência de IU na gestação e uma redução de 16,1 (p.p.) e de 21,2 (p.p.) aos dois e aos seis meses pós-parto, respectivamente. A prevalência de IA, foi de $6,1 \%$, aos dois meses após o parto e aos seis meses, somente uma mulher persistiu com incontinência de flatos. Aos dois e seis meses pós-parto, a prevalência de dispareunia foi referida por 44,3\% e 9,5\% das mulheres, respectivamente. Apesar da maior média da FMAP das mulheres após o parto normal comparada à cesariana $\left(22,0\right.$ e $21,0 \mathrm{cmH}_{2} \mathrm{O}$, na etapa 2 versus 26,8 e $24,4 \mathrm{cmH}_{2} \mathrm{O}$, na etapa3, respectivamente), não houve diferença estatística $(\mathrm{p}=0,508)$. A análise bivariada apontou diferença estatística nas médias da FMAP em relação à idade $(\mathrm{p}=0,001)$, e o exercício perineal ficou próximo da significância $(p=0,054)$. Não foram observadas interações entre idade e exercícios com as etapas 2 e 3. Também ocorreu associação significante entre FMAP de mulheres que relataram ITU $(\mathrm{p}=0,012)$ e aquelas sem IU $(\mathrm{p}=0,021)$. Foi obtida maior FMAP entre as participantes que não receberam anestesia $(\mathrm{p}=0,028)$, com diferença estatística. A FMAP não diferiu quanto às variáveis cor da pele, situação conjugal, ocupação, IMC, dispareunia, intervenções no parto e condições do RN. A análise pelo modelo longitudinal preditivo mostrou associação estatística entre idade, exercício e FMAP ( $\mathrm{p}=0,005)$, indicando diminuição da FMAP em 0,709 a cada ano de vida da mulher e aumento de 3,359 $\mathrm{cmH}_{2} \mathrm{O}$ na média da FMAP naquelas que realizaram exercícios perineais. Conclusão: A FMAP não difere quanto ao tipo de parto. As primíparas, com ITU e sem IU, que realizaram exercícios perineais e que não receberam anestesia local apresentaram estatísticamente maior FMAP. 
Não foi possível realizar análise comparativa da IA devido ao baixo número de ocorrências. As prevalências de IU, IA e dispareunia foram menores com seis meses após o parto.

PALAVRAS-CHAVE: Assoalho pélvico. Incontinência urinária. Dispareunia. Períneo. Enfermagem obstétrica. Lacerações. 
Oliveira SG. Pelvic floor muscle strength in primiparous women according to type of delivery: a cohort study [dissertation]. São Paulo: Escola de Enfermagem, Universidade de São Paulo; 2017.

\begin{abstract}
Introduction: The childbirth can affect the pelvic floor muscle strength (PFMS), with possible morbidity in the genitourinary and anal tracts in a transitory or permanent way. Objectives: 1 . To investigate the prevalence of urinary tract infection, urinary incontinence, anal incontinence and dyspareunia, in primiparas with 50 to 70 days (2months) and 170 to 190 days (6 months) after delivery. 2. To analyze the PFMS variation, through perineometry in primiparas according to the type of delivery, mother's age, school background, skin color, marital status, occupation, body mass index (BMI), urinary tract infection (UTI), urinary incontinence (UI), anal incontinence (AI), perineal exercises, dyspareunia, interventions and conditions of the perineum during childbirth and of the newborn baby (NB), at 50 to 70 and 170 to 190 days after birth. Methodology: Prospective cohort with 99 primiparas recruited from a public maternity in Itapecerica da Serra, Sao Paulo. The data collection was realized in three steps: the $1^{\text {st }}$, from the hospital admittance until the hospital discharge; the $2^{\text {nd }}$ and $3^{\text {rd }}$, 50-70 days and 170-190 days after delivery, respectively, in which we measured the PFMS. The study was approved by the Ethics and Research Committee at the University of Sao Paulo Nursing School (CAAE:13545113.5.0000.5392). Results: Taking into consideration the period prior to the pregnancy, there was an increase of 13.1 percent points (p.p.) in the prevalence of UI during gestation and a decrease of 16.1 (p.p.) and of 21.2 (p.p.) at two and at six months postpartum, respectively. The prevalence of AI was of $6.1 \%$ at two months postpartum and, at six months, only one woman remained with flatus incontinence. At two and six months, the prevalence of dyspareunia was referred to by $44.3 \%$ and $9.5 \%$ of women, respectively. Despite the greater average of women's PFMS after normal labor in comparison with the c-section (22.0 and $21.0 \mathrm{cmH}_{2} \mathrm{O}$ versus 26.8 and $24.4 \mathrm{cmH}_{2} \mathrm{O}$, at the $3^{\text {rd }}$ step, respectively), there was no statistical difference $(\mathrm{p}=0.508)$. The bivariate analysis showed statistical difference in the PFMS average regarding age $(\mathrm{p}=0.001)$ and the perineal exercise remained near the significance $(\mathrm{p}=0.054)$. We did not observe interactions between age and exercise during steps 2 and 3. There was also significant association between the PFMS of women who reported UTI $(\mathrm{p}=0.012)$ and those with no UI $(\mathrm{p}=0.021)$. A greater PFMS was obtained among the participants who were not anesthetized $(\mathrm{p}=0.028)$, with statistical difference. The PFMS did not differ as to the variables skin color, marital status, occupation, BMI, dyspareunia, labor interventions and the NB conditions. The analysis by the longitudinal predictive model showed statistical association between age, exercise and PFMS, indicating decrease in the PFMS of 0.709 each year in the woman's life and increase of 3.359 $\mathrm{cmH} 2 \mathrm{O}$ in the PFMS average in those who carried out perineal exercises. Conclusion: The PFMS does not differ as to the delivery type. The primiparas, with UTI and without UI, who carried out perineal exercises and who did not receive local anesthetic presented greater statistical PFMS. It was not possible to perform a comparative analysis of the AI due to the low number of occurrences. The prevalences of UI, AI and dyspareunia were smaller within six months after childbirth.
\end{abstract}

KEYWORDS: Pelvic Floor. Urinary Incontinence. Dyspareunia. Perineum. Obstetric Nursing. Lacerations. 


\section{LISTA DE FIGURAS E QUADRO}

Figura 1 - Músculos do assoalho pélvico 20

Figura 2 - Perineômetro de pressão, com sensor vaginal, Peritron ${ }^{\mathrm{TM}}$, Laborie, Canadá 49

Figura 3 - Ordinograma do método utilizado no estudo, Itapecerica da Serra, SP - 2017 _ 55 Figura 4 - Fluxograma referente ao recrutamento das participantes do estudo transversa1 e da coorte, Itapecerica da Serra, SP - 2014 a 2016 59 Figura 5 - Representação da associação da força muscular do assoalho pélvico (FMAP) com o tipo de parto, de acordo com as etapas 2 e 3, Itapecerica da Serra, SP - 2014 a 2016 68 Figura 6 - Representação da associação da força muscular do assoalho pélvico (FMAP) com a incontinência urinária que persiste nas etapas 2 e 3, Itapecerica da Serra, SP - 2014 a 201673 Figura 7 - Representação da associação da força muscular do assoalho pélvico (FMAP) com o exercício perineal nas etapas 2 e 3, Itapecerica da Serra, SP - 2014 a 2016 74 Figura 8 - Representação da associação da força muscular do assoalho pélvico (FMAP) e o reparo perineal sob anestesia nas etapas 2 e 3, Itapecerica da Serra, SP - 2014 a 2016 76 Figura 9 - Representação da dispersão da idade, exercício perineal e força muscular do assoalho pélvico (FMAP), de acordo com as etapas 2 e 3, Itapecerica da Serra, SP - 2014 a 2016 78

Quadro 1 - Estudos sobre a FMAP, durante o ciclo gravídico-puerperal, em relação IU, IA e a Dispareunia, São Paulo, SP - 2017 34 


\section{LISTA DE TABELAS}

Tabela 1 - Cronograma das etapas de coleta de dados, Itapecerica da Serra - 2014 a $2016 \ldots .57$

Tabela 2 - Número e percentagem de primíparas segundo as características

sociodemográficas e hábitos comportamentais, Itapecerica da Serra, SP - 2014 a 2016

Tabela 3 - Estatística descritiva das variáveis quantitativas segundo as características

sociodemográficas e clínicas, Itapecerica da Serra, SP - 2014 a 2016 (n=99)

Tabela 4 - Número e percentagem de primíparas segundo sintomas do trato genito-urinário,

IA e exercícios perineais, Itapecerica da Serra, SP - 2014 a 2016 (n=99).....

Tabela 5 - Número e percentagem de primíparas, segundo o retorno à atividade sexual,

motivo de não retorno à atividade sexual, dispareunia e uso de contraceptivo nas etapas 2 e 3 ,

Itapecerica da Serra, SP - 2014 a 2016.

Tabela 6 - Número e percentagem de primíparas, de acordo com os dados do parto,

Itapecerica da Serra, SP - 2014 a 2016.

Tabela 7 - Medidas de tendência central e dispersão dos dados clínicos do recém-nascido (RN), Itapecerica da Serra, SP - 2014 a 2016 (n=99).

Tabela 8 - Estatística descritiva das médias da FMAP $\left(\mathrm{cmH}_{2} \mathrm{O}\right)$ nas etapas 2 e 3, Itapecerica da Serra, SP - 2014 a $2016(n=99)$......

Tabela 9 - Comparação da força muscular do assoalho pélvico (FMAP) de primíparas por meio da perineometria segundo o tipo de parto nas etapas 2 e 3, Itapecerica da Serra, SP 2014 a $2016(n=99)$.

Tabela 10 - Comparação da força muscular do assoalho pélvico (FMAP) de primíparas de acordo com a idade e escolaridade nas etapas 2 e 3, Itapecerica da Serra, SP - 2014 a 2016.69 Tabela 11 - Comparação da força muscular do assoalho pélvico (FMAP) de primíparas de acordo com as características sociodemográficas nas etapas 2 e 3, Itapecerica da Serra, SP 2014 a $2016(n=99)$.

Tabela 12 - Comparação da força muscular do assoalho pélvico (FMAP) de primíparas de acordo com o índice de massa corpórea (IMC) nas etapas 2 e 3, Itapecerica da Serra, SP 2014 a $2016(n=99)$.

Tabela 13 - Comparação da força muscular do assoalho pélvico (FMAP) de acordo com as características do trato genito-urinário e dispareunia nas etapas 2 e 3, Itapecerica da Serra, SP - 2014 a $2016(n=99)$.

Tabela 14 - Comparação da força muscular do assoalho pélvico (FMAP) de acordo com o exercício perineal nas etapas 2 e 3, Itapecerica da Serra, SP - 2014 a 2016 (n=99) . 
Tabela 15 - Comparação da força muscular do assoalho pélvico (FMAP) após parto normal, de acordo com as intervenções no parto nas etapas 2 e 3, Itapecerica da Serra, SP - 2014 a $2016(n=74)$

Tabela 16 - Comparação da força muscular do assoalho pélvico (FMAP), de acordo com as condições do períneo após o parto normal nas etapas 2 e 3, Itapecerica da Serra, SP - 2014 a $2016(n=74)$

Tabela 17 - Comparação da força muscular do assoalho pélvico (FMAP) de primíparas de acordo com os dados do recém-nascido (RN) nas etapas 2 e 3, Itapecerica da Serra, SP - 2014 a 2016

Tabela 18 - Modelo longitudinal preditivo para FMAP com base nas etapas 2 e 3, idade e exercício perineal, Itapecerica da Serra, SP - 2014 a 2016. 


\section{SUMÁRIO}

\section{RESUMO}

\section{ABSTRACT \\ LISTA DE FIGURAS E QUADRO \\ LISTA DE TABELAS}

INTRODUCÃO

1.1 ANATOMIA DO ASSOALHO PÉLVICO .

1.2 DISFUNÇÕES DO ASSOALHO PÉLVICO RELACIONADAS À GRAVIDEZ, AO PARTO E AO PÓS-PARTO

1.3 MÉTODOS UTILIZADOS PARA ANALISAR A FORÇA MUSCULAR DO ASSOALHO PÉLVICO.

1.4 EXERCÍCIOS UTILIZADOS PARA FORTALECER OS MÚSCULOS DO ASSOALHO PÉLVICO

1.5 ASSISTÊNCIA OBSTÉTRICA ÀS PUÉRPERAS COM DISFUNÇÕES DO ASSOALHO PÉLVICO.

OBJETIVOS

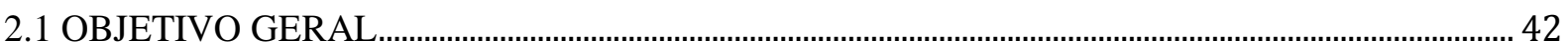

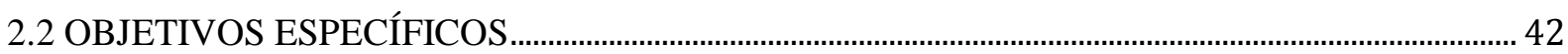

MÉTODO

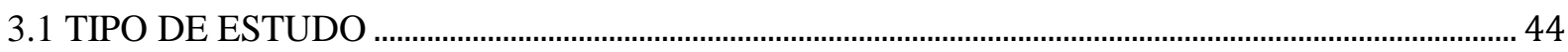

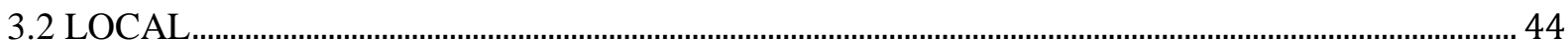

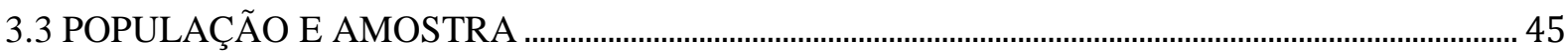

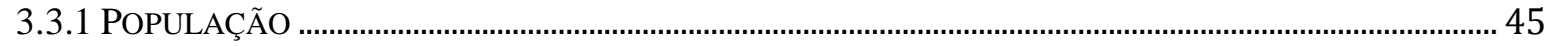

3.3.2 CRITÉRIOS DE INCLUS ÃO DOS ESTUDOS TRANSVERSAL ................................................................ 45

3.3.3 CRITÉRIOS DE INCLUS ÃO DA COORTE................................................................................................... 46

3.3.4 CRITÉRIO DE EXCLUSÃO DOS ESTUDOS TRANSVERSAL E COORTE..................................................... 46

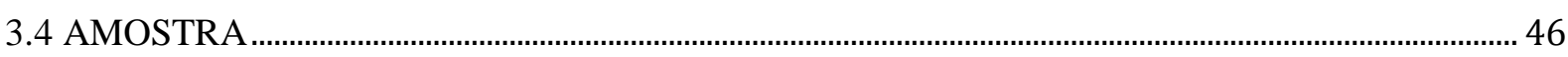

3.5 COLETA DE DADOS .................................................................................................................. 47

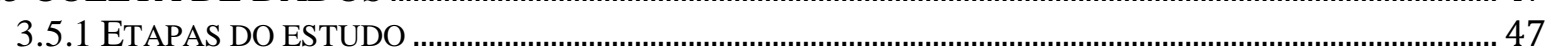

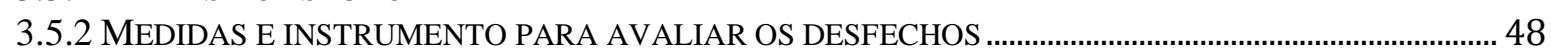

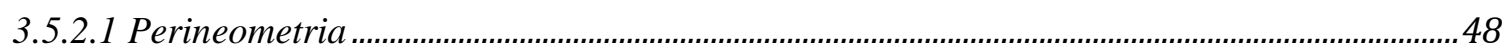

3.5.2.2 PROCEDIMENTOS PARA MENSURAR A FMAP NO ESTUDO TRANSVERSAL E NA COORTE

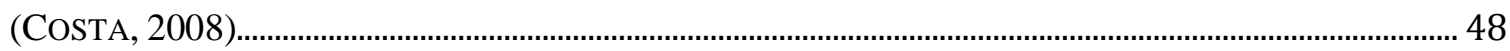

3.5.2.3 International Consultation on Incontinence Questionnaire-Short Form (ICIQ-SF) ...........50

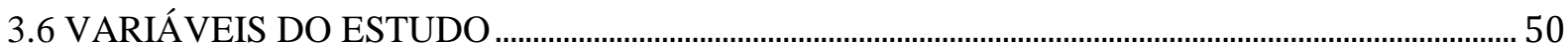

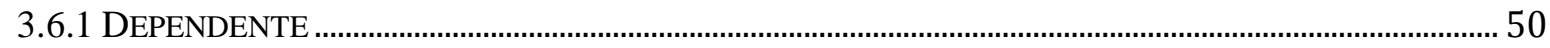

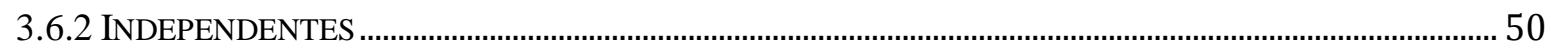

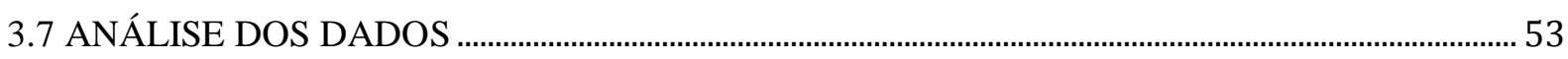

3.8 ASPECTOS ÉTICOS........................................................................................................................ 54 
3.9 APRESENTAÇÃO DO PERÍODO EM QUE HOUVE INÍCIO E TÉRMINO DA COLETA DE DADOS DAS PUÉRPERAS NAS TRÊS ETAPAS ............................................................................................ 57

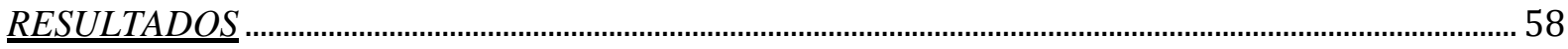

4.1 CARACTERIZAÇÃO DA AMOSTRA.......................................................................................................... 60

4.2 ANÁLISE COMPARATIVA DA FMAP ............................................................................................................ 67

DISCUSSÃO

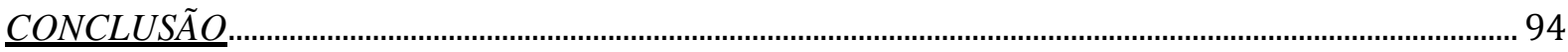

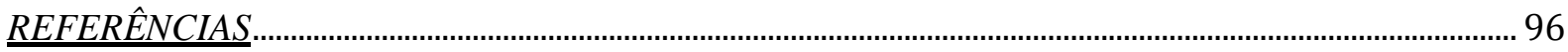

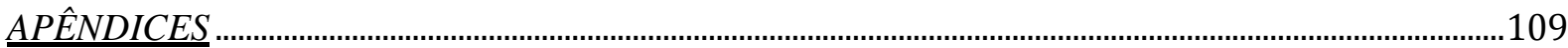

APÊNDICE 1 …...................................................................................................................110

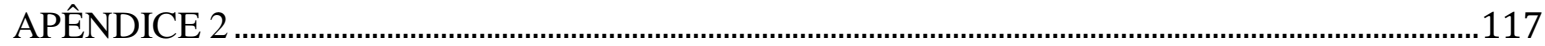

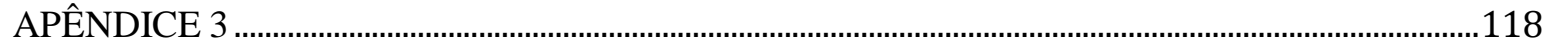

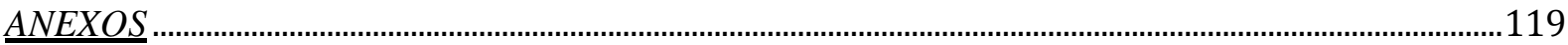

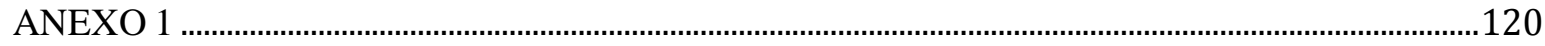

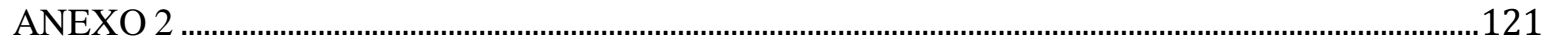

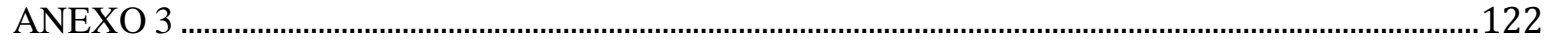

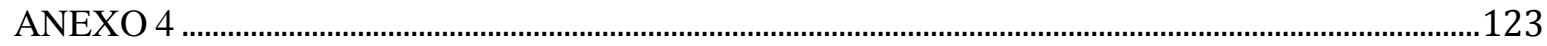


$\mathrm{Na}$ gestação, ocorrem diversas alterações anatômicas e fisiológicas no corpo da mulher a fim de prepará-la para sustentar o feto durante os nove meses e aprontá-la para o trabalho de parto e parto. As alterações que acometem a musculatura pélvica estão associadas ao aumento da vascularização vaginal, ao afrouxamento do tecido conjuntivo e à hipertrofia da musculatura lisa vulvar e vaginal (Fleming, Newton, Roberts, 2003; Montenegro, Rezende Filho, 2014). Alguns autores consideram que o parto normal (PN) e o instrumental estejam mais relacionados às alterações que ocorrem no assoalho pélvico (AP) quando comparadas às mulheres que são submetidas às cesarianas, mas acreditam que estas também podem apresentar algumas alterações no AP (Blomquist, McDermott, Handa, 2014; Rikard-Bell, Iyer, Rane, 2014). Essas mudanças que ocorrem no AP podem levar a disfunções dos músculos do esfíncter anal e, consequentemente, provocar prolapsos genitais, incontinência urinária (IU), incontinência anal (IA), dispareunia, dor pélvica não associada à menstruação ou à relação sexual e a outras morbidades (Glazener, Cooper, 2003; Andrews et al., 2006; Buhling et al., 2006; Blomquist, McDermontt, Handa, 2014; Brown et al., 2014; Petricelli et al., 2014; Yeniel, Petri, 2014; Bø et al., 2015; Dumoulin et al., 2015; Sut, Kaplan, 2016).

Apoiando a teoria de que a gestação e o parto causam impacto nos músculos do assoalho pélvico (MAP), alguns estudos mostram que a FMAP foi menor entre as mulheres com PN ou com cesárea anterior em relação à nulíparas (Elenskaia et al., 2011; Caroci et al., 2014), porém essa diminuição da FMAP pode ser temporária, pois a contratilidade parece recuperar-se um ano após o parto, independentemente do tipo de parto (Elenskaia et al., 2011; Silva et al., 2013). Outro estudo não encontrou associação entre o parto normal e a cesariana com a dispareunia, mas sim com o parto fórcipe e com bebê pesando mais do que quatro quilogramas. No entanto, sugerem que essa associação ocorre apenas nos primeiros seis meses depois do parto (Blomquist, McDermott, Handa, 2014).

Além da gestação e do parto, outros fatores mecânicos, endócrinos e neurais também podem causar diminuição da força muscular do assoalho pélvico (FMAP) e essa alteração pode ser constatada pela realização de diferentes exames como: perineometria, eletromiografia de superfície, palpação digital vaginal, manometria, ultra-sonografia, estudos urodinâmicos e neurofisiológicos do AP (Braekken et al., 2009; Resende et al., 2011; Vasconcelos, Ribeiro, 2013; Petricelli et al., 2014). A mensuração da FMAP é mais comum utilizando o método da perineometria e da palpação digital vaginal (Petricelli et al., 2014; Tennfjord et al., 2014). 
Costa et al. (2014) afirmam que mais estudos devem ser feitos sobre a mensuração da FMAP com o objetivo de estabelecer seu perfil na gestação e no puerpério e, assim, poder diagnosticar e tratar as morbidades causadas pela diminuição dessa força.

Diante disso, como mulher, enfermeira obstétrica e defensora do PN, tenho preocupação com a análise da FMAP tanto em mulheres que têm partos normais como entre aquelas que são submetidas às cesarianas. Este trabalho objetiva contribuir para a construção de um perfil da FMAP e fornecer dados para elaborar programas de treinamento do assoalho pélvico (PTMAP), buscando a prevenção e a redução de morbidades causadas no trato gênitourinário e anal que podem surgir durante a gestação e/ou parto e continuar no pós-parto. Este estudo propõe responder aos seguintes questionamentos: $\mathrm{O}$ tipo de parto pode diminuir a FMAP? O PN aumenta os sintomas do trato gênito-urinário e de incontinência anal durante o pós-parto? A FMAP da mulher com 50 a 70 dias após o parto é menor do que aos 170 a 190 dias após o parto? A FMAP é maior entre as puérperas que tiveram lacerações perineais espontâneas no parto do que aquelas que tiveram episiotomia? A diminuição da FMAP no pós-parto é transitória?

\subsection{ANATOMIA DO ASSOALHO PÉLVICO}

As estruturas do AP possuem duas principais funções: uma é fechar as cavidades pélvica e abdominal e, assim, suportar a carga dos órgãos viscerais contidos na cavidade abdominal e a outra é controlar as aberturas do reto e órgãos urogenitais (Calais-Germain, 2005).

O AP é composto de várias camadas sobrepostas de músculos e tecidos conjuntivos chamados de diafragma pélvico. O diafragma pélvico tem por função sustentar a musculatura do AP que constitui o períneo em que se encontram os músculos levantador do ânus e o isquiococcígeo. O diafragma urogenital é constituído pelos músculos transverso superior do períneo, bulboesponjoso, isquiocavernoso e esfíncter externo do ânus (Bunduki, Cabar, Nomura, 2012; Montenegro, Rezende Filho, 2014). Para Oliveira (2006), preservar a integridade do AP é fundamental a fim de manter a continência urinária. 
Figura 1 - Músculos do assoalho pélvico

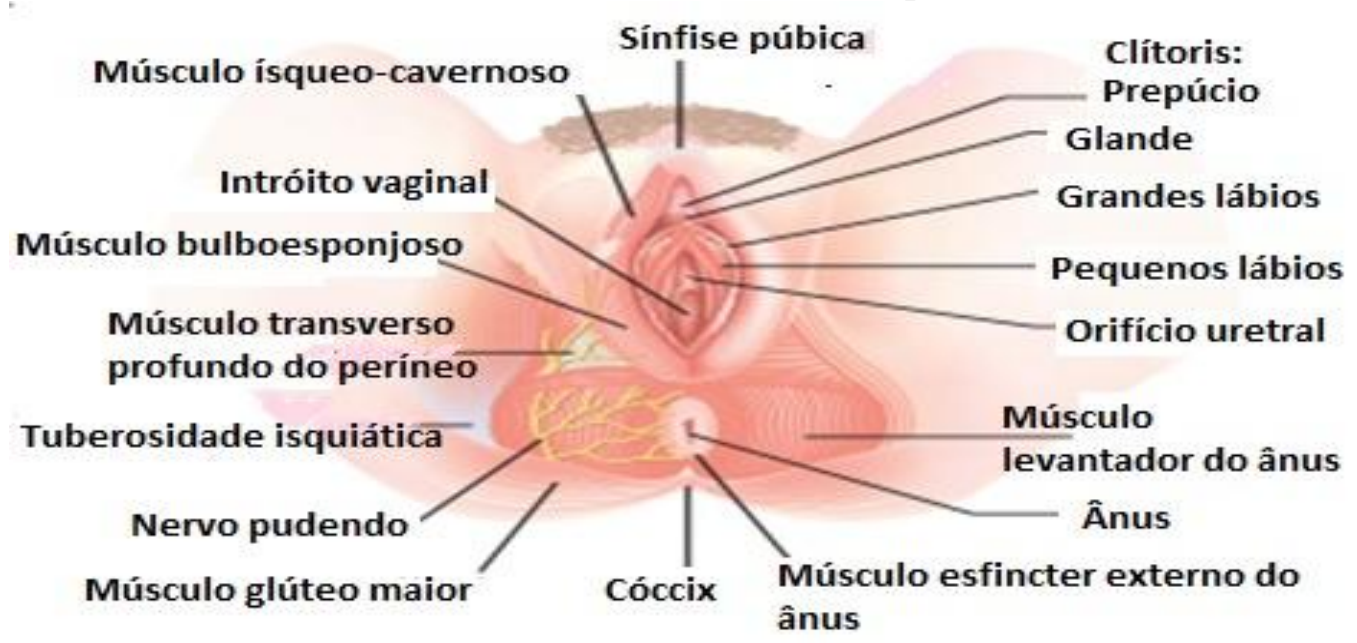

Fonte: Cabar et al. 2016, p.47.

O períneo é um conjunto de partes moles composto pelos músculos e pela aponeurose, sendo uma região limitada, anteriormente, pela sínfise púbica, posteriormente, pelo cóccix, lateralmente, pelas tuberosidades isquiáticas e com formato de um losango. O traçado da linha bi-isquiática divide o períneo em região anterior ou genital, composto pelos órgãos genitais externos (uretra e vagina) e região anal posterior, contendo o ânus. (Montenegro, Rezende Filho, 2014; Cabar, Codarin, Bunduki , 2016).

\subsection{DISFUNÇÕES DO ASSOALHO PÉLVICO RELACIONADAS À GRAVIDEZ, AO PARTO E AO PÓS-PARTO}

Entre as disfunções do assoalho pélvico (DAP) mais frequentes nas mulheres encontram-se a diminuição da FMAP, a IU e a IA, o prolapso de órgãos pélvicos (POP), as anormalidades sensoriais do trato urinário inferior, dor crônica relacionada aos órgãos pélvicos, disfunções sexuais e dispareunia (Buhling et al., 2006; Luthander et al., 2011; Lavy et al., 2012; Laine et al., 2013; Silva et al., 2013; Rørtveit, Hannestad, 2014; Yeniel, Petri, 2014). Essas morbidades podem causar impacto negativo na saúde mental e na qualidade de vida (QV) das mulheres (Clarkson et al., 2001; Leroy, Lopes, 2012; Yeniel, Petri, 2014; Sut, Kaplan, 2016).

Convém destacar que a Sociedade Internacional de Incontinência (International Continence Society - ICS) define Incontinência Urinária (IU) como queixa de qualquer perda involuntária de urina, podendo, ainda, ser definida de acordo com os sintomas apresentados: 
incontinência urinária de urgência (IUU) - queixa de perda involuntária de urina acompanhada ou imediatamente procedida por urgência; incontinência urinária de esforço (IUE) - perda de urina simultânea a um esforço físico; incontinência urinária mista (IUM) queixa de perda involuntária de urina nas duas situações anteriores associadas (Abrams et al., 2010).

Um estudo de coorte prospectivo teve como objetivo investigar o impacto da gravidez e do parto em mulheres primíparas sobre a prevalência e os tipos de IU durante a gravidez e um ano depois do parto. Um questionário foi aplicado entre dois e três dias depois do parto e outro em um ano depois do parto. Os resultados identificaram uma prevalência de 32,1\% de IU comparado com 13,2\% no grupo controle (nulíparas). A prevalência de IU entre as mulheres primíparas com um ano depois do parto foi de 29,3\% contra 16,6\% entre as nulíparas, concluindo que houve aumento da prevalência de IU durante a gravidez e após o parto (Hansen et al., 2012).

Estudo longitudinal com 230 primíparas encontrou uma prevalência de IU de 12,2\% (28 mulheres), sendo que 19 (67,9\%) relataram grau de IU leve, e nove $(22,1 \%)$, de moderado a forte. As prevalências de IU no momento da alta hospitalar, com seis semanas e três meses após o parto, foram de 2,6\% (6/230), 10,4\% (24/230) e 7,4\% (17/230), respectivamente. Os autores concluíram que a idade materna superior a 34 anos, a multiparidade, a classe socioeconômica desfavorecida, o período expulsivo prolongado e a macrossomia fetal estão associados à IU (Obioha et al., 2015).

Outras pesquisas sugerem que o tipo de parto pode estar relacionado ao aparecimento de IU (Valeton, Amaral, 2011; Findik et al., 2012; Barbosa et al., 2013; Chang, et al., 2014). Um estudo indicou correlação entre o PN e a IU, pois à medida que houve aumento do número de partos, a frequência de IU aumentou. Essa associação não foi observada na cesariana, que se mostrou como um fator de proteção para IU. Também se verificou que quanto maior foi o número de gestações maior foi a ocorrência de IU (Findik et al., 2012).

Estudo transversal que incluiu 220 mulheres e teve por objetivo avaliar a prevalência de IU e DAP com dois anos após o parto, concluiu que a IU e o ganho de peso adquiridos na gestação aumentaram o risco de IU, mas considera que a cesárea não pode ser indicada como uma estratégia para evitar IU (Barbosa et al., 2013).

Um estudo transversal com 60 gestantes que comparou a FMAP entre nulíparas e multíparas, no terceiro trimestre de gestação, por meio da análise da atividade elétrica (eletromiografia superficial - EMG) e da palpação digital (escala de Oxford modificada) observou que tanto as nulíparas como as multíparas apresentaram resultados semelhantes em 
relação à DAP e às queixas de IU. A FMAP e a atividade elétrica foram maiores entre as nulíparas comparadas às multíparas. Por meio da palpação digital, os resultados mostraram que existe uma correlação tal entre os valores médios da EMG de superfície e os valores das medidas da FMAP de acordo com a escala de Oxford modificada, que quanto maior a atividade elétrica, maior a FMAP (Petricelli et al., 2014).

Com o objetivo de caracterizar as queixas de IU no pós-parto, um estudo transversal mostrou que a ocorrência de IU foi discretamente maior entre as primíparas comparadas às outras paridades, sendo mais frequente a queixa de IUE com perda diária e moderada de urina. A condição do períneo no pós-parto revelou que 32,3\% das puérperas foram submetidas à episiotomia e, dessas, 40,8\% (29/93) relataram IU, indicando a relação positiva da episiotomia à IU. Concluiu-se que do total de 288 mulheres, 24,6\% apresentaram IU após o parto, sendo que as perdas aconteceram com maior frequência entre o primeiro e o terceiro mês depois do parto com interferência negativa na vida diária da mulher (Lopes, Praça, 2012).

Um estudo caso controle teve por objetivo verificar se a IU comprometeu a QV de 344 puérperas primíparas com até 90 dias de pós-parto, sendo que dentre essas, 77 relataram ter algum tipo de incontinência urinária. Os autores verificaram que a IUE ocorreu com maior frequência do que os demais tipos de IU. Essas puérperas relataram uma pequena perda urinária diversas vezes ao dia. Concluiu-se que a IU causou um forte impacto na realização das atividades comuns da vida diária e na QV da mulher, sobretudo com limitações físicas e emocionais. Essa perda urinária, no entanto, pode ser transitória, uma vez que foram avaliadas somente até 90 dias após o parto (Leroy, Lopes, 2012). Vale mencionar que esse estudo utilizou o questionário Internanational Consultation on Incontinence Questionnaire Short Form (ICIQ-SF), que é o instrumento mais empregado para avaliar a QV da mulher com IU e se destaca por sua rapidez, praticidade na aplicação e precisão durante a avaliação (Avery et al., 2004).

Estudo que comparou a FMAP com a QV das mulheres com IU entre 233 daquelas que tiveram PN concluiu que a QV relacionada à IU diminuiu entre aquelas que tiveram seis ou mais filhos, ou seja, à medida que o número de partos aumentou, a QV relacionada à IU das mulheres diminuiu. Entretanto, acredita-se que a causa mais importante da diminuição da FMAP ocorreu porque nenhuma dessas mulheres participou do PTMAP após o parto (Özdemir et al., 2015). Em contrapartida, outro estudo concluiu que entre as mulheres com IU as quais realizaram o PTMAP, houve melhora na sua QV. (Dumoulin et al., 2015).

Em um ensaio clínico controlado, foram avaliadas 175 primíparas no pós-parto normal com POP e idade média de 29,8 anos submetidas a um PTMAP. Observou-se que as mulheres 
que seguiram as orientações gerais do PTMAP em grupo tiveram um resultado eficaz na redução da IU, porém para prevenir e tratar o POP pode ser necessário um treinamento individual. Os autores concluíram que as mulheres que realizaram o PTMAP, individualmente ou em grupo, não demonstraram uma mudança significativa na melhora do POP. Por outro lado, o estado hormonal é diferente no período pós-parto e pode ter influenciado negativamente o tecido conjuntivo e a FMAP (Bø et al., 2015). Assim, é necessário acompanhamento por um período maior para verificar se existe diferença significativa entre os grupos que realizam ou não um PTMAP.

Outro ensaio clínico que envolveu 36 mulheres verificou que o PTMAP proporcionou melhora significativa na QV daquelas com IUE além de ocorrer uma diminuição significativa na frequência urinária noturna e na perda urinária bem como um aumento significativo na FMAP (Fitz et al., 2012).

Chamochumbi et al. (2012) compararam a FMAP durante a contração e o repouso em mulheres continentes e incontinentes ao esforço. Eles concluíram que a FMAP durante a contração foi maior entre as mulheres continentes do que naquelas que eram incontinentes ao esforço, com diferença significativa entre os dois grupos avaliados [unidade de força medida em Newtons $(\mathrm{N}) ; 0,3 \pm 0,2 \mathrm{~N}$ versus $0,1 \pm 0,1 \mathrm{~N}]$.

Estudo com 238 mulheres nulíparas que estavam com seis semanas de pós-parto vaginal teve por objetivo comparar a função da FMAP (resistência, repouso e contração) em relação à ocorrência de IU de mulheres com ou sem episiotomia mediolateral ou lateral. A avaliação da FMAP foi realizada utilizando-se um perineômetro, e a ocorrência de IU e da IUE foram avaliadas sendo utilizado o questionário ICIQ-SF. As mulheres com episiotomia tiveram o segundo estágio do parto, significantemente, mais prolongado e os recém-nascidos (RN) possuíam pesos maiores. No grupo com episiotomia, houve mais mulheres com partos vaginais e analgesia epidural e parto instrumental comparado com aquelas sem episiotomia. $\mathrm{Na}$ análise de regressão linear multivariada e ajustada para a duração do período expulsivo, o peso do RN, a analgesia epidural e o parto instrumental, não houve diferença estatística na função da FMAP (repouso, contração e resistência) entre as mulheres que tiveram ou não episiotomia nas seis semanas pós-parto. Também não houve diferença significante quanto à prevalência de IU ou IUE nos grupos com ou sem episiotomia. Entretanto, os resultados mostraram que não houve associação significante entre a episiotomia, a FMAP e a IU com seis semanas após o parto (Bø, et al., 2016). Considerando que as complicações no trato gênito-urinário também estão associadas ao traumatismo perineal, a redução e a prevenção 
desses traumas são essenciais e devem ser vistas como prioridade para as mulheres e para os profissionais que as assistem (Riesco et al., 2011).

Outra disfunção pélvica observada em mulheres é a IA. Laine et al. (2013) verificaram em seu estudo com 1.792 mulheres que as que tiveram lesão obstétrica do esfíncter anal referiram IA. Os autores observaram, também, menor prevalência de IA em mulheres submetidas à cesariana, concluindo assim, que o tipo de parto pode representar um fator de risco para IA enquanto a gestação em si não.

De acordo com o estudo anterior desses mesmos autores, a assistência prestada durante o pré-natal e as variáveis obstétricas como: idade materna, etnia, peso materno, ganho de peso durante a gestação, apresentação fetal, episiotomia e perímetro cefálico do RN não conseguem prever a incontinência anal, mas destacam que o fórcipe foi o principal fator de risco para as lesões obstétricas do esfíncter anal (Laine et al., 2011). Em outra investigação de Laine, Skjeldestad e Sandvik (2012) observou-se que a técnica de proteção do períneo durante o período expulsivo foi capaz de diminuir a frequência de lesão obstétrica do esfíncter anal e IA.

Estudo envolvendo 666 mulheres teve por objetivo estimar o efeito do tipo de parto e outras práticas obstétricas sobre o AP num período entre 6 e 11 anos após o primeiro parto. Foi investigada a relação entre a FMAP, mensurada pela perineometria, e as DMAP. Concluiu-se que a FMAP foi significativamente menor entre as mulheres que tiveram parto fórcipe e vaginal do que as que foram submetidas à cesariana $(\mathrm{P}<0,001)$ mesmo depois de um longo período após o parto. A diminuição da FMAP também esteve associada aos sintomas de IA e prolapso de órgãos pélvicos (Friedman et al., 2012).

A dispareunia é mais uma das morbidades referidas pelas mulheres durante o pósparto. Em estudo com 85 puérperas que estavam com dois e seis meses após o parto encontraram-se $69,7 \%$ e $29,2 \%$ de dispareunia com dois e seis meses de pós-parto, respectivamente (Silva et al., 2013). Contudo, manter a FMAP fortalecida entre as mulheres não está relacionada à proteção de possíveis DAP, mas está, positivamente, associada à aspectos sexuais, tais como, excitação, orgasmo, satisfação e desejo sexual (Martinez et al., 2014).

Estudo prospectivo que avaliou a ocorrência de dispareunia em 1.122 mulheres com três, seis, doze e dezoito meses após o parto, verificou que $85,7 \%$ delas referiram dispareunia na primeira relação após o parto, sendo que 44,7\%, 43,7\% e 22,6\% continuaram com dispareunia aos três, aos seis e aos dezoito meses após o parto, respectivamente (McDonald et al., 2016). 
No estudo de coorte de Tennjjord et al., (2014) foram analisadas 300 nulíparas. Os pesquisadores não constataram relação entre as variações da FMAP e a dispareunia, no entanto ressaltam que futuras pesquisas devem estar voltadas para estratégias preventivas e tratamentos para essa queixa no pós-parto.

Segundo a pesquisa de Blomquist e Handa (2014), a dispareunia no pós-parto está associada ao uso de fórcipe e bebê com quatro quilogramas ou mais de peso, enquanto que o parto normal não esteve associado à dispareunia ou à dismenorréia.

Um estudo de coorte teve por objetivo verificar a relação entre a função sexual e a ocorrência de IU e IA entre mulheres que tiveram parto vaginal com ou sem laceração do esfíncter anal ou que foram submetidas à cesariana eletiva. Foram realizadas entrevistas seis meses após o parto. Os autores verificaram que as mulheres com lacerações obstétricas do esfíncter anal ou que foram submetidas à cesariana demoraram mais tempo para retornar à atividade sexual do que aquelas que tiveram parto vaginal sem essa complicação. Dentre aquelas que retornaram à atividade sexual, um terço referiu dispareunia. Concluiu-se que houve associação entre a atividade sexual e o tipo de trauma perineal (Brubaker et al., 2008).

Estudo retrospectivo com 116 mulheres objetivando analisar a ocorrência, os fatores de risco e os sintomas dos músculos do ânus relacionados com as lacerações perineais de terceiro grau após parto vaginal verificou que dentre as 72,4\% (84) entrevistadas, $25 \%$ (21) tinham sintomas anais (IA, incontinência fecal, dor ou sangramento durante a evacuação, esvaziamento incompleto das fezes durante a evacuação, segundo reparo cirúrgico por IA) relacionados às lacerações perineais de terceiro grau e 17,2\% (20) referiram ter IA. Os autores concluíram que os fatores de risco relacionados às lacerações perineais de terceiro grau foram a primiparidade, o fórcipe, a episiotomia, o peso do $\mathrm{RN}$ superior a 4.000 gramas e a maior duração do período expulsivo (Wood, Amos, Rieger, 1998).

Estudo prospectivo de coorte avaliou os efeitos dos PTMAP em relação à FMAP e aos sintomas do trato urinário durante a gravidez e após o parto. As participantes foram distribuídas, aleatoriamente, em 30 gestantes no grupo que realizou o PTMAP e 30 no controle. A FMAP foi mensurada pela perineometria e os sintomas urinários, avaliados por questionários validados. As mulheres foram examinadas com 28 e 36-38 semanas de gestação e entre 6 e 8 semanas após o parto. Os resultados mostraram que a FMAP diminuiu, significativamente, durante a gravidez. Por outro lado, a FMAP foi muito maior no grupo que realizou o PTMAP em comparação ao controle. A função sexual foi, negativamente, afetada em ambos os grupos, tendo sua frequência diminuída entre 36 e 38 semanas de gestação e, melhorando com seis semanas após o parto. O PTMAP durante a gravidez e o período pós- 
parto aumentou a FMAP, preveniu os sintomas do trato urinário e melhorou a QV das mulheres, enquanto no grupo controle observou-se diminuição da FMAP na gravidez. Concluiu-se que a gravidez e o parto afetam negativamente a FMAP, os sintomas urinários, a função sexual e a QV das mulheres enquanto que a realização de um PTMAP, durante a gravidez, melhora essas variáveis no pós-parto (Sut, Kaplan, 2016).

Em estudo retrospectivo com 247 mulheres que foram seguidas por quatro anos após o parto a fim de serem avaliadas as características clínicas perineais, verificou-se que as lacerações perineais de terceiro ou quarto graus afetaram 62,3\% (154) das mulheres, a IU ocorreu em 13,4\% (33), a dispareunia em 10,1\% (25), a IA em 8,5\% (21) e o POP em 4,5\% (11). A maioria das participantes que tinha IA (19 mulheres) apresentava lacerações perineais de terceiro e quarto graus. Os autores concluíram que o exame clínico perineal durante o pósparto é uma prática viável e que oferece oportunidade para avaliar e tratar as DAP (Brincat et al., 2015).

Desse modo, vários estudos têm mostrado associação entre o tipo de parto, condições perineais, peso do RN, idade materna, índice de massa corpórea (IMC), presença de IU prévia e a FMAP (Brubaker et al., 2008; Baracho et al., 2012; Blomquist, McDermott, Handa, 2014; Obioha et al., 2015). Considera-se que as complicações que ocorrem no trato gênito-urinário podem estar relacionadas ao tipo de parto e ao trauma perineal.

\subsection{MÉTODOS UTILIZADOS PARA ANALISAR A FORÇA MUSCULAR DO ASSOALHO PÉLVICO}

Muitos autores consideram importante a avaliação correta da FMAP, pois isso pode ajudar no diagnóstico e tratamento das DAP, uma vez que essas morbidades, geralmente, são causadas pela diminuição da FMAP (Stephenson, O’Connor, 2004; Voortham-van der Zalm et al., 2008; Resende et al., 2011; Costa et al., 2014).

A avaliação dos MAP costuma ser realizada em repouso, por meio da resistência, ou durante a atividade, pela contração muscular. A avaliação da FMAP pode ser efetuada pelo exame ginecológico, empregando-se os métodos de palpação digital vaginal, perineometria, ultrassonografia, eletromiografia, manometria, ressonância magnética, tomografia computadorizada, ecografia endoanal, eletromiografia de superfície e cones vaginais (Kearney et al., 2006; Braekken et al., 2009; Dietz, Simpson, 2008; Örnö, Marsál, Herbst, 2008; Barbosa et al., 2009; Gameiro et al., 2011; Rahmani, Mohseni-Bandpei, 2011; Resende 
et al., 2011; Rojas et al., 2013; Vasconcelos, Ribeiro, 2013; Chevalier et al., 2014; Costa et al., 2014; Rodríguez et al., 2015; Martinho et al., 2016).

Os métodos mais utilizados para avaliar a FMAP são a perineometria e a palpação vaginal digital (Menta, Schirmer, 2006; Gameiro et al., 2011; Costa et al., 2014). Entretanto, o estudo de Bø e Finckenhagen (2001) mostrou que não há concordância quanto à correlação entre esses métodos na mensuração da FMAP. Alguns autores, no entanto, defendem que embora esses métodos sejam diferentes, eles estão correlacionados positivamente (Barbosa et al., 2005; Oliveira et al., 2007; Riesco et al., 2010; Chevalier et al., 2014; Petricelli et al., 2014; Martinho et al., 2016).

Empregando dois métodos para avaliar a FMAP (palpação digital vaginal e perineômetro - eletromiógrafo de pressão/mmHg) Barbosa et al. (2005) compararam nulíparas e primíparas com parto vaginal e cesariana entre 4 e 6 meses depois do parto. Houve aumento do risco relativo (RR) em 2,5 vezes pela palpação e 2,3 vezes pelo perineômetro no parto vaginale em 1,5 pela palpação e 1,3 vezes pelo perineômetro na cesariana, porém o intervalo de confiança (IC) foi significativo apenas para o parto vaginal. Os achados mostraram que os resultados da FMAP foram semelhantes pela palpação digital vaginal e perineômetro (coeficiente de Kappa=0,87). Concluiu-se que houve diminuição da FMAP entre as mulheres que tiveram parto vaginal ou foram submetidas à cesariana em comparação com as nulíparas. Essa FMAP foi menor, ainda, entre as primíparas com partos vaginais em comparação com as mulheres que tiveram cesariana ou eram nulíparas.

Outro estudo brasileiro verificou a existência de concordância da FMAP entre três diferentes marcas de equipamentos, relatando dificuldade de converter uma unidade de medida personalizada criada por um dos fabricantes, pois os autores não conseguiram encontrar uma forma de conversão direta. Observaram-se, também, que os resultados dos valores de medição da FMAP dependem do diâmetro da sonda utilizada, da sua consistência e do diâmetro da vagina de cada mulher. Concluiu-se, no entanto, que existe uma concordância moderada entre os resultados com o perineômetro Periton ${ }^{T M}$ (Laborie, Canadá) e NeurodynTM (Ibramed, Brasil), uma justa concordância entre as marcas Periton ${ }^{T M} \mathrm{e}$ SensuPower $^{T M}$ (Kroman, Brasil) e uma baixa concordância entre os produtos Neurodyn ${ }^{T M}$ (Ibramed, Brasil) e SensuPower ${ }^{T M}$ (Kroman, Brasil) (Barbosa et al., 2009).

Resende et al. (2011), em uma revisão da literatura, consideraram que a eletromiografia de superfície é um dos métodos de maior especificidade na avaliação da FMAP ainda que não exista um consenso quanto à sua aplicação. Eles salientam, também, que, embora não haja uma padronização quanto a sua metodologia, esse é um instrumento 
importante para a prática clínica e pesquisa, pois apresenta boa confiabilidade e reprodutividade.

Estudo prospectivo que utilizou o perineômetro Dynamed (Model DM 01) e a palpação vaginal bidigital da região anterior e posterior do intróito vaginal como métodos de avaliação da FMAP comparou nuligestas e primíparas. Estas contavam com 20 e 36 semanas de gravidez, com 45 dias após o parto e foram divididas conforme o tipo de parto (vaginal e cesariana). Não houve diferença significativa entre os grupos com 20 e 36 semanas de gravidez, no entanto, com 45 dias após o parto, constatou-se redução significativa na FMAP das primíparas comparadas às nulíparas $\left(15,6 \mathrm{cmH}_{2} \mathrm{O}\right.$ versus $8,3 \mathrm{cmH}_{2} \mathrm{O}$ e $13,7 \mathrm{cmH}_{2} \mathrm{O}$; sendo os valores das nulíparas e das primíparas com parto vaginal e cesariana, respectivamente; $\mathrm{p}<0,05)$ (Gameiro et al., 2011).

Riesco et al. (2014) realizaram um estudo transversal com 500 gestantes no primeiro trimestre da gestação para analisar a FMAP, a continência urinária e a QV associada à IU,

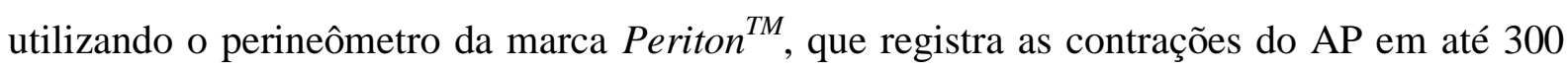
$\mathrm{cmH}_{2} \mathrm{O}$. Observou-se idade materna avançada (OR=1,06 IC95\% 1,02-1,11) e antecedente de IU (OR=15,12 IC95\% 8,19-27,92) juntos, acarretam maior chance de as mulheres apresentarem IU no primeiro trimestre da gestação. A FMAP <28,5 $\mathrm{cmH}_{2} \mathrm{O}$ representa o ponto de corte para IU, tendo sido encontrada a média de 30,5 $\mathrm{cmH}_{2} \mathrm{O}(\mathrm{dp}=17,3)$, independente de ter ou não IU, sendo $27,2 \mathrm{cmH}_{2} \mathrm{O}(\mathrm{dp}=15,8)$ entre as gestantes com IU e 31,3 $\mathrm{cmH}_{2} \mathrm{O}(\mathrm{dp}=17,6)$ naquelas sem IU. As primigestas apresentaram uma taxa de IU de 7,4\% e as multíparas de $11,6 \%$.

Outro estudo transversal africano com 122 nulíparas entre 18 e 45 anos de idade que utilizou perineômetro (Periton ${ }^{T M}$ 9300, Cardio Design, Castle Hill, Austrália) teve como objetivo comparar a FMAP em diferentes grupos étnicos. A amostra constou de 36,1\% mulheres que se classificaram como negras, 36,1\% como brancas e 27,8\% como pardas. Verificou-se que os valores da FMAP foram, significativamente, mais elevados nas negras $\left(25 \mathrm{cmH}_{2} \mathrm{O}\right)$ cotejados aos das brancas $\left(18,4 \mathrm{cmH}_{2} \mathrm{O}\right)$ e das pardas $\left(15,6 \mathrm{cmH}_{2} \mathrm{O}\right)$. Os autores concluíram que a FMAP é $26 \%$ mais forte na raça negra comparada a das mulheres brancas e $37 \%$ mais forte que nas pardas (Walt et al., 2014).

Estudo transversal brasileiro que avaliou a FMAP por perineometria (Periton ${ }^{T M}$ 9301, Laborie, Canadá) e palpação digital vaginal (escala de Oxford modificada) constatou que a média da FMAP em gestantes com antecedentes de parto normal ou cesariana foi $33,4 \mathrm{cmH}_{2} \mathrm{O}$ $(\mathrm{dp}=21,2)$. Pela escala de Oxford, $75,4 \%$ das gestantes com partos ou cesarianas anteriores 
apresentaram grau $\leq 2$ e 5,5\%, grau $\geq 4$; entre primigestas, 39,9\% exibiram grau $\leq 2$ e $50,9 \%$, grau $\geq 4$, com diferença, estatisticamente, significante ( $p<0,001)$ (Caroci et al., 2014).

\subsection{EXERCÍCIOS UTILIZADOS PARA FORTALECER OS MÚSCULOS DO ASSOALHO PÉLVICO}

Durante o pré-natal e o pós-parto, as mulheres devem ser orientadas e estimuladas a realizarem exercícios para os MAP, objetivando evitar ou reduzir as morbidades que podem ter ocorrido na gestação e no parto (Fitzpatrick, O’Herlihy, 2001; Menta, Schirmer, 2006; Zanetti et al., 2007; Pelaez et al., 2014; Gagnon, Boucher, Robert, 2016; Sut, Kapplan, 2016; Yohay et al., 2016), embora os estudos sejam contraditórios quanto à eficiência dos exercícios com os MAP para o tratamento das lesões ocorridas no AP (Grant, Sleep, 2002; Braekken et al., 2010; Hilde et al., 2013; Moore et al., 2013; Hagen et al., 2014, Bø et al., 2015). Alguns autores recomendam que os exercícios para os MAP sejam realizados com a supervisão de um fisioterapeuta, outros recomendam que os exercícios devam ser orientados individualmente, ao invés de serem praticados em grupo e, ainda, que sejam executados, pelo menos, três vezes por semana (Zanetti et al., 2007; Pelaez et al., 2014; Reilly et al., 2014, Bø et al., 2015).

Ensaio clínico controlado com 169 mulheres divididas em um grupo que realizou exercício perineal de Kegel $(n=73)$ e um outro controle $(n=96)$ mostrou que aquelas que foram submetidas ao PTMAP, durante a gestação, apresentaram resultados eficazes na prevenção, tratamento ou melhora da IU, bem como na sua QV (Pelaez et al., 2014).

Uma revisão sistemática da Biblioteca Cochrane, a qual incluiu 21 ensaios clínicos, envolvendo 1.281 mulheres, avaliou os efeitos do PTMAP em mulheres com IUE, IUU ou mista em comparação com nenhum tratamento, placebo ou outros tratamentos. Verificou-se que as mulheres com IUU e que estavam nos grupos de PTMAP tiveram oito vezes mais probabilidades de informar que elas estavam curadas ( $\mathrm{RR}=8,38$; IC de 95\%, 3,68-19,07) e 17 vezes mais propensão a relatar a cura ou melhora ( $R R=17,33$; IC 95\% 4,31-69,64). As mulheres que apresentaram qualquer tipo de IU e fizeram parte dos PTMAP, também, foram mais propensas a relatar a cura ou melhoria do que aquelas dos outros grupos. Os revisores concluíram que a avaliação fornece suporte para a recomendação generalizada de que o PTMAP seja incluído como prioridade nos programas de gestão conservadora entre as mulheres com IUE ou qualquer outro tipo de IU, contudo a eficácia a longo prazo do PTMAP precisa ser mais investigada (Dumoulin et al., 2015). 
Estudo retrospectivo com primíparas comparou as condições do períneo entre as mulheres que praticavam exercícios perineais em casa e as que não praticavam. Os exercícios eram praticados com a introdução intravaginal de um dilatador perineal de silicone e deveriam ser realizados durante 10 minutos por dia e entre 37 e 40 semanas de gestação. Houve redução na ocorrência de episiotomia entre as mulheres que praticavam exercícios perineais em relação às taxas desse procedimento publicadas no mesmo país do estudo (Cohain, 2004).

Uma revisão sistemática em que foram avaliados dez estudos com 688 mulheres grávidas, saudáveis e que realizaram exercícios aeróbicos regularmente, constatou-se que a maioria dos estudos utilizou uma metodologia inadequada. Entre os estudos selecionados observou-se que a prática de exercício aeróbico regular, durante a gravidez, parece melhorar a aptidão física e a autoimagem corporal, porém os dados disponíveis foram insuficientes para concluir se houve riscos ou benefícios importantes para a mãe ou filho (Kramer, 2003).

Em estudo sobre a realização de exercícios musculares do assoalho pélvico e estímulos eletrônicos e fisiológicos para sua reabilitação, os investigadores concluíram que, fortalecendo-se a musculatura pélvica ocorre uma redução nos sintomas do trato gênitourinário e incontinência anal. Os resultados indicam que a terapêutica combinada de recursos permitem melhores resultados do que somente intervenções isoladas (Pedraza et al., 2014).

Estudo transversal que avaliou a Função da Estimulação Magnética Contínua (FEMC) em 56 mulheres que fizeram o PTMAP por quatro semanas concluiu que a FEMC associada ao PTMAP é eficaz no tratamento de IU (Suzuki et al., 2004).

Oliveira et al. (2007) analisou 23 gestantes nulíparas que praticava o PTMAP, semanalmente, em comparação com um grupo controle de 23 gestantes nulíparas. A avaliação da FMAP foi realizada pela palpação digital vaginal usando a escala de Oxford e a perineometria (com e sem biofeedback), com até 20 semanas e 36 semanas de gestação. Os grupos eram semelhantes quanto à idade materna, cor da pele, escolaridade e peso materno. Para ambos os grupos, não houve diferença significante observada nas médias das FMAP avaliadas com até 20 semanas de gestação, tanto pelo método de palpação digital vaginal como pela perineometria. Houve aumento significante da FMAP entre a primeira avaliação realizada (com até 20 semanas de gestação) e a segunda avaliação (com 36 semanas de gestação) ( $\mathrm{p}<0.001$ ), tanto pela avaliação digital vaginal como pela perineometria. Contudo, houve um aumento ainda maior e significante da média da FMAP no grupo que praticava o PTMAP em comparação ao grupo controle $(47,4 \%$ versus $17,3 \%, \mathrm{p}<0.001)$, segundo os dois 
métodos utilizados. Houve correlação positiva significante entre os métodos de palapação digital vaginal e a perineometria.

Zanetti et al. (2007) comparou dois grupos de mulheres com IUE. Um realizava exercícios perineais supervisionados por fisioterapeutas duas vezes por semana, durante três meses. O outro grupo, porém, era orientado a realizar os exercícios em casa. Os fisioterapeutas avaliaram a FMAP em ambos os grupos, uma vez por mês, por meio da palpação digital vaginal. Observou-se melhores resultados no grupo que praticou os exercícios perineais supervisionados por fisioterapeutas. Esses autores sugerem que os profissionais da saúde devem, portanto, nas consultas de pré-natal e de puerpério, estimular as mulheres a realizarem um programa de exercícios de fortalecimento do AP para que elas possam aprender a identificar os MAP e fortalecê-los.

Em pesquisa observacional e retrospectiva avaliou a eficácia de um PTMAP iniciado com um mês depois do parto comparado com o mesmo PTMAP iniciado entre seis e oito semanas depois do parto em mulheres que tiveram lesões do esfíncter anal após parto vaginal. Os pesquisadores incluiram 211 mulheres que tiveram lacerações de terceiro e quarto graus após o parto vaginal que foram alocadas em dois grupos, sendo que 102 mulheres iniciaram o PTMAP no primeiro mês após o parto e 109 inciaram com seis a oito semanas após o parto. Vale salientar que os dados foram coletados entre 10 e 20 dias e entre seis e oito meses após o parto. A análise multivariada ajustada para o tipo de lesão demonstrou que no grupo que iniciou a reabilitação, precocemente, houve uma redução significativa de perda de gases, de fezes líquida e de IUE em comparação com o grupo que iniciou o PTMAP entre seis e oito semanas após o parto. Em relação às variáveis perda de fezes sólida, urgência para evacuar e atividade sexual não houve diferença estatística entre os grupos. Os autores recomendam que as mulheres com lesões do esfíncter anal façam um PTMAP desde o primeiro mês após o parto vaginal. Também referem que essa reabilitação seja acompanhada por um fisioterapeuta especializado em períneo (Mathé et al., 2016).

\subsection{ASSISTÊNCIA OBSTÉTRICA ÀS PUÉRPERAS COM DISFUNÇÕES DO ASSOALHO PÉLVICO}

Os profissionais que assistem as mulheres durante o ciclo gravídico-puerperal precisam ter um melhor treinamento formal e especializado para identificar, avaliar e tratar as DAP, além de saber como abordar o tema com as mulheres, a fim de compreendê-las. Os traumas perineais mais graves devem ser avaliados não apenas nos primeiros dias depois do parto, mas 
ter um seguimento por meses ou anos (Fitzpatrick, O’Herlihy, 2001; Rojas et al., 2013; Costa et al., 2014; Glazener et al., 2014). Segundo Brown et al. (2014) é necessário essa avaliação e um acompanhamento por um ano ou mais, com um sistema de vigilância que inclua um inquérito de rotina sobre IU e IA a fim de superar a relutância das mulheres em procurar ajuda. A avaliação da FMAP pode servir de referência para o tipo de orientação, prevenção ou redução de agravamentos em longo prazo ou permanentes (Riesco et al., 2010).

Alguns autores consideram que é fundamental que os profissionais saibam avaliar a FMAP de forma criteriosa e que estimule a mulher a referir as queixas do trato gênitourinário, do esfíncter anal, de disfunções sexuais ou qualquer outro problema dos MAP, pois muitas delas podem apresentar alguma disfunção mesmo não pronunciada e, provavelmente, por acreditarem que devam resignar-se a terem esses sintomas ou por pensarem que não sejam graves, uma vez que tiveram filhos ou não serem mais novas (Rajeshkannan, Pathmeswaran, 2013; Costa et al., 2014).

Evans et al. (2014) recomendam uma consulta de acompanhamento para todas as mulheres que passaram pela gestação e ou parto. Acrescentam que o ideal seria que fosse oferecido o exame de ultrassonografia endovaginal para todas as mulheres. Johannessen et al. (2015) sugerem que as mulheres que já possuem IA durante a gravidez sejam monitoradas e tratadas depois do parto.

Para fortalecer os MAP e tratar as disfunções causadas pelo seu enfraquecimento, as mulheres podem realizar a reposição hormonal, os exercícios com biofeedback utilizando um perineômetro, a estimulação elétrica e o aconselhamento nutricional a fim de evitar diuréticos e substâncias que possam irritar a bexiga, além dos exercícios perineais com ou sem supervisão os quais já foram citados anteriormente (Stephenson, O’Connor, 2004; Thompson, O’Sullivan, Briffa, 2006; Dinc, Beji, Yalcin, 2009; Dumoulin, Hay, 2010; Hagen, Stark, 2011; Boyle et al., 2012; Hilde et al., 2012; Glazener et al., 2014; Dumoulin et al., 2015; Sut, Kaplan, 2016).

As lesões causadas aos músculos do esfíncter anal, também, podem ser restauradas, com eficiência, por meio de técnicas cirúrgicas anatômicas das lesões desses músculos (esfincteroplastia) por médicos devidamente treinados. Por outro lado, o reparo inadequado dessas lesões pode estar associado às altas taxas de IA que poderão ser minimizadas se forem recuperadas cirurgicamente (Andrews et al., 2013; Rodríguez et al., 2015). A terapia de neuro-estimulação elétrica na região sacral ou tibial, também, parece trazer resultados promissores para o reparo desses músculos (Brower, Duthie, 2010; Hotouras et al., 2012; Ratto et al., 2012; Arroyo et al., 2014, Rodríguez et al., 2015). 
Obioha et al. (2015) consideram que é importante identificar os preditores obstétricos de IU e IA. Além disso, recomendam mudanças nas práticas obstétricas que podem ser fatores de risco para essas ou outras morbidades. Embora as evidências científicas ainda sejam incertas, alguns fatores obstétricos são considerados de risco ou de proteção para a ocorrência das DAP, entre outros, as mudanças hormonais; mecânicas e neuromuscular que ocorrem na gravidez; a genética; a idade materna elevada; a obesidade; as mulheres de cor branca; o comprimento reduzido do períneo; a proteção perineal; a macrossomia fetal; o primeiro e o segundo períodos do parto prolongados; a persistência da posição fetal em occípto-posterior (occípto-sacro) ou puxo prolongado durante o período expulsivo; a saída rápida da cabeça ou ombro fetal; o parto normal ou instrumental; a cesariana; a maior paridade; a episiotomia; as lacerações perineais de terceiro ou quarto graus (Hadi et al., 2004; Lukacz et al., 2006; Boran et al., 2013; Petricelli et al., 2014; Rikard-Bell, Iyer, Rane, 2014; Rørtveit, Hannestad, 2014; Yeniel, Petri, 2014; Brincat et al., 2015; Burrell et al., 2015; Johannessen et al., 2015; Kabakian-Khasholian et al., 2015; Obioha et al., 2015; Rodríguez et al., 2015; ; Yohay et al., 2016; Sut, Kaplan, 2016).

Apesar da infecção do trato urinário (ITU) não ser classificada como uma DAP, as mulheres portadoras de IU e IA apresentam maior propensão para desenvolvê-la (FloresMireles et al., 2015).

De acordo com o Ministério da Saúde (2012), durante a gestação, a ITU ocorre com frequência e sua prevalência está citada em 20\%. A ITU é classificada na gestação como bacteriúria assintomática, cistite e pielonefrite, sendo a bacteriúria assintomática a mais presente entre as gestantes.

Estudo observacional analisou a prevalência de infecções no pós-parto por meio de questionário respondido por mais de $99 \%$ das participantes $(n=11.124)$. Concluiu-se que das infecções mais frequentes após o parto, havendo necessidade de antibioticoterapia foi a ITU, apresentando prevalência de 3\% (Axelsson, Blomberg, 2014).

O Quadro 1, apresentado a seguir, mostra os principais estudos sobre a análise da FMAP durante o ciclo gravídico-puerperal em relação à Incontinência Urinária (IU), à Incontinência Anal (IA) e à Dispareunia. 
Quadro 1 - Estudos sobre a FMAP, durante o ciclo gravídico-puerperal, em relação IU, IA e a Dispareunia, São Paulo, SP - 2017

\section{Autor, ano e \\ local do estudo \\ Zizzi et al.}

2017

Brasil

\section{Objetivos do estudo}

Analisar a FMAP e a IU e IA no período pós-parto.
Tipo de estudo, amostra, período e instrumento de avaliação da FMAP Estudo transversal com 128 mulheres nos primeiros sete meses pós-parto. Foi utilizado a perineômetria para avaliação da FMAP e para IU o International Consulation on Incontinence Questiomaire-shot Form (ICIQ-SF).

Estudo randomizado controlado, com 60 gestantes, randomizadas em grupo treinamento $[n=30]$ e controle $[n=30]$. O grupo treinamente foi orientado a realizar o exercício de Kegel. A exercício da musculatu pélvica, durante a gravidez e pós-parto, na atividade muscular do assoalho pélvico e função urinária.

\section{Mendes et al. 2016}

Brasil

\section{Comparar a FMAP em} primíparas após o parto e relacionar às características sociodemográficas, IMC, IU, dispareunia, exercício perineal, condição perineal e peso do RN.
FMAP foi avaliada por perineômetro e a função urinária por urofluxômetro e questionários validados (UDI-6, IIQ-7 e OAB-q). Os dados foram coletados com $28,36-38$ semanas de gestação e com 6-8 semanas pós-parto. Estudo transversal realizado entre 50 e 70 dias de pós-parto, com 24 primíparas submetidas à cesariana e 72 ao parto normal. Utilizou-se

Peritron TM $9301\left(\mathrm{cmH}_{2} \mathrm{O}\right)$ para análise da força muscular. Comparou-se as médias da força muscular entre os grupos pela Análise de Variância a dois fatores.

\section{Principais resultados e conclusões}

A média da FMAP foi de 33,1 cmH2O. Na análise múltipla, as variáveis associadas à FMAP foram: tipo de parto atual e coabitação com parceiro. O peso do RN, gestação anterior, IU na gestação e atividade sexual mostraram associação. Apenas a IA prévia associou-se à IA pós-parto. O PN reduziu a FMAP e a cesariana exerceu função protetora à sua redução. A ocorrência de IU na gestação é preditora da IU no pós-parto e maior propensão de IU em mulheres com gestação anterior e RN com maior peso.

Houve redução significativa na FMAP na gravidez e melhora na FMAP no grupo treinamento comparado ao controle. A função urinária foi afetada negativamente nos dois grupos, reduzindo com 36-38 semanas de gravidez e melhorando no pós-parto. Gravidez e parto afetam a FMAP, sintomas urinários e QV. O exercício perineal aumenta a FMAP, previne disfunções urinárias e melhora a $\mathrm{QV}$. A FMAP foi maior após PN com $\geq 12$ anos de estudo (42,0 versus $14, \mathrm{cmH} 2 \mathrm{O} ; \mathrm{p}=0,036)$ e que realizaram exercício perineal (42,6 versus $11,8 \mathrm{cmH} 2 \mathrm{O} ; \mathrm{p}=0,010)$, comparadas às de cesariana. Não houve diferença na FMAP segundo o tipo de parto, IMC, IU, dispareunia, condição perineal e peso do RN. A FMAP não difere entre primíparas quanto ao tipo de parto.

(continua) 
Quadro 1 - Estudos sobre a FMAP, durante o ciclo gravídico-puerperal, em relação IU, IA e a Dispareunia, São Paulo, SP - 2017

\section{Autor, ano e}

local do estudo

Bø et al.

2015

Noruega

Obioha et al.

2015

Nigéria

2015

Brasil

\section{Objetivos do estudo}

Avaliar o efeito do Programa de Treinamento dos

Músculos do Assoalho Pélvico (PTMAP) na prevenção e tratamento de sinais e sintomas de Prolapso de Órgãos Pélvicos (POP) em primíparas pós-parto.

Identificar a prevalência e os preditores da incontinência urinária (IU) e incontinência anal (IA), com seis semanas e três meses após o parto vaginal.

Avaliar a IU, a IA e a FMAP ao longo da gestação e sua evolução clínica nos três trimestres gestacionais.
Tipo de estudo, amostra, período e instrumento de avaliação da FMAP

Ensaio clínico, com 175 primíparas, que participaram por quatro meses do PTMAP, a partir de 6-8 semanas pós- parto. Os dois grupos tiveram instrução individual, para realizar contrações dos MAP. Fisioterapeutas treinados ensinaram e avaliaram a contrair os MAP pela observação perineal e palpação vaginal. A FMAP foi medida por um transdutor de pressão de alta precisão ligado a um catéter com balão. Estudo longitudinal com 230 parturientes, recrutadas no pós-parto normal imediato, sem complicações e continentes antes da gestação.

Estudo longitudinal, prospectivo, analítico que integrou uma coorte. Foram incluídas 500 gestantes que utilizaram a perineometria para avaliação da FMAP

\section{Principais resultados e conclusões}

Idade média de 29,8 anos, $96 \%$ do grupo de intervenção aderiram às intervenções

realizadas em grupo e em casa, efetuando $80 \%$ dos exercícios propostos. Após a intervenção, não houve diferença estatística do risco nos POP (Risco Relativo, RR=1,62; Intervalo de Confiança, IC de 95\% 0,55-4,75), na posição do colo da bexiga ou nos sintomas de abaulamento vaginal.

No geral, 28 mulheres com prevalência de $12,2 \%$ para IU, $13,5 \%$ para IA e $3 \%$ para IU e IA combinadas. A idade, classe social, paridade, expulsivo prolongado e peso do RN foram associados à IU pós-parto $(\mathrm{p}<0,05)$. A idade, paridade, expulsivo prolongado, episiotomia e parto forceps foram associados a IA pós-parto $(\mathrm{p}<0,05)$.

A FMAP não teve associação ao longo da gestação. A prevalência de IU foi de $19,1 \%$, $42,5 \%$ e $35,8 \%$, no $1^{\circ}, 2^{\circ}$ e $3^{\circ}$ trimestres de gestação, respectivamente. A prevalência de IA variou de $7,5 \%$ a $11,5 \%$. $\mathrm{Na}$ análise multivariada, as variáveis que explicam a variação da FMAP foram: IG, gestação anterior, IU prévia e realização de exercícios perineais que aumentou a FMAP e reduziu a ocorrência de IU. 
Quadro 1 - Estudos sobre a FMAP, durante o ciclo gravídico-puerperal, em relação IU, IA e a Dispareunia, São Paulo, SP - 2017

Autor, ano e

local do estudo Dumoulin et al. 2015

Canadá

Blomquist,

McDermontt,

Handa

2014

EUA

\section{Caroci et al.}

2014

Brasil

\section{Objetivos do estudo}

Analisar os efeitos do

PTMAP em mulheres com

IU em comparação com o não treinamento, placebo ou outros tratamentos de controle inativos.

Avaliar o efeito do tipo de parto sobre a dor pélvica com seis a onze anos após o parto.

\section{Avaliar a FMAP em} gestantes com um ou mais partos normais ou cesarianas e comparar a FMAP dessas gestantes com a de primigestas.
Tipo de estudo, amostra, período e instrumento de avaliação da FMAP

Revisão sistemática da biblioteca Cochrane que incluiu 21 ensaios clínicos randomizados ou quase randomizados com 1.281 mulheres (665 PTMAP, 681 controles) com IU de esforço, urgência ou mista.

Estudo de coorte, com 1.115 mulheres entre seis a sete anos após o primeiro parto, sendo 577 após a cesariana e 538 após um ou mais parto vaginal. A dor pélvica foi avaliada pelo questionário de estudo em saúde da mulher Oxfordshire, sendo que os fatores obstétricos foram avaliados pelos registros hospitalares.

Estudo transversal com 220 gestantes até 12 semanas de gestação, sendo 110 gestantes com um ou mais partos normais ou cesarianas e 110 primigestas. A FMAP foi avaliada pela perineometria e palpação digital vaginal (escala de Oxford modificada).

\section{Principais resultados e conclusões}

Em mulheres com IU de esforço, houve forte evidência de que o PTMAP está associado à cura (RR 17,33; IC 95\% 4,31 - 69,64). Em mulheres com qualquer tipo de IU houve também evidência, embora moderada, de que o PTMAP está associado à cura (RR 5,5; IC95\% 2,87 - 10,52) ou cura e melhora (RR 2,39; IC95\% 1,64 - 3,47).

A prevalência da dor pélvica entre as mulheres dos dois grupos foi semelhante; e entre aquelas de pós-parto vaginal que tiveram pelo menos um fórcipe ou recém-nascido $(\mathrm{RN})$ menor que quatro quilogramas, houve maior relato de dispareunia. $\mathrm{O}$ trauma perineal não foi associado à dispareunia. $\mathrm{O}$ parto normal não foi associado à maior taxa de dor pélvica comparado à cesariana.

A média da FMAP em gestantes com antecedentes de parto normal ou cesariana foi $33,4(\mathrm{dp}=21,2)$. Pela escala de Oxford, $75,4 \%$ das gestantes com partos ou cesarianas anteriores apresentaram grau $\leq 2$ e $5,5 \%$, grau $\geq 4$; entre as primigestas, $39,9 \%$ apresentaram grau $\leq 2$ e $50,9 \%$, grau $\geq 4$, com diferença estatisticamente significante $(\mathrm{p}<0,001)$. 
Quadro 1 - Estudos sobre a FMAP, durante o ciclo gravídico-puerperal, em relação IU, IA e a Dispareunia, São Paulo, SP - 2017

\begin{tabular}{ll}
\multicolumn{1}{c}{$\begin{array}{c}\text { Autor, ano e } \\
\text { local do estudo }\end{array}$} & \multicolumn{1}{c}{ Objetivos do estudo } \\
Martinez et al. & Investigar a relação entre a \\
2014 & FMAP e a função sexual \\
Brasil & $\begin{array}{l}\text { entre as mulheres com maior } \\
\text { e menor FMAP. }\end{array}$
\end{tabular}

Pelaez et al.

2014

Madri
Investigar o efeito do

PTMAP, como parte de uma

aula de exercícios na gestação, para prevenção de incontinência urinária em gestantes nulíparas continentes.
Tipo de estudo, amostra, período e instrumento de avaliação da FMAP

Estudo transversal, com 40 multíparas entre 20 28 anos, sem disfunções no Assoalho Pélvico (DAP). Foi utilizado para avaliação da função sexual, o FSFI (Female Sexual Function Index) e a FMAP através da palpação digital vaginal (escala de Ortiz) e perineômetro (Perina 996-2®, Quark Medical).

Ensaio clínico randomizado, com 169 nulíparas, com feto único, continentes e com idade gestacional entre 10 e 14 semanas. As mulheres foram dividas em grupo experimental (GE) e controle (GC) e avaliadas pela frequência e quantidade de perda de urina e o impacto na vida diária, por meio do Questionário Internacional de Incontinência Urinária (QIIU) e o Formulário Reduzido de Incontinência Urinária (FRIU).

\section{Principais resultados e conclusões}

Concluiu-se que multíparas com maior FMAP apresentaram escore elevado em relação ao desejo sexual, excitação, orgasmo e pontuação geral do questionário $(\mathrm{p}<0,001)$. Observou-se também uma correlação entre a pressão dos músculos do AP e satisfação sexual $(\mathrm{r}=0,47$, $\mathrm{p}=0,03)$ e lubrificação $(r=-0,69, \mathrm{p}=0,001)$. Os autores concluíram que as mulheres que apresentaram maior FMAP possuem melhor função sexual.

Após intervenção, com 36 semanas de gestação, houve aumento de mulheres continentes significantes no GE. O relato de não ter IU foi GC: 54-60,7\%, GE: 60-95,2\% ( $\mathrm{p}<0,001$ ). Mulheres no GC tiveram

frequência de perda de urina de mais de uma vez por semana (17-19,1\%). A quantidade de perda urinária pelas mulheres incontinentes no GE foi mencionada como pequena quantidade $(3-4,8 \%)$. No GC relatam pequena quantidade (27-30,6\%), quantidade moderada $(5-5,6 \%)$ e grande quantidade $(3-3,4 \%)$. Houve também diferença significativa nos resultados dos testes QIIU-FRIU entre os grupos: GC: 2,7 $(\mathrm{dp}=4,1)$ GE: $0,2(\mathrm{dp}=1,2)(\mathrm{p}<0,001)$. 
Quadro 1 - Estudos sobre a FMAP, durante o ciclo gravídico-puerperal, em relação IU, IA e a Dispareunia, São Paulo, SP - 2017

\begin{tabular}{ll}
\multicolumn{1}{c}{$\begin{array}{c}\text { Autor, ano e } \\
\text { local do estudo }\end{array}$} & \multicolumn{1}{c}{ Objetivos do estudo } \\
Petricelli et al. & Comparar função dos MAP \\
$\mathbf{2 0 1 4}$ & entre nulíparas e multíparas \\
Brasil & no terceiro trimestre da \\
& gravidez, analisando a \\
& relação entre a atividade \\
& elétrica (eletromiografia de \\
& superfície- EMG), palpação \\
& digital vaginal (escala de \\
& Oxford modificada), e \\
& distensibilidade perineal \\
& (Epi-no).
\end{tabular}

(Epi-no).

\section{Tipo de estudo, amostra, período e} instrumento de avaliação da FMAP Estudo transversal, com 60 grávidas (30 nulíparas e 30 multíparas), com idade gestacional entre 35 e 40 semanas e idade materna de 15 a 40 anos. Os métodos utilizados foram a palpação digital vaginal (escala de Oxford modificada, graduada de zero a cinco), EMG de superfície (atividade elétrica durante a contração voluntária máxima), e distensibilidade perineal (Epi-no).

Estudo transversal com 500 gestantes que iniciaram o pré-natal no primeiro trimestre de gestação. Utilizou-se a perineometria (modelo Peritron) e o instrumento International Consultation on Incontinence Questionnaireshort Form (ICIQ-SF).

\section{Principais resultados e conclusões}

Nulíparas apresentaram maior FMAP $(2,53 \pm 0,57$ versus $2,06 \pm 0,64)$ e o aumento da atividade eléctrica $(45,35 \pm 12,24 \mu \mathrm{V}$ contra $35,79 \pm 11,66 \mu \mathrm{V} ; \mathrm{p}=0,003)$, e as multíparas, a distensibilidade foi maior $(19,39 \pm 1,92$ versus $18,05 \pm 2,14)$. Não houve correlação entre distensibilidade perineal e atividade elétrica durante a contração voluntária máxima. Evidenciouse uma relação positiva entre palpação vaginal e eletromiografia de superfície, mas nenhuma entre os valores no Epi-no.

Observou-se que as variáveis idade materna $(\mathrm{OR}=1,06$; IC95\% 1,02-1,11) e antecedente de IU (OR=15,12; IC95\% 8,19-27,92) juntas, tem maior chance de apresentar IU no primeiro trimestre da gestação. A FMAP $<28,5 \mathrm{cmH}_{2} \mathrm{O}$ representa o ponto de corte para IU, tendo sido encontrada a média de $30,5(\mathrm{dp}=17,3) \mathrm{cmH}_{2} \mathrm{O}$, sendo que 27,2 $(\mathrm{dp}=15,8) \mathrm{cmH}_{2} \mathrm{O}$ ocorreu nas gestantes com IU e $31,3(\mathrm{dp}=17,6) \mathrm{cmH}_{2} \mathrm{O}$ naquelas sem IU. As primigestas apresentaram taxa de IU de 7,4\% e as multíparas de 11,6\%. 
Quadro 1 - Estudos sobre a FMAP, durante o ciclo gravídico-puerperal, em relação IU, IA e a Dispareunia, São Paulo, SP - 2017

\begin{tabular}{|c|c|}
\hline $\begin{array}{l}\text { Autor, ano e } \\
\text { local do estudo }\end{array}$ & Objetivos do estudo \\
\hline Tennfjord et al. & Investigar a ocorrência de \\
\hline Noruega & incômodo anterior à gravidez \\
\hline & $\begin{array}{l}\text { até } 12 \text { meses após o parto; } \\
\text { comparar a pressão de } \\
\text { repouso vaginal (VRP), } \\
\text { resistência e FMAP das } \\
\text { nulíparas com e sem } \\
\text { dispareunia, e avaliar o } \\
\text { impacto das variáveis de } \\
\text { confusão na dispareunia e } \\
\text { função da FMAP. }\end{array}$ \\
\hline
\end{tabular}

\section{Yeniel e Petri 2014} Alemanha
Investigar na literatura as transformações e os efeitos da gravidez e da via de parto na função sexual e demais DAP.

\section{Tipo de estudo, amostra, período e} instrumento de avaliação da FMAP

Estudo de coorte prospectiva, realizado com 300 nulíparas avaliadas entre 22 e 37 semanas de gestação, 6 e 12 meses após o parto e retrospectivamente, antes da gravidez usando o questionário The International Consultation on Incontinence Modular Questionnaire, sexual matters module/ICIQ- FLUTSsex. O perineômetro em $\mathrm{cmH}_{2} \mathrm{O}$ (Camtech AS, Sandvika, Norway), foi utilizado para avaliar a FMAP

Revisão sistemática com estudos randomizados, retrospectivos e prospectivos que foram

publicados no idioma inglês entre 1960 e 2012 . Incluíram-se estudos com mais de 100

participantes que usaram questionários validados relacionados à função sexual. Foram incluídos 20 estudos, 14 prospectivos e 6 retrospectivos.

\section{Principais resultados e conclusões}

Entre as nulíparas, $28 \%$ citaram dispareunia antes da gravidez e $30 \%$ com 22 semanas de gestacão. Houve $40 \%, 45 \%$ e $33 \%$, de mulheres com queixa de dispareunia 37 semanas, e seis e 12 meses depois do parto, respectivamente. Não houve diferença na FMAP das nulíparas com e sem dispareunia, porém o nível de incômodo foi maior no pósparto do que antes e durante a gravidez. A FMAP aos seis meses pós-parto foi 34,2 e 29,8 $\mathrm{cmH}_{2} \mathrm{O}$ nas nulíparas com e sem dispareunia, respectivamente.

Observou-se que a atividade sexual diminui durante a gravidez e essa redução se agrava com o avanço da gestação. Foram relatados aumento da dispareunia, diminuição do desejo e do orgasmo e outros problemas de disfunção sexual nos primeiros três meses de gestação, alterações que melhoraram gradualmente até seis meses após o parto. Não houve evidências relacionando o tipo de parto e alterações na função sexual. 
Quadro 1 - Estudos sobre a FMAP, durante o ciclo gravídico-puerperal, em relação IU, IA e a Dispareunia, São Paulo, SP - 2017

\begin{tabular}{ll}
\multicolumn{1}{c}{$\begin{array}{c}\text { Autor, ano e } \\
\text { local do estudo }\end{array}$} & \multicolumn{1}{c}{ Objetivos do estudo } \\
Barbosa et al. & $\begin{array}{l}\text { Avaliar a prevalência de IU e } \\
\text { disfunção muscular do AP }\end{array}$ \\
2013 & com dois anos após o parto e \\
Brasil & os fatores associados.
\end{tabular}

Caroci et al.
2010

Brasil

\section{Barbosa et al. 2009}

Brasil
Comparar a média da FMAP durante a gravidez e pósparto segundo: idade materna, cor da pele, situação conjugal, dispareunia, estado nutricional, característica das fezes, tipo de parto, condição do períneo e peso do recémnascido.

Analisar os resultados obtidos pela avaliação da FMAP, usando três diferentes perineômetros.

\section{Tipo de estudo, amostra, período e} instrumento de avaliação da FMAP Estudo transversal com 212 primíparas, com dois anos de pós-parto, sendo parto vaginal $(n=106)$ e cesariana eletiva $(n=106)$. Como método de avaliação da FMAP, foi utilizado a palpação digital vaginal e a perineometria (mmHg).

Estudo de coorte prospectiva, com 226 gestantes com seguimento de 110 mulheres.

Avaliou-se a FMAP em 3 etapas (até 12 semanas de gestação; entre 36-40 semanas de gestação; 42 a 60 dias após o parto através da perineometria (Perina ${ }^{\circledR}$ em mmHg) e palpação digital vaginal (escala de Oxford).

Estudo observacional, com amostra de conveniência que incluiu 20 mulheres nulíparas e não grávidas, entre 18 e 35 anos, IMC $<25$ quilogramas $(\mathrm{Kg}) /$ metro $(\mathrm{m})^{2}$, sem alterações anatômicas, funcionais ou DAP. Avaliou-se a FMAP pela palpação digital vaginal e com três diferentes perineômetros, Peritron ${ }^{\mathrm{TM}}$ (CardioDesign, Austrália), Neurodyn ${ }^{\mathrm{TM}}$ (Ibramed, Brasil) e SensuPower ${ }^{\mathrm{TM}}$ (Kroman, Brasil).

\section{Principais resultados e conclusões}

A prevalência de IU com dois anos após o parto vaginal foi de $17 \%$, enquanto na cesariana foi de $18,9 \%$. O ganho de peso na gestação foi o único fator de risco para a disfunção muscular do AP, assim o índice de massa corpórea (IMC) inferior a $25 \mathrm{~kg} / \mathrm{m}^{2}$ e a FMAP normal foram considerados fatores de proteção contra a IU. A cesariana eletiva não foi fator de proteção para a IU, e a IU gestacional foi um precursor de IU pós-parto.

Não houve diferença significativa na FMAP durante a gravidez ou após o parto. Em todas as etapas prevaleceu uma FMAP de baixa intensidade (etapa1 $=15,9 \mathrm{mmHg}$, etapa2 $=$ $15,2 \mathrm{mmHg}$ ) de 0-3 na escala de Oxford. Não houve diferença significativa na FMAP em relação à idade materna, cor de pele, situação conjugal, dispareunia, característica das fezes, tipo de parto, condição do períneo. Gravidez e parto não reduziram significativamente a FMAP

Encontrou-se moderada concordância entre os resultados do perineômetro Peritron ${ }^{\mathrm{TM}}$ e o Neurodyn $^{\mathrm{TM}}$, razoável concordância entre o Peritron $^{\mathrm{TM}}$ e o SensuPower ${ }^{\mathrm{TM}}$ e fraca concordância entre o Neurodyn ${ }^{\mathrm{TM}}$ e o SensuPower ${ }^{\mathrm{TM}}$. Constatou-se variação nas medidas da FMAP (fraca a moderada) sugerindo que perineômetros de diferentes fabricantes geram resultados divergentes. 


\subsection{OBJETIVO GERAL}

- Analisar a variação da FMAP, por meio da perineometria, em primíparas entre 50 e 70 dias e com 170 a 190 dias após o parto.

\subsection{OBJETIVOS ESPECÍFICOS}

- Investigar a prevalência de infecção do trato urinário, incontinência urinária, incontinência anal e dispareunia, em primíparas com 50 a 70 e 170 a 190 dias após o parto.

- Avaliar a associação da força muscular do assoalho pélvico com o tipo de parto, idade materna, escolaridade, cor da pele, situação conjugal, ocupação, índice de massa corpórea (IMC), infecção do trato urinário (ITU), incontinência urinária (IU), incontinência anal (IA), exercícios perineais, dispareunia, intervenções e condições do períneo no parto e do RN, em primíparas com 50 a 70 e 170 a 190 dias após o parto. 


\subsection{TIPO DE ESTUDO}

Trata-se de um estudo de coorte prospectiva sobre a análise da Força Muscular do Assoalho Pélvico (FMAP) de primíparas segundo o tipo de parto entre 50 e 70 dias e com 170 a 190 dias após o parto. A presente pesquisa é uma continuidade de um estudo transversal denominado "Força muscular perineal de primíparas segundo o tipo de parto: estudo transversal". A coleta de dados desse estudo transversal ocorreu no período de janeiro a setembro de 2014 e teve por objetivos: Identificar a FMAP em primíparas no pós-parto normal e cesariana entre 50 e 70 dias pós-parto e comparar a FMAP de primíparas após o parto normal e cesariana em relação às características sociodemográficas, clínicas e uroginecológicas da mulher, exercício perineal, dados do parto, condições do períneo e dados clínicos do RN (Mendes, 2015).

\subsection{LOCAL}

Os dois estudos foram realizados no Centro do Parto Normal (CPN) do Pronto Socorro e Maternidade Municipal Zoraide Eva das Dores (PSMMZED) e nas Unidades Básicas de Saúde (UBS), situados no município de Itapecerica da Serra, região metropolitana da grande São Paulo. O PSMMZED é referência para gestante de risco habitual e sua área de abrangência inclui os municípios de Itapecerica da Serra, Juquitiba, São Lourenço e EmbuGuaçu. As gestantes de alto risco são encaminhadas para o Hospital Geral Itapecerica da Serra.

Tendo como referência os anos de 2014 e 2015, o CPN atendeu uma demanda de aproximadamente 117 partos por mês, sendo que $78 \%$ deles foram normais e $22 \%$ cesarianas. Em relação às condições perineais verificou-se que do total de partos normais, $34,1 \%$ das mulheres tiveram períneo íntegro, 49,8\% laceração perineal de primeiro e segundo graus e $16,1 \%$ episiotomia. Dentre os partos normais, 36,9\% eram primíparas, sendo que, 19,8\% apresentaram períneo íntegro, 55,3\% tiveram laceração perineal de primeiro e segundo graus e $24,9 \%$ episiotomia. ${ }^{1}$

Nessa instituição, os partos normais são assistidos por duas enfermeiras obstétricas por plantão; a equipe médica é composta por dois obstetras, um anestesista e um neonatologista. O protocolo dessa maternidade recomenda atender as normas da Organização Mundial de Saúde (OMS) que preconiza o mínimo de intervenções possíveis na assistência ao parto (OMS, 1996; Brasil 2001).

\footnotetext{
${ }^{1}$ Centro de Parto Normal. Livro de registro de partos. Itapecerica da Serra, 2014 e 2015.
} 
Após a internação, a parturiente é encaminhada ao CPN, sendo estimulada a deambular, a tomar banho de aspersão, a realizar exercícios com a bola suíça e com o cavalinho. Os procedimentos como, tricotomia perineal, jejum e enema não fazem parte da rotina das mulheres que estão em trabalho de parto. É protocolo do serviço que a infusão venosa de ocitocina, durante o trabalho de parto, seja utilizada com critério de indicação, porém alguns médicos prescrevem rotineiramente e outros não. Os partos normais, em geral, são realizados na posição semissentada ou na posição de escolha das parturientes. A episiotomia não é adotada como rotina nos partos normais e quando indicada é realizada sob anestesia local. Para o reparo das lacerações perineais e da episiotomia é empregada a técnica convencional de sutura com o fio categute zero simples.

É oferecido a todas as parturientes o direito de manter um acompanhante de sua escolha durante o trabalho de parto e o parto e esse acompanhante é encorajado pelas enfermeiras a realizar o corte do cordão umbilical após o $\mathrm{RN}$ ter o primeiro contato pele a pele com a mãe. O clampeamento precoce só deve ocorrer com indicação da enfermeira obstetra ou do pediatra. Após o parto, é prescrito de rotina analgésico via oral a cada seis horas e em casos de episiotomia um anti-inflamatório a cada oito horas. Em condições normais, o tempo de internação da puérpera e do RN é de 50 horas.

A escolha do local de estudo justifica-se pelo fato de se tratar de um Centro de Parto Normal, que busca seguir as boas práticas obstétricas recomendadas pela OMS e porque a maioria das mulheres que ganha bebê nesse local, reside na área de abrangência da maternidade.

\subsection{POPULAÇÃO E AMOSTRA}

\subsubsection{População}

A população deste estudo foi constituída por primíparas que tiveram o parto no local referido anteriormente.

\subsubsection{Critérios de inclusão dos estudos Transversal}

- Ter apenas um parto normal ou cesariana a termo (entre 37 e 42 semanas);

- Estar no período de internação;

- Ter recém-nascido único e vivo em apresentação cefálica no parto normal;

- Não ter sido submetida à cirurgia abdominal ou urogenital prévia; 
- Não ser acometida por doenças ou condições físicas que possam interferir na FMAP (prolapso de órgãos pélvicos, doenças neurológicas, diabetes, lesão pélvica ou da coluna vertebral);

- Não ter dificuldade no entendimento do idioma português ou na comunicação por diminuição da acuidade auditiva ou limitação da fala.

\subsubsection{Critérios de inclusão da Coorte}

- Puérpera ter feito parte do estudo transversal e ter retornado para a consulta com 170 a 190 dias após o parto;

- Caso a puérpera não tenha participado do estudo transversal, os critérios adotados foram os mesmos da etapa 1 .

\subsubsection{Critério de exclusão dos estudos Transversal e Coorte}

- Apresentar dificuldade à inserção do perineômetro na vagina.

\subsection{AMOSTRA}

Para o estudo Transversal, a amostra foi calculada considerando a comparação da FMAP entre mulheres com parto normal e cesariana do estudo de Menta e Schirmer (2006), no qual foi observado um tamanho de efeito d de Cohen igual a 0,669 para erro tipo I igual a $5 \%$ e poder de teste de $90 \%$. Tomando como base o registro da distribuição dos partos, no livro de partos da maternidade, entre os anos de 2011 e 2012, verificou-se que para cada mulher submetida à cesariana ocorriam três partos normais, assim seriam necessárias 96 primíparas, sendo 24 submetidas à cesariana e 72 de parto normal. O cálculo da amostra foi feito com o programa $G^{*}$ Power 3.1.9.2 (Faul et al., 2007) que segue a metodologia descrita por Chow et al. (2002).

A amostra da Coorte foi por conveniência uma vez que iria avaliar as mesmas puérperas analisadas no estudo Transversal. Considerando, no entanto, a grande possibilidade de perdas de seguimento dessas mulheres, optou-se por ampliar em $30 \%$ o recrutamento com a previsão de analisar, ao final, 96 mulheres que estavam entre 170 e 190 dias de pós-parto, de acordo com a amostra calculada para o estudo Transversal. 


\subsection{COLETA DE DADOS}

Antes do início da coleta de dados, o estudo foi apresentado aos profissionais da saúde do local em estudo com a finalidade de obter aceitação, colaboração e integração da equipe com as pesquisadoras.

A coleta de dados do estudo transversal foi realizada pela pesquisadora principal auxiliada pela pesquisadora da coorte e ocorreu em duas etapas, sendo que a etapa 1, durante a internação hospitalar e a etapa 2, de 50 a 70 dias depois do parto, quando foi entregue um folheto com orientações sobre exercícios perineais (Anexo 1). Ao final de cada etapa, a puérpera foi convidada a participar da etapa seguinte. Entre sete e dois dias anteriores à próxima etapa, a pesquisadora fazia contato com a participante, por telefone, a fim de lembrála da consulta. Em caso de não comparecimento à consulta, foi realizado novo contato telefônico para marcar o retorno.

A coleta de dados da Coorte é composta de três etapas, sendo duas delas do estudo transversal e da etapa 3, que deu seguimento com as mesmas mulheres que retornaram entre 170 e 190 dias após o parto. Em razão de muitas perdas houve necessidade de recrutar novas

puérperas, desde a etapa 1 até a 3, a fim de completar a amostra de 96 primíparas calculada para o estudo transversal. O formulário para o registro de dados (Apêndice 1) foi adaptado do estudo já referido anteriormente na introdução (Costa, 2008) e do questionário criado por Clarkson et al. (2001). Para coletar as informações sobre a gestação foi utilizado o cartão de pré-natal e sobre o parto e puerpério imediato utilizou-se o prontuário da participante além da entrevista.

Durante a coleta de dados, no caso de identificar qualquer intercorrência com a mulher, como IU ou outras queixas, elas foram encaminhadas ao ginecologista de referência da UBS, seguindo o fluxo de atendimento da maternidade.

\subsubsection{Etapas do estudo}

\section{Etapa 1: Recrutamento (entrevista, cartão de pré-natal e prontuário)}

O recrutamento das participantes tanto do estudo transversal como da coorte foi realizado na mesma maternidade, logo após o parto e aquelas que atenderam aos critérios de inclusão foram abordadas e convidadas a participarem da pesquisa. Nesse momento, as puérperas receberam todas as informações sobre o estudo e assinaram o Termo de Consentimento Livre e Esclarecido (TCLE) (Apêndice 2) e quando as participantes tinham 
menos de 18 anos, assinaram o Termo de Assentimento (Apêndice 3). Nessa etapa foi feita a coleta de dados referentes à gestação, ao trabalho de parto e ao parto.

$\mathrm{Na}$ alta hospitalar, foi agendado o retorno da puérpera e do RN à UBS ou à maternidade, de acordo com a preferência da participante, a fim de realizar a etapa 2 do estudo que consta de consulta puerperal.

\section{Etapa 2: Análise da FMAP}

Nessa etapa, realizou-se a entrevista e a mensuração da FMAP entre 50 e 70 dias de pós-parto. A seguir, foi novamente agendado um segundo retorno, com 170 a 190 dias, para a próxima entrevista e avaliação da FMAP.

\section{Etapa 3: Seguimento e análise da FMAP}

Participaram dessa etapa as mesmas mulheres das duas etapas do estudo transversal além de outras puérperas que foram recrutadas para a coorte desde a etapa 1. Nessa etapa, foi realizada a terceira entrevista e a segunda avaliação da FMAP.

\subsubsection{Medidas e instrumento para avaliar os desfechos}

Todas as participantes foram submetidas à mensuração da FMAP por meio da perineometria. Para avaliar a qualidade de vida da puérpera com queixa de perda de urina, optou-se por utilizar o instrumento ICIQ-SF.

A coleta de dados do estudo transversal e da coorte foi realizada por duas pesquisadoras previamente treinadas para utilizar o perineômetro e o ICIQ-SF.

\subsubsection{Perineometria}

O aparelho que foi utilizado para mensurar a FMAP é um perineômetro eletrônico de pressão modelo Peritron ${ }^{\mathrm{TM}} 9300$ (Cardio-Design, Austrália). Esse aparelho possui uma sonda vaginal de silicone de oito centímetros $(\mathrm{cm})$ de comprimento por três $\mathrm{cm}$ de diâmetro. A sonda possui um sensor conectado a um microprocessador portátil que realiza o registro da contração muscular do AP a partir de $0,1 \mathrm{~cm}$ de água $\left(\mathrm{cmH}_{2} \mathrm{O}\right)$ até $300 \mathrm{cmH}_{2} \mathrm{O}$ embora quando os valores são inferiores a $5,0 \mathrm{cmH}_{2} \mathrm{O}$, não ocorre o registro na sua memória, mas o valor aparece no aparelho.

\subsubsection{Procedimentos para mensurar a FMAP no estudo transversal e na coorte (Costa, 2008)}

1. Orientar a mulher a colocar-se em posição ginecológica, cobrir com o lençol a região genital e os membros inferiores; 
2. Calçar luvas de procedimentos;

3. Ensinar a mulher a fazer contrações como se estivesse "segurando" a urina, usando somente os músculos do AP, evitando contrair os músculos abdominais, da coxa e das nádegas;

4. Revestir a sonda elástica com um preservativo descartável, sem lubrificante;

5. Lubrificar o preservativo com gel lubrificante;

6. Introduzir a sonda na vagina até a marca indicada;

7. Insuflar o balão até a marca de $100 \mathrm{cmH}_{2} \mathrm{O}$ e zerar o nível de pressão;

8. Orientar a mulher a relaxar os MAP;

9. Solicitar que a mulher contraia, voluntariamente, os músculos perineais ao redor da sonda vaginal e permaneça, o máximo de tempo possível, realizando sequência de três sessões, com intervalo de 15 segundos entre elas;

10. Permanecer com a sonda vaginal durante todas as mensurações da FMAP;

11. Registrar os valores das três sessões realizadas para verificar a força da contração voluntária dos músculos do AP.

Observação: Considerar o valor máximo que aparece no aparelho durante as contrações da FMAP, pois na memória só fica registrado os valores superiores a 5,0 $\mathrm{cmH}_{2} \mathrm{O}$.

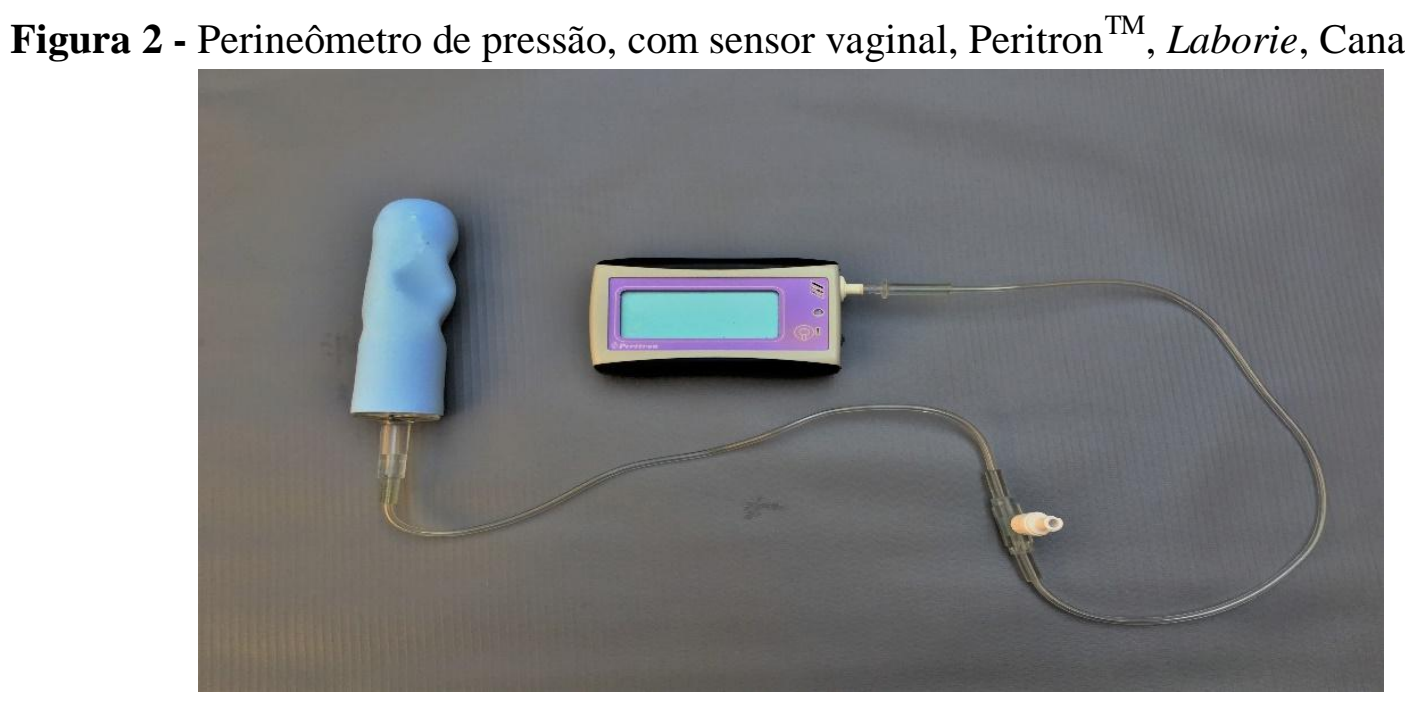

Fonte: a pesquisadora

O fabricante do perineômetro utilizado no estudo considera que este aparelho pode ser mais preciso do que os outros disponíveis no mercado, pois na leitura efetuada pelo Peritron $^{\mathrm{TM}} \mathrm{o}$ erro não supera $1 \mathrm{cmH}_{2} \mathrm{O}$. 


\subsubsection{International Consultation on Incontinence Questionnaire-Short Form (ICIQ-SF)}

Diante da necessidade de um questionário que fosse prático e que avaliasse a qualidade de vida de pessoas com queixa de perda de urina, a OMS incentivou o desenvolvimento do questionário ICIQ-SF (Anexo 2) (OMS, 1998). Os autores Avery et al. (2004) referem que por meio desse questionário é possível avaliar os sintomas e o impacto da IU na qualidade de vida das pessoas, e que seu emprego é apropriado para a pesquisa e a prática clínica.

O ICIQ-SF está traduzido em 35 idiomas. No Brasil, foi traduzido e validado por Tamanini et al. (2004). Esse instrumento consta de quatro questões relativas à frequência e quantidade de perda urinária, à interferência da perda na vida diária e situações nas quais podem ocorrer a IU. Para as respostas das três primeiras perguntas são concedidas pontuações com escore final que pode ser de 0 a 21 . A última questão referente às situações em que a IU pode ocorrer tem oito opções de resposta qualitativa.

Nessa coorte, esse questionário foi utilizado apenas para as puérperas que referiram perdas urinárias persistentes com a finalidade de padronizar o tipo de perda e medir ou identificar os sintomas, contudo sem analisar o impacto da IU na qualidade de vida.

\subsection{VARIÁVEIS DO ESTUDO}

\subsubsection{Dependente}

- Força Muscular do Assoalho Pélvico (FMAP): tônus da musculatura do AP, avaliado na contração por meio da perineometria e considerado o maior valor.

\subsubsection{Independentes}

- Tipo de parto: normal ou cesariana (eletiva, urgência, precedida ou não de trabalho de parto);

- Posição materna adotada durante o parto: posição referida pela mulher e ou registrada no prontuário em que ela manteve-se durante o parto, podendo ser classificada como sentada, semissentada, lateral, genitu-peitoral e de cócoras;

- Condição do períneo no parto: verificada pelo registro no prontuário e foi classificada como períneo íntegro, lacerações de primeiro, segundo, terceiro e quarto graus e episiotomia médio-lateral direita; Períneo íntegro: quando não ocorre qualquer solução de continuidade tecidual. O grau de laceração perineal foi avaliado de acordo com os critérios estabelecidos pelo National Institute for Health and Clinical Excellence (NICE, 2014), segundo definição de Sultan, 1999 como: Primeiro grau: lesão somente de 
pele; Segundo grau: lesão dos músculos perineais, mas não o músculo do esfíncter anal; Terceiro grau: lesão do conjunto de músculos do esfíncter do ânus: $3 \mathrm{a}$ - menos de 50\% da espessura do esfíncter anal; $3 b$ - mais de $50 \%$ da espessura do esfíncter anal e 3cesfíncter anal interno lesionado; Quarto grau: lesão do períneo que envolve o conjunto de músculos do esfíncter anal;

- Uso de ocitocina durante o trabalho de parto e parto: sim ou não e com quantos centímetros de dilatação cervical iniciou-se o uso;

- Uso de misoprostol: sim ou não e com quantos centímetros de dilatação cervical iniciou-se o uso e o número de comprimidos utilizados;

- Puxo dirigido ou espontâneo: tipo de puxo referido pela mulher e ou registrado no prontuário. Entende-se por puxo dirigido aquele que o profissional orientou a mulher a fazer força comprida para expulsar o bebê, mesmo quando ela não teve vontade. É considerado puxo espontâneo quando a mulher faz força somente quando tem vontade e, no máximo, o profissional orienta como deve ser essa força, mas não a dirige;

- Manobra de Kristeller: referida ou não pela mulher e registrada ou não no prontuário. Essa força é exercida por um profissional no fundo do útero, objetivando auxiliar a parturiente a empurrar o bebê durante o período expulsivo;

- Incontinência urinária (IU) antes e durante a gestação: refere-se à perda de urina em qualquer quantidade, frequência ou tipo;

- Incontinência urinária (IU) após o parto: avaliada por meio do ICIQ-SF com escore entre 0 e 21 de pontuação, refere-se à perda de urina em qualquer quantidade, frequência ou tipo nas últimas quatro semanas;

- Dispareunia: dor referida durante a relação sexual, nas últimas quatro semanas, classificada em sim ou não e, se isso incomoda ou não o relacionamento com o parceiro;

- Idade materna: em anos, coletado na etapa 1 do estudo;

- Escolaridade: classificada em nenhuma; ensino fundamental incompleto e completo; ensino médio incompleto e completo; ensino superior incompleto e completo; pósgraduação incompleta e completa;

- Cor da pele: autorreferida, classificada em preta, parda e branca;

- Situação conjugal: classificada como tem ou não parceiro;

- Ocupação: classificada em atividade remunerada sim e não; 
- Idade gestacional no momento do parto: classificada em semanas pela ultrassonografia ou pela data da última menstruação e, em casos incertos, confirmada pelo Capurro e verificada pelo registro no prontuário;

- Peso materno: classificado em quilogramas, referente ao peso verificado na primeira consulta do pré-natal de acordo com o registro no cartão de pré-natal e os pesos mensurados na internação para o parto e nas consultas puerperais;

- Estatura materna: classificada em centímetros e verificada na primeira consulta de pré-natal, dado utilizado no cálculo do índice de massa corpórea;

- Índice de massa corpórea (IMC): calculado dividindo o peso pela estatura ao quadrado e classificado de acordo com o IMC e a idade gestacional em: baixo peso, adequado, sobrepeso e obesidade (Atalah et al., 1997).Tendo como base para cálculo o peso atual na etapa 2 e na etapa 3 ;

- Ganho de peso na gestação: calculado pela diferença de peso da primeira consulta do pré-natal e o peso da internação para o parto;

- Ganho de peso entre as etapas 2 e 3: calculado pela diferença de peso entre 50-70 dias e 170-190 dias de pós-parto;

- Idade da primeira menstruação: em anos, obtida por entrevista;

- Idade da primeira relação sexual: em anos, obtida por entrevista;

- Tempo de atividade sexual ativa: em anos, obtida por entrevista;

- Retorno da atividade sexual após o parto: classificado em sim ou não e caso não, especificar o motivo;

- Uso de anticoncepcional: sim ou não. Sendo a resposta afirmativa, informar se o uso era esporádico ou rotineiro e especificar qual o medicamento;

- Anestesia: local, raquidiana, peridural ou peridural combinada com a raquidiana (duplo bloqueio), registrada no prontuário;

- Infecção do trato urinário (ITU): infecção diagnosticada na gestação ou puerpério por meio do resultado de Urina 1 com leucócitos aumentados ou urocultura positiva, com ou sem sintomas, segundo o registro em cartão de pré-natal ou autorreferida e classificada em sim ou não;

- ITU recorrente: infecção urinária recorrente, duas crises ou mais em seis meses, tendo ocorrido após o tratamento e causada pelo mesmo ou por outro microorganismo;

- Tratamento para ITU: referido pela mulher em sim ou não; 
- Incontinência urinária: perda involuntária da urina, ocorrida antes e durante a gestação, após o parto e atualmente.

- Incontinência anal: perda involuntária de flatos ou fezes após o parto em qualquer frequência, quantidade e situação (sim ou não);

- Consumo: álcool, tabaco e drogas ilícitas, classificado como sim ou não. Em caso afirmativo, perguntou-se a frequência;

- Exercício perineal realizado durante a gestação ou após o parto: qualquer tipo de exercício para fortalecimento do AP, como Kegel, segurar o jato urinário ou outros, referido pela mulher como sim ou não e sem supervisão de um profissional, independente da frequência com que o realizava;

- Peso do recém-nascido: imediatamente após o nascimento, classificado em gramas e registrado no prontuário;

- Circunferência cefálica: avaliada em centímetros, registrada no prontuário;

- Vitalidade fetal: avaliada pelo boletim de Apgar no primeiro e quinto minuto de vida, registrada no prontuário.

\subsection{ANÁLISE DOS DADOS}

Os dados registrados no formulário foram armazenados no aplicativo Excel, em planilhas separadas daqueles que completaram a coorte e das perdas de seguimento e, posteriormente, analisados estatisticamente. Foram calculadas as frequências absolutas e relativas das variáveis qualitativas e as medidas de tendência central e dispersão (média, mediana, desvio-padrão e valores máximo e mínimo) para as variáveis quantitativas.

Para análise das perdas foram utiliados o teste Qui-quadrado ou exato de Fisher para as variáveis categóricas e o teste $\mathrm{T}$ de Student para as variáveis numéricas.

A análise foi realizada pelo programa Statistical Package for Social Sciences (SPSS) versão 22.0. Para a comparação da FMAP com as seguintes variáveis: tipo de parto, idade materna, escolaridade, cor da pele, situação conjugal, atividade remunerada, IMC, ITU, IU, IA, exercícios perineais, intervenções no parto, condições perineais e caracteristicas do RN foi utilizado o modelo de efeitos mistos. As variáveis cujo efeito de interação foram significativas nas comparações bivariadas com a FMAP $(p<0,05)$ foram incluídas no modelo longitudinal preditivo.

Os resultados foram considerados, estatisticamente, significantes quando os valores de $\mathrm{p}$ foram $<0,05$. 


\subsection{ASPECTOS ÉTICOS}

O estudo foi aprovado pelo Conselho Municipal de Saúde da Autarquia de Saúde de Itapecerica da Serra (Anexo 3) e pelo Comitê de Ética em Pesquisa da Escola de Enfermagem da Universidade de São Paulo, junto à Plataforma Brasil (CAAE:13545113.5.0000.5392) (Anexo 4).

De acordo com as determinações da Resolução 466/2012 do Conselho Nacional de Saúde (CNS), a fim de assegurar os direitos humanos das mulheres envolvidas, elas só foram inscritas na pesquisa depois que as pesquisadoras orientaram-nas quanto aos objetivos da mesma e solicitaram que essas mulheres assinassem o Termo de Consentimento Livre e Esclarecido (CNS, 2012). Quando a participante era menor de idade, foi solicitada a assinatura do Termo de Assentimento por parte da participante e do responsável pela menor.

Merece destacar que não há nenhum tipo de conflito de interesse entre as pesquisadoras e o fabricante em relação ao aparelho utilizado neste estudo.

A Figura 3 apresenta o ordinograma esquematizando o método utilizado no estudo. 
Figura 3 - Ordinograma do método utilizado no estudo, Itapecerica da Serra, SP - 2017

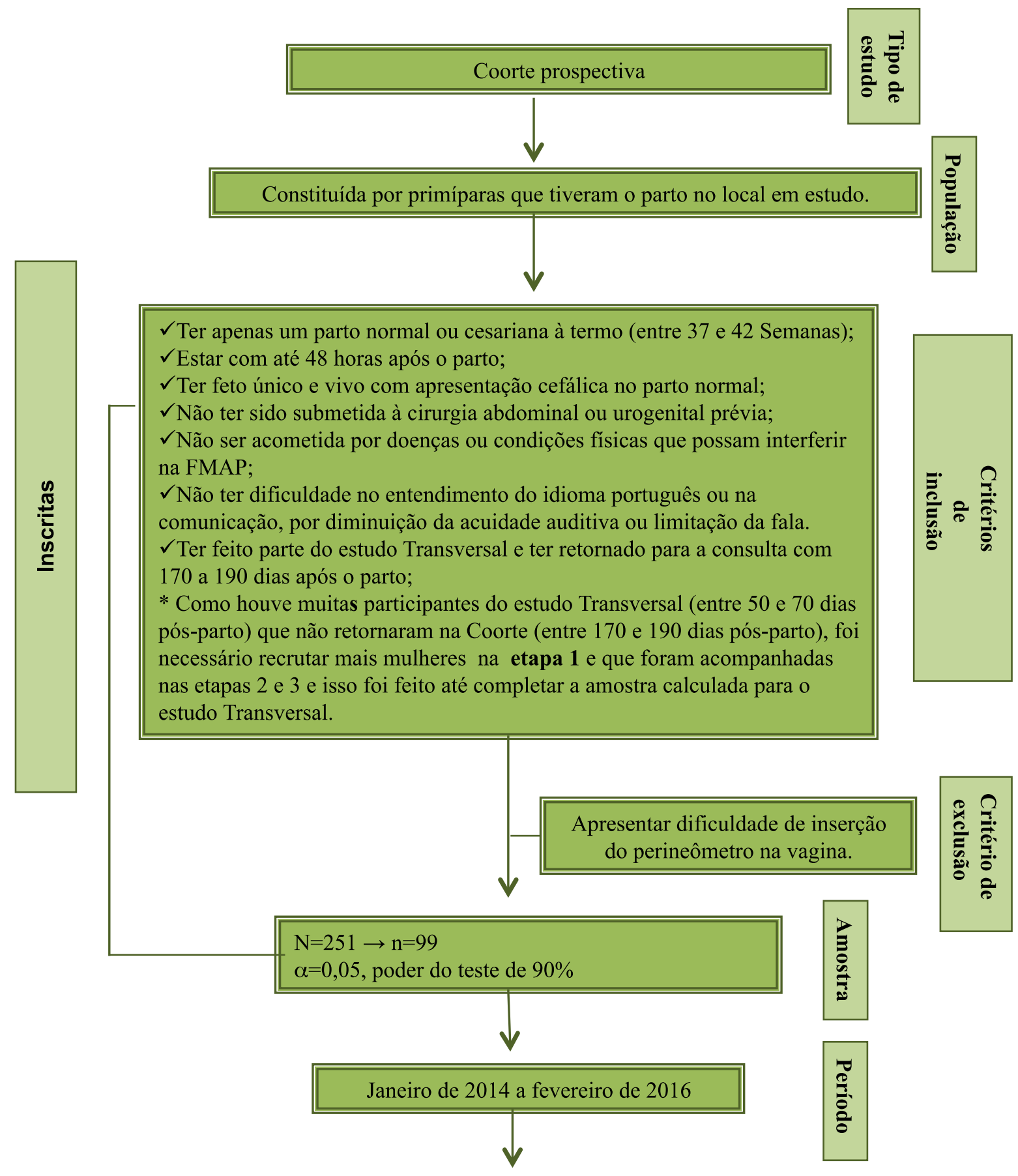

(continua) 
(cont.)

Figura 3 - Ordinograma do método utilizado no estudo, Itapecerica da Serra, SP - 2017

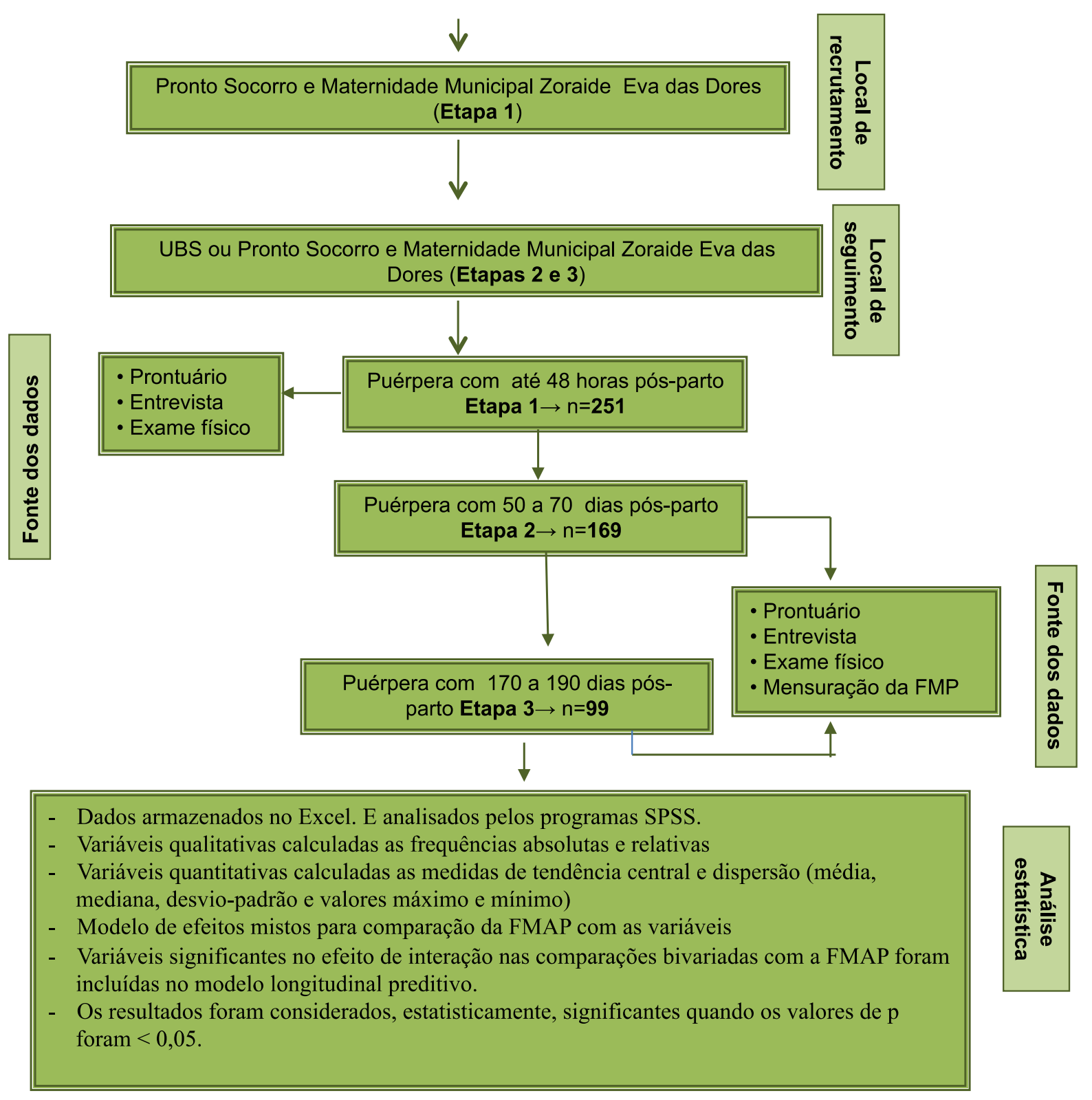


Figura 3 - Ordinograma do método utilizado no estudo, Itapecerica da Serra, SP - 2017

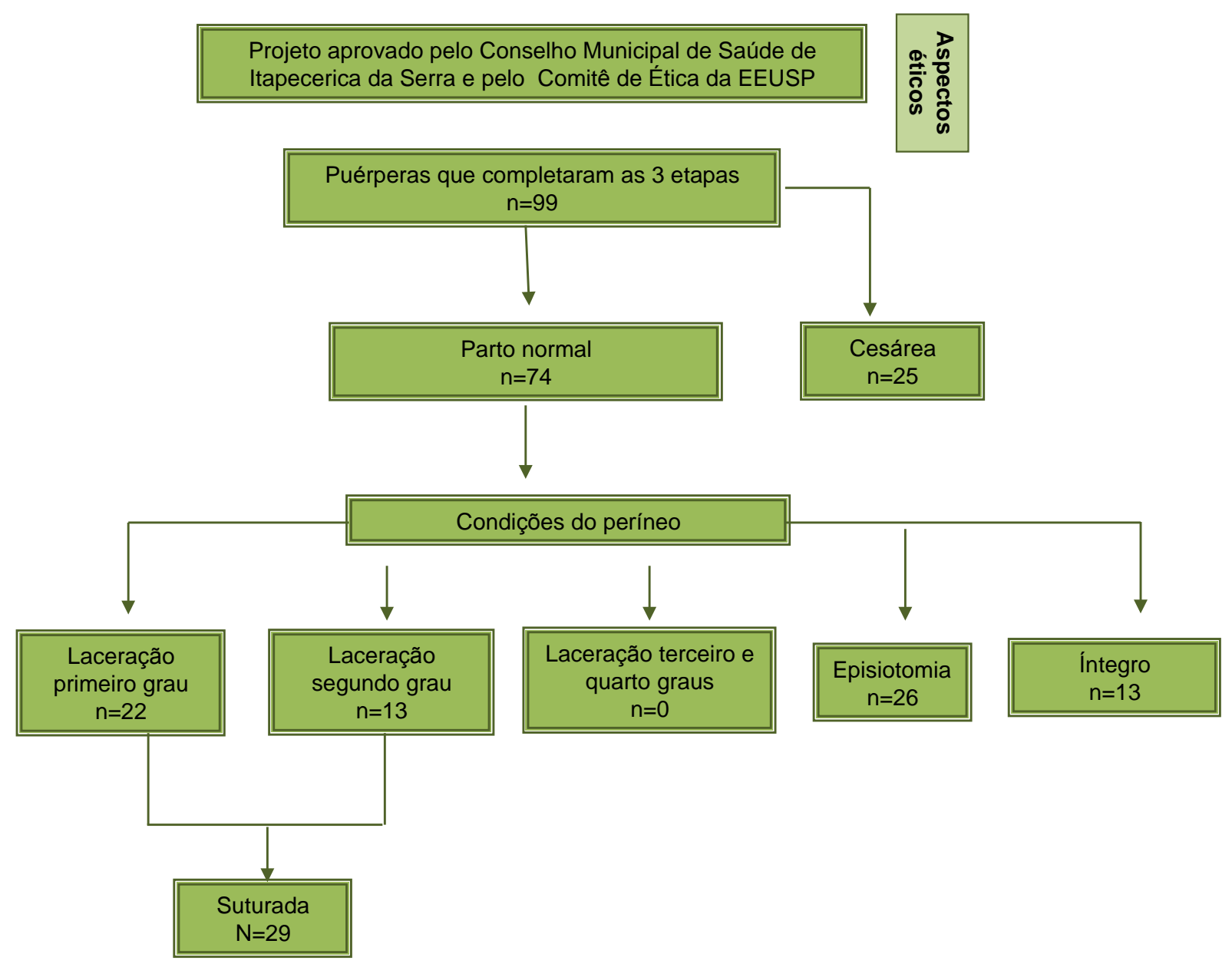

\subsection{APRESENTAÇÃO DO PERÍODO EM QUE HOUVE INÍCIO E TÉRMINO DA COLETA DE DADOS DAS PUÉRPERAS NAS TRÊS ETAPAS}

Tabela 1 - Cronograma das etapas de coleta de dados, Itapecerica da Serra - 2014 a 2016

\begin{tabular}{lll}
\hline Etapa & Início & Término \\
\hline $\mathbf{1}$ & 02 de janeiro de 2014 & 05 de setembro de 2015 \\
$\mathbf{2}$ & 12 de março de 2014 & 06 de outubro de 2015 \\
$\mathbf{3}$ & 23 de junho de 2014 & 02 de fevereiro 2016 \\
\hline
\end{tabular}


Foram recrutadas 251 mulheres para a etapa 1, sendo que 169 foram incluídas no estudo transversal e, posteriormente, 82 na coorte. Dentre as 169 mulheres do estudo transversal, somente 96 concluíram a etapa 2 (50 a 70 dias pós-parto) e, apenas, 54 retornaram para a etapa 3 (170 a 190 dias pós-parto) na coorte. Fizeram parte da amostra da coorte 99 mulheres, sendo 54 do estudo transversal e 45 que foram incluídas desde a etapa 1 para completar a amostra (Figura 4).

Figura 4 - Fluxograma referente ao recrutamento das participantes do estudo transversa1 e da coorte, Itapecerica da Serra, SP - 2014 a 2016

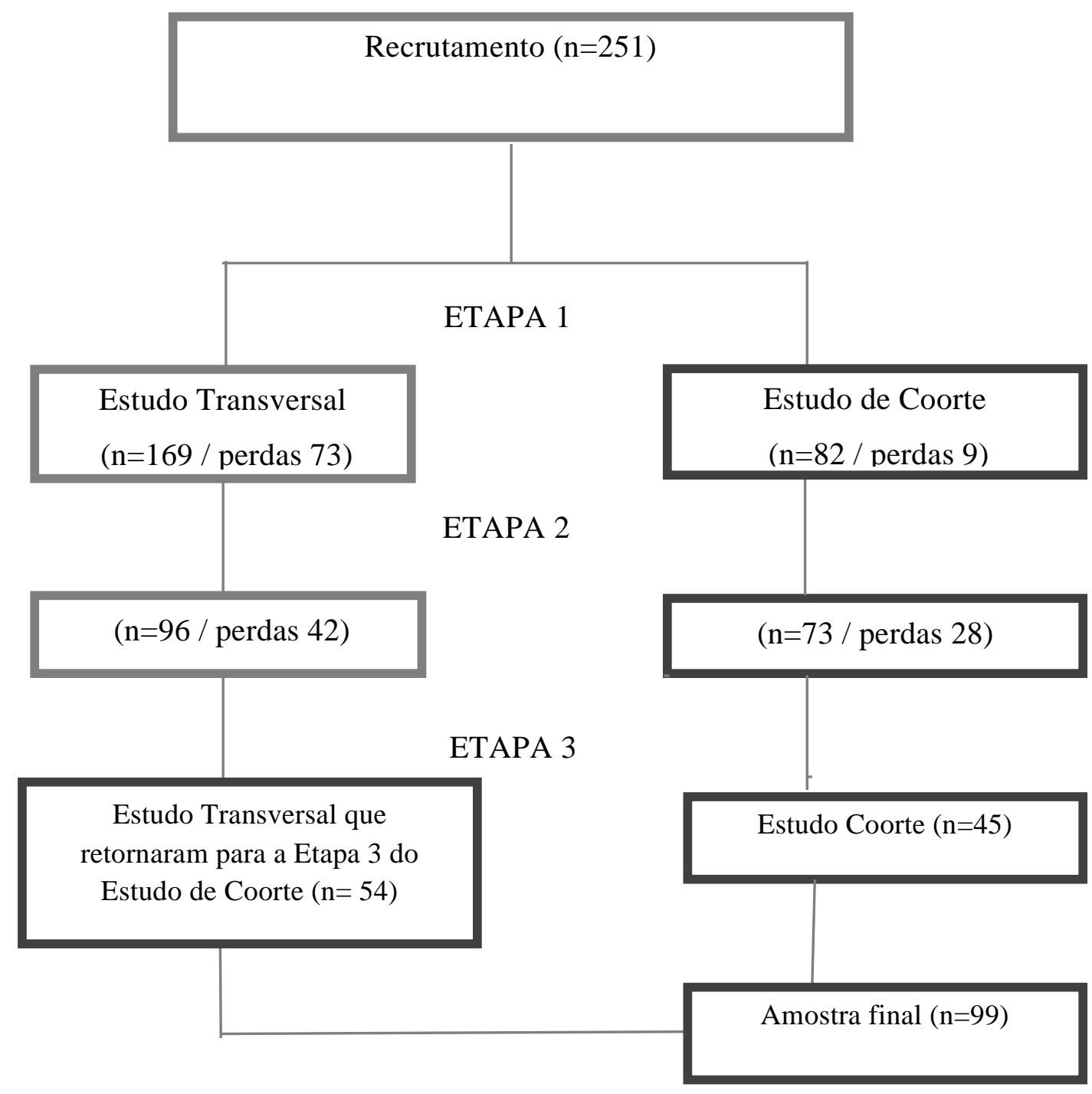

A análise das perdas de seguimento das 152 mulheres (tanto do estudo transversal como da coorte) apontou que a maioria das variáveis (idade materna, cor da pele, escolaridade, ocupação e tipo de parto) foram semelhantes às daquelas que permaneceram na 
coorte, exceto a variável "vive com parceiro" que foi menos prevalente no grupo das perdas $(\mathrm{p}=0,003)$. Os motivos mais frequentes das perdas foram mudança de endereço e número do telefone inexistente.

Os resultados estão apresentados nos seguintes itens: 4.1 Caracterização da Amostra (Tabelas 2 a 8) e 4.2 Análise Comparativa da FMAP (Tabelas 9 a 18).

\subsection{CARACTERIZAÇÃO DA AMOSTRA}

As características sociodemográficas e comportamentais das primíparas que concluíram as etapas 1 a 3 mostraram que a maioria considerou-se de cor parda; três quartos tinham nove anos ou mais de estudo; grande número vivia com o companheiro e não possuía ocupação remunerada. Em relação aos hábitos comportamentais, nota-se que um pequeno número delas era usuários de álcool, tabagista e drogas ilícitas (Tabela 2). 
Tabela 2 - Número e percentagem de primíparas segundo as características sociodemográficas e hábitos comportamentais, Itapecerica da Serra, SP - 2014 a 2016

\begin{tabular}{|c|c|c|}
\hline Variável & $\mathbf{n}$ & $\%$ \\
\hline \multicolumn{3}{|c|}{ Cor da pele } \\
\hline Parda & 56 & 56,6 \\
\hline Branca & 35 & 35,3 \\
\hline Preta & 8 & 8,1 \\
\hline \multicolumn{3}{|c|}{ Escolaridade (anos) } \\
\hline$\leq 8$ & 24 & 24,2 \\
\hline 9 a 11 & 67 & 67,7 \\
\hline$\geq 12$ & 8 & 8,1 \\
\hline \multicolumn{3}{|l|}{ Parceiro } \\
\hline Sim & 86 & 86,9 \\
\hline Não & 13 & 13,1 \\
\hline \multicolumn{3}{|c|}{ Atividade remunerada } \\
\hline Sim & 29 & 29,3 \\
\hline Não & 70 & 70,7 \\
\hline \multicolumn{3}{|c|}{ Hábitos comportamentais } \\
\hline \multicolumn{3}{|l|}{ Álcool } \\
\hline Sim & 4 & 4,0 \\
\hline Não & 95 & 96,0 \\
\hline \multicolumn{3}{|l|}{ Tabaco } \\
\hline Sim & 12 & 12,1 \\
\hline Não & 87 & 87,9 \\
\hline \multicolumn{3}{|l|}{ Drogas } \\
\hline $\operatorname{Sim}$ & 1 & 1,0 \\
\hline Não & 98 & 99,0 \\
\hline Total & 99 & 100 \\
\hline
\end{tabular}

A média da idade materna foi de 21,7 (d.p.=5,0) anos, com idade mínima de 13 e máxima de 39 anos. As parturientes foram internadas com idade gestacional média de 39,6 (d.p.=0,9) semanas, variando entre 37 e 41 semanas. A menarca ocorreu, em média, de 12,7 (d.p.=1,4) anos, variando entre nove e 16 anos. As mulheres referiram que iniciaram a atividade sexual, em média, com 16,6 (d.p.=2,9) anos, com, no mínimo 12 anos e, no máximo 
30 anos, e uma média de tempo de vida sexual ativa de 5,4 (d.p.=3,9) anos, sendo o mínimo de um ano e o máximo de 21 anos. O ganho de peso na gestação apresentou uma média de 11,7 (d.p.=4,2) kg, com o máximo de $24,3 \mathrm{Kg}$. A menor média do IMC foi na primeira consulta de pré-natal $(23,8)$ e a maior média foi na última consulta de pré-natal $(28,5)$. Durante o puerpério foram apresentados valores próximos ao início do pré-natal (Tabela 3).

Tabela 3 - Estatística descritiva das variáveis quantitativas segundo as características sociodemográficas e clínicas, Itapecerica da Serra, SP - 2014 a 2016 (n=99)

\begin{tabular}{|c|c|c|c|c|c|}
\hline Variável & Média & d.p. & Med & Mín & Máx \\
\hline Idade materna (anos) & 21,7 & 5,0 & 21,0 & 13,0 & 39,0 \\
\hline IG na internação (semanas) & 39,6 & 0,9 & 40,4 & 37,0 & 41,4 \\
\hline Idade da $1^{a}$. relação sexual (anos) & 16,6 & 2,9 & 16,0 & 12,0 & 30,0 \\
\hline $\begin{array}{l}\text { Tempo de vida sexual ativa } \\
\text { (anos) }\end{array}$ & 5,4 & 3,9 & 4,0 & 1,0 & 21,0 \\
\hline Ganho de peso na gestação (Kg) & 11,9 & 4,2 & 11,8 & 3,0 & 24,3 \\
\hline \multicolumn{6}{|l|}{ IMC } \\
\hline Primeira consulta de pré-natal & 23,8 & 3,5 & 23,8 & 16,5 & 33,7 \\
\hline Última consulta de pré-natal & 28,5 & 3,9 & 28,8 & 19,7 & 40,4 \\
\hline Etapa 2 (50 a 70 dias pós-parto) & 24,9 & 3,8 & 24,6 & 17,0 & 37,4 \\
\hline Etapa 3 (170 a 190 dias pós-parto) & 24,4 & 4,1 & 24,0 & 15,8 & 36,5 \\
\hline
\end{tabular}

Os casos de ITU na gestação estiveram presentes em 42 mulheres $(42,4 \%)$, sendo que dez $(10,1 \%)$ relataram ITU recorrente e $37(83,3 \%)$ trataram a ITU na gestação. Com cerca de dois meses depois do parto, a ITU ocorreu em três $(3,1 \%)$ das mulheres e, aproximadamente, aos seis meses em sete $(9,1 \%)$ delas (Tabela 4$)$.

Verificou-se que dez $(10,1 \%)$ mulheres relataram IU antes da gestação, $23(23,2 \%)$ na gestação, $15(15,2 \%)$ logo após o parto, 7,1\% persistiram com a queixa de IU entre 50 e 70 dias após o parto e somente duas (2,0\%) continuaram com os sintomas entre 170 e 190 dias após o parto. Entre essas duas mulheres, uma mencionou perda involuntária de urina em 
pequena quantidade e a outra em moderada quantidade, que ocorria antes de chegar ao banheiro e ao espirrar ou tossir. O valor médio do escore do ICIQ-SF foi de 13 pontos (dados não apresentados em tabela). Quanto à prática de exercícios perineais durante a gestação, sete $(7,1 \%)$ mulheres relataram fazer algum tipo de exercício, sendo que o mais praticado foi o de segurar o jato urinário. No pós-parto, ocorreu um aumento expressivo de 36,3 pontos percentuais (p.p.) de mulheres que realizaram exercícios perineais (Tabela 4). Entre 50 e 70 dias pós-parto, seis $(6,1 \%)$ puérperas referiram IA, sendo que dessas, todas citaram incontinência de flatos e apenas duas (2\%) incontinência de fezes. Entre 170 e 190 dias pósparto, somente uma mulher persistiu com incontinência de flatos, mas não com incontinência de fezes.

Tabela 4 - Número e percentagem de primíparas segundo sintomas do trato genitourinário, IA e exercícios perineais, Itapecerica da Serra, SP - 2014 a 2016 (n=99)

\begin{tabular}{|c|c|c|}
\hline Variável & $\mathbf{n}$ & $\%$ \\
\hline \multicolumn{3}{|c|}{ ITU $^{\S}$ na gestação } \\
\hline Sim & 42 & 42,4 \\
\hline Não & 57 & 57,6 \\
\hline \multicolumn{3}{|c|}{ ITU recorrente na gestação $(n=42)$} \\
\hline Sim & 10 & 10,1 \\
\hline Não & 32 & 89,9 \\
\hline \multicolumn{3}{|c|}{ Tratou ITU na gestação $(n=42)$} \\
\hline Sim & 37 & 83,3 \\
\hline Não & 5 & 16,7 \\
\hline \multicolumn{3}{|c|}{ ITU na etapa 2} \\
\hline Sim & 3 & 3,1 \\
\hline Não & 96 & 96,9 \\
\hline \multicolumn{3}{|c|}{ ITU na etapa 3} \\
\hline Sim & 7 & 9,1 \\
\hline Não & 92 & 90,9 \\
\hline \multicolumn{3}{|c|}{$\mathrm{IU}^{¥}$ anterior a gestação } \\
\hline Sim & 10 & 10,1 \\
\hline Não & 89 & 89,9 \\
\hline
\end{tabular}


(cont.)

\section{IU durante a gestação}

$\begin{array}{lll}\text { Sim } & 23 & 23,2 \\ \text { Não } & 76 & 76,8\end{array}$

IU logo após o parto

$\begin{array}{lll}\text { Sim } & 15 & 15,2 \\ \text { Não } & 84 & 84,8\end{array}$

IU presente na etapa 2

$\begin{array}{lll}\text { Sim } & 7 & 7,1 \\ \text { Não } & 92 & 92,9\end{array}$

IU persiste na etapa 3

$\begin{array}{lll}\text { Sim } & 2 & 2,0 \\ \text { Não } & 97 & 98,0\end{array}$

IA presente na etapa 2

$\begin{array}{lll}\text { Sim } & 6 & 6,1 \\ \text { Não } & 93 & 93,9\end{array}$

IA presente na etapa 3

$\begin{array}{lll}\text { Sim } & 1 & 1,0 \\ \text { Não } & 98 & 99,0\end{array}$

Exercício perineal na gestação

\begin{tabular}{lll} 
Sim & 7 & 7,1 \\
Não & 92 & 92,9 \\
Exercício perineal pós-parto & & \\
Sim & 43 & 43,4 \\
Não & 56 & 56,6 \\
\hline
\end{tabular}

${ }^{\S} \mathrm{ITU}=$ Infecção do trato urinário; ${ }^{\sharp} \mathrm{IU}=$ Incontinência urinária

Os resultados da Tabela 5 mostram que a maioria das mulheres havia retornado à atividade sexual entre 50 e 70 dias e das restantes, quase a totalidade delas retornou entre 170 e 190 dias. Aquelas que não retornaram, relataram como justificativas o medo de sentir dor, o fato de não ter parceiro ou outros motivos. A dispareunia foi referida por $35(44,3 \%)$ mulheres entre 50 e 70 dias, e nove (9,5\%) entre 170 e 190 dias. O uso de medicamento 
contraceptivo foi citado por $47(47,5 \%)$ mulheres entre 50 e 70 dias, e por $65(65,7 \%)$ entre 170 e 190 dias.

Tabela 5 - Número e percentagem de primíparas, segundo o retorno à atividade sexual, motivo de não retorno à atividade sexual, dispareunia e uso de contraceptivo nas etapas 2 e 3, Itapecerica da Serra, SP - 2014 a 2016

\begin{tabular}{|c|c|c|c|c|}
\hline \multirow{2}{*}{ Variável } & \multicolumn{2}{|c|}{ Etapa 2} & \multicolumn{2}{|c|}{ Etapa 3} \\
\hline & $\mathbf{n}$ & $\%$ & $\mathbf{n}$ & $\%$ \\
\hline Retornou à atividade sexual & \multicolumn{2}{|c|}{$(\mathbf{n}=99)$} & \multicolumn{2}{|c|}{$(\mathbf{n}=\mathbf{2 0})$} \\
\hline Sim & 79 & 79,8 & 16 & 80,0 \\
\hline Não & 20 & 20,2 & 4 & 20,0 \\
\hline Motivo de não retornar à atividade sexual & \multicolumn{2}{|c|}{$(\mathbf{n}=\mathbf{2 0})$} & \multicolumn{2}{|c|}{$(n=4)$} \\
\hline Medo de sentir dor & 3 & 15,0 & 0 & 0 \\
\hline Não ter parceiro & 10 & 50,0 & 3 & 75 \\
\hline Outros motivos & 7 & 35,0 & 1 & 25 \\
\hline Dispareunia & \multicolumn{2}{|c|}{$(n=79)$} & \multicolumn{2}{|c|}{$(\mathbf{n}=95)$} \\
\hline Sim & 35 & 44,3 & 9 & 9,5 \\
\hline Não & 44 & 55,7 & 86 & 90,5 \\
\hline Uso de contraceptivo & \multicolumn{2}{|c|}{$(n=99)$} & \multicolumn{2}{|c|}{$(n=99)$} \\
\hline Sim & 47 & 47,5 & 65 & 65,7 \\
\hline Não & 52 & 52,5 & 34 & 4,3 \\
\hline
\end{tabular}

Da amostra total, $74(74,7 \%)$ mulheres tiveram partos normais e $25(25,3 \%)$ foram submetidas à cesariana. A medicação mais utilizada, 61 parturientes $(61,6 \%)$, foi a ocitocina/misoprostol. Um grande número de mulheres adotou a posição semissentada durante o período expulsivo, a maioria delas referiu realizar o puxo espontâneo e apenas quatro $(5,4 \%)$ informaram que foram submetidas à manobra de Kristeller (Tabela 6).

Entre as parturientes que tiveram parto normal, a maioria apresentou algum tipo de trauma perineal, sendo que pouco mais de um terço delas foi submetida à episiotomia e as demais tiveram lacerações perineais de primeiro e de segundo graus. Dentre aquelas com trauma perineal, quase a totalidade foi submetida ao reparo perineal sob anestesia local. $\mathrm{O}$ períneo manteve-se íntegro em pouco menos de um quinto das mulheres e não houve casos de laceração de terceiro e quarto graus (Tabela 6). 
Tabela 6 - Número e percentagem de primíparas, de acordo com os dados do parto, Itapecerica da Serra, SP - 2014 a 2016

\begin{tabular}{|c|c|c|}
\hline Variável & $\mathbf{n}$ & $\%$ \\
\hline \multicolumn{3}{|l|}{ Tipo de parto $(n=99)$} \\
\hline Normal & 74 & 74,7 \\
\hline Cesariana & 25 & 25,3 \\
\hline \multicolumn{3}{|c|}{ Medicações utilizadas no trabalho de parto $(n=99)$} \\
\hline Ocitocina/Misoprostol & 67 & 67,7 \\
\hline Nenhuma & 32 & 32,3 \\
\hline \multicolumn{3}{|c|}{ Posição no expulsivo (n=74) } \\
\hline Semissentada & 64 & 86,5 \\
\hline Outras posições & 4 & 13,5 \\
\hline \multicolumn{3}{|c|}{ Intervenções realizadas no período expulsivo $(n=74)$} \\
\hline Puxo espontâneo & 60 & 81,1 \\
\hline Puxo dirigido & 14 & 18,9 \\
\hline \multicolumn{3}{|l|}{ Manobra de Kristeller } \\
\hline Sim & 4 & 5,4 \\
\hline Não & 70 & 94,6 \\
\hline \multicolumn{3}{|c|}{ Condições do períneo no parto normal $(n=74)$} \\
\hline Episiotomia & 26 & 35,1 \\
\hline Laceração de $1^{\circ}$ grau & 22 & 29,7 \\
\hline Laceração de $2^{\circ}$ grau & 13 & 17,6 \\
\hline Íntegro & 13 & 17,6 \\
\hline \multicolumn{3}{|l|}{ Reparo perineal $(n=74)$} \\
\hline Sim & 57 & 77,0 \\
\hline Não & 17 & 23,0 \\
\hline \multicolumn{3}{|l|}{ Anestesia $(n=99)$} \\
\hline Local & 57 & 61,6 \\
\hline Raquidiana & 25 & 25,3 \\
\hline Nenhuma & 17 & 13,1 \\
\hline
\end{tabular}


O peso médio dos $\mathrm{RN}$ foi 3.217,5 gramas (g) (d.p.=409) e a circunferência cefálica média de 33,9 cm. Quanto à vitalidade neonatal, observou-se, também, que a maioria dos RN obteve índice de Apgar médio de 8,2 no primeiro minuto e 9,4 no quinto minuto, indicando boa vitalidade (Tabela 7).

Tabela 7 - Medidas de tendência central e dispersão dos dados clínicos do recém-nascido (RN), Itapecerica da Serra, SP - 2014 a 2016 (n=99)

\begin{tabular}{lccccc}
\hline Variável & Média & d.p. & Med & Min & Max \\
\hline Peso do RN (g) & $3.217,5$ & 409,0 & $3.235,0$ & $2.420,0$ & $4.540,0$ \\
Circunferência cefálica (cm) & 33,9 & 34,0 & 33,9 & 31,0 & 37,0 \\
Índice de Apgar no 10 min & 8,2 & 1,5 & 9 & 0 & 9 \\
Índice de Apgar no 50 $\mathbf{~ m i n}$ & 9,4 & 1,1 & 10 & 2 & 10 \\
\hline
\end{tabular}

Med=mediano; Min=mínimo; Max=máximo; $\mathrm{cm}=$ =entímetros; $\mathrm{g}=$ gramas; min=minutos

A média geral da FMAP encontrada nas duas epapas foi $24,0 \mathrm{cmH}_{2} \mathrm{O}$, sendo que na etapa 2 e 3 os valores dessas médias foram, respectivamente 21,7 $\mathrm{cmH}_{2} \mathrm{O}$ e 26,3 $\mathrm{cmH}_{2} \mathrm{O}$. Observou-se um aumento da média da etapa 2 para a etapa 3 , independente do tipo de parto (Tabela 8).

Tabela 8 - Estatística descritiva das médias da FMAP $\left(\mathrm{cmH}_{2} \mathrm{O}\right)$ nas etapas 2 e 3, Itapecerica da Serra, SP - 2014 a $2016(n=99)$

\begin{tabular}{cccccc}
\hline Variável & Média & d.p. & Med & Min & Max \\
\hline Média da FMAP $\left(\mathbf{c m H}_{2} \mathbf{O}\right)$ na etapa 2 & 21,7 & 13,4 & 18,2 & 0 & 63,2 \\
Média da FMAP $\left(\mathbf{c m H}_{2} \mathbf{O}\right)$ na etapa 3 & 26,3 & 13,4 & 23,25 & 0 & 63,4 \\
\hline
\end{tabular}

\subsection{ANÁLISE COMPARATIVA DA FMAP}

A média da FMAP das mulheres após o parto normal e cesariana foi, respectivamente, 22,0 (d.p.=14,0) $\mathrm{cmH}_{2} \mathrm{O} ; 21,0$ (d.p.=11,6) entre 50 e 70 dias e 26,8 (13,7) $\mathrm{cmH}_{2} \mathrm{O} ; 24,4$ (d.p.=12,4) com 170 a 190 dias. Embora a média da FMAP entre as mulheres que tiveram parto normal tenha apresentado valores maiores do que aquelas submetidas à cesariana, não houve diferença estatística significativa $(\mathrm{p}=0,557)$. Nota-se, também, que ao longo do período 
de seis meses houve um discreto aumento da FMAP, tanto no parto normal como na cesariana, mas sem diferença estatística $(\mathrm{p}=0,508)$ (Tabela 9 e Figura 5).

Tabela 9 - Comparação da força muscular do assoalho pélvico (FMAP) de primíparas por meio da perineometria segundo o tipo de parto nas etapas 2 e 3, Itapecerica da Serra, $\underline{S P}-2014$ a $2016(n=99)$

\section{FMAP $\left(\mathbf{c m H}_{2} \mathbf{O}\right)$}

\begin{tabular}{lcccccc} 
& \multicolumn{2}{c}{ Etapa 2 } & \multicolumn{2}{c}{ Etapa 3 } & & \\
\cline { 2 - 5 } Tipo de Parto & n & $\begin{array}{c}\text { Média } \\
\text { (d.p.) }\end{array}$ & n & $\begin{array}{c}\text { Média } \\
\text { (d.p.) }\end{array}$ & $\begin{array}{c}\text { valor-p } \\
\text { Efeito } \\
\text { Principal }\end{array}$ & $\begin{array}{c}\text { valor-p } \\
\text { Efeito de } \\
\text { Interação }\end{array}$ \\
\hline Normal & 74 & $22,0(14,0)$ & 74 & $26,8(13,7)$ & 0,557 & 0,508 \\
Cesariana & 25 & $21,0(11,6)$ & 25 & $24,4(12,4)$ & & \\
\hline
\end{tabular}

${ }^{\S}$ Modelo de efeitos mistos

Figura 5 - Representação da associação da força muscular do assoalho pélvico (FMAP) com o tipo de parto, de acordo com as etapas 2 e 3, Itapecerica da Serra, SP 2014 a 2016

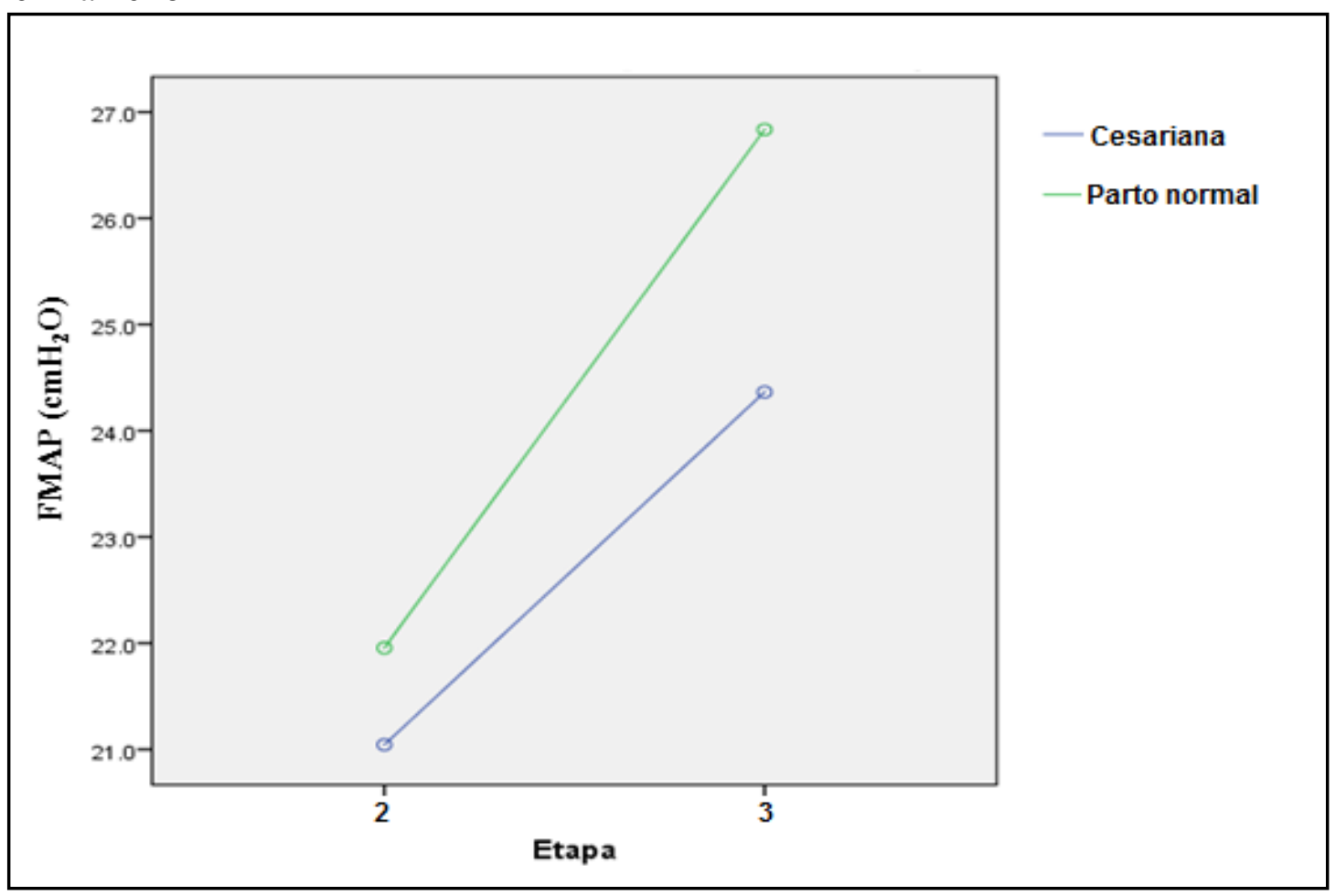


Os dados da Tabela 10 apresentam os valores médios da FMAP em relação às variáveis: idade materna e escolaridade (anos de estudo). Verificou-se diferença estatisticamente significante (efeito principal $\mathrm{p}=0,001$ ) nas médias da FMAP, apenas em relação à idade, não sendo observadas interações entre idade e etapas $(\mathrm{p}=0,756)$. Nota-se que à medida que aumenta a idade diminui a FMAP.

Tabela 10 - Comparação da força muscular do assoalho pélvico (FMAP) de primíparas de acordo com a idade e escolaridade nas etapas 2 e 3, Itapecerica da Serra, SP - 2014 a 2016

FMAP $\left(\mathbf{c m H}_{2} \mathbf{O}\right)$

\begin{tabular}{lcccccc} 
& \multicolumn{2}{c}{ Etapa 2 } & Etapa 3 & \\
\cline { 2 - 6 } & n & Média (d.p.) & n & Média (d.p.) & $\begin{array}{l}\text { valor-p } \\
\text { Efeito } \\
\text { Principal }\end{array}$ & $\begin{array}{c}\text { valor-p } \\
\text { Efeito de } \\
\text { Interação }\end{array}$ \\
\hline Idade (n=99) & 41 & $24,4(14,0)$ & 41 & $28,3(12,8)$ & & \\
$\leq 19$ & 36 & $22,8(13,7)$ & 36 & $26,9(15,0)$ & $\mathbf{0 , 0 0 1}$ & 0,756 \\
20 a 24 & 14 & $17,0(8,9)$ & 14 & $23,5(12,0)$ & & \\
25 a 29 & 8 & $11,5(9,1)$ & 8 & $18,3(7,9)$ & & \\
$\geq 30$ & & & & & & \\
Escolaridade (anos) $(\mathbf{n = 9 9 )}$ & & & & & \\
$\leq 8$ & 24 & $24,3(14,2)$ & 24 & $27,1(12,0)$ & & \\
9 a 11 & 67 & $20,6(12,6)$ & 67 & $25,2(13,0)$ & 0,418 & \\
$\geq 12$ & 8 & $23,6(7,6)$ & 8 & $32,0(19,5)$ & & \\
\hline
\end{tabular}

${ }^{\S}$ Modelo de efeitos mistos

A comparação das médias da FMAP das etapas 2 e 3 com a cor da pele, ter ou não parceiro e a atividade remunerada não apresentou diferença estatística (Tabela 11). 
Tabela 11 - Comparação da força muscular do assoalho pélvico (FMAP) de primíparas de acordo com as características sociodemográficas nas etapas 2 e 3, Itapecerica da Serra, SP 2014 a $2016(n=99)$

\section{FMAP $\left(\mathbf{c m H}_{2} \mathbf{O}\right)$}

\begin{tabular}{|c|c|c|c|c|c|c|}
\hline \multirow{2}{*}{ Variável } & \multicolumn{2}{|r|}{ Etapa 2} & \multicolumn{2}{|r|}{ Etapa 3} & \multirow[b]{2}{*}{$\begin{array}{l}\text { valor-p } \\
\text { Efeito } \\
\text { Principal }\end{array}$} & \multirow[b]{2}{*}{$\begin{array}{c}\text { valor-p }^{\S} \\
\text { Efeito de } \\
\text { Interação }\end{array}$} \\
\hline & $\mathbf{n}$ & Média (d.p.) & $\mathbf{n}$ & Média (d.p.) & & \\
\hline \multicolumn{7}{|c|}{ Cor da pele } \\
\hline Parda & 58 & $22,6(12,7)$ & 58 & $28,6(13,0)$ & & \\
\hline Branca & 33 & $20,6(14,9)$ & 33 & $23,0(13,6)$ & 0,302 & 0,203 \\
\hline Preta & 8 & $20,0(12,0)$ & 8 & $22,3(12,5)$ & & \\
\hline \multicolumn{7}{|l|}{ Parceiro } \\
\hline Sim & 86 & $21,1(13,1)$ & 86 & $25,7(13,3)$ & 0,248 & 0,721 \\
\hline Não & 13 & $25,9(14,5)$ & 13 & $29,4(14,1)$ & & \\
\hline \multicolumn{7}{|c|}{ Atividade remunerada } \\
\hline Sim & 29 & $22,5(14,7)$ & 29 & $27,1(16,3)$ & 0,668 & 0,943 \\
\hline Não & 70 & $21,4(12,8)$ & 70 & $25,8(12,0)$ & & \\
\hline
\end{tabular}

${ }^{\S}$ Modelos de efeitos mistos

Apesar dos valores da FMAP serem mais elevados na faixa do IMC adequado (18,524,9), a comparação entre as médias das primíparas não mostrou diferença estatisticamente significante (Tabela 12). 
Tabela 12 - Comparação da força muscular do assoalho pélvico (FMAP) de primíparas de acordo com o índice de massa corpórea (IMC) nas etapas 2 e 3, Itapecerica da Serra, $\mathrm{SP}-2014$ a $2016(\mathrm{n}=99)$

\begin{tabular}{lccc}
\hline \multirow{2}{*}{ IMC } & \multicolumn{3}{c}{$\mathbf{F M A P}\left(\mathbf{c m H}_{\mathbf{2}} \mathbf{O}\right)$} \\
\cline { 2 - 4 } & $\mathbf{n}$ & Média (d.p.) & valor-p $^{\S}$ \\
\hline Etapa 2 & 3 & $21,8(20,3)$ & \\
$<18,5$ & 48 & $23,3(13,5)$ & 0,715 \\
$18,5-24,9$ & 39 & $19,0(13,2)$ & \\
$25,0-29,9$ & 9 & $20,9(13,6)$ & \\
$\geq 30$ & & & 0,201 \\
Etapa 3 & 7 & $24,4(17,0)$ & \\
$<18,5$ & 49 & $28,8(13,5)$ & \\
$18,5-24,9$ & 33 & $24,8(12,6)$ & \\
$25,0-29,9$ & 10 & $19,8(13,4)$ & \\
$\geq 30$ & &
\end{tabular}

${ }^{\S}$ Modelo de efeitos mistos

Os resultados da Tabela 13 mostraram diferença estatística na comparação das médias da FMAP, independente da etapa, entre as mulheres com ITU, após o parto, nas quais houve uma maior FMAP (efeito principal $\mathrm{p}=0,012$ ). Observou-se, também, que a FMAP foi estatisticamente maior nas mulheres sem IU (efeito principal $p=0,021$ ), independente da etapa (Figura 6). Convém comentar que as sete mulheres incontinentes na etapa 2, cinco delas tiveram PN e as outras duas cesarianas. Na etapa 3, das duas participantes com queixa de IU todas tiveram PN.

Por outro lado, a dispareunia não mostrou interação e nem diferença significativa nas médias da FMAP.

Quanto à incontinência anal, em razão do pequeno número de casos encontrados, não foi possível realizar análise comparativa da FMAP. 
Tabela 13 - Comparação da força muscular do assoalho pélvico (FMAP) de acordo com as características do trato genito-urinário e dispareunia nas etapas 2 e 3, Itapecerica da Serra, SP - 2014 a 2016 ( $n=99)$

\section{FMAP $\left(\mathrm{cmH}_{2} \mathrm{O}\right)$}

Etapa $2 \quad$ Etapa 3

Variável

\begin{tabular}{ccccc}
\hline & & & & \\
Média & Média & & valor-p & valor-p \\
(d.p.) & Efeito & Efeito de \\
(d.p.) & Principal & Interação
\end{tabular}

\section{ITU pós-parto}

$\begin{array}{lcccccr}\text { Sim } & 3 & 31,8(17,1) & 7 & 20,9(7,5) & \mathbf{0 , 0 1 2} & 0,223 \\ \text { Não } & 96 & 21,4(13,2) & 92 & 26,6(13,6) & & \end{array}$

IU anterior a gestação

$\begin{array}{lllllll}\text { Sim } & 10 & 22,2(20,0) & 10 & 29,0(16,0) & & 0,437 \\ \text { Não } & 89 & 21,7(12,5) & 89 & 25,9(13,1) & & 0,664\end{array}$

\section{IU durante a gestação}

$\begin{array}{lllllll}\text { Sim } & 23 & 19,1(14,0) & 23 & 26,5(14,2) & & 0,610 \\ \text { Não } & 76 & 22,5(13,2) & 76 & 26,1(13,2) & & 0,113\end{array}$

\section{IU logo após o parto}

$\begin{array}{lllllll}\text { Sim } & 15 & 20,9(13,3) & 15 & 26,4(14,7) & & \\ \text { Não } & 84 & 21,9(12,9) & 84 & 26,2(13,2) & & 0,615\end{array}$

\section{IU que persiste}

\begin{tabular}{lcccccc} 
Sim & 7 & $16,0(12,7)$ & 2 & $19,5(4,8)$ & $\mathbf{0 , 0 2 1}$ & 0,665 \\
Não & 92 & $22,2(13,4)$ & 97 & $26,3(13,5)$ & & \\
Dispareunia & & & & & & \\
Sim & 35 & $22,6(15,5)$ & 10 & $25,3(6,3)$ & & \\
Não & 44 & $20,6(11,6)$ & 86 & $26,1(14,0)$ & & 0,402 \\
\hline
\end{tabular}

${ }^{\S}$ Modelo de efeitos mistos 
Figura 6 - Representação da associação da força muscular do assoalho pélvico (FMAP) com a incontinência urinária que persiste nas etapas 2 e 3, Itapecerica da Serra, SP - 2014 a 2016

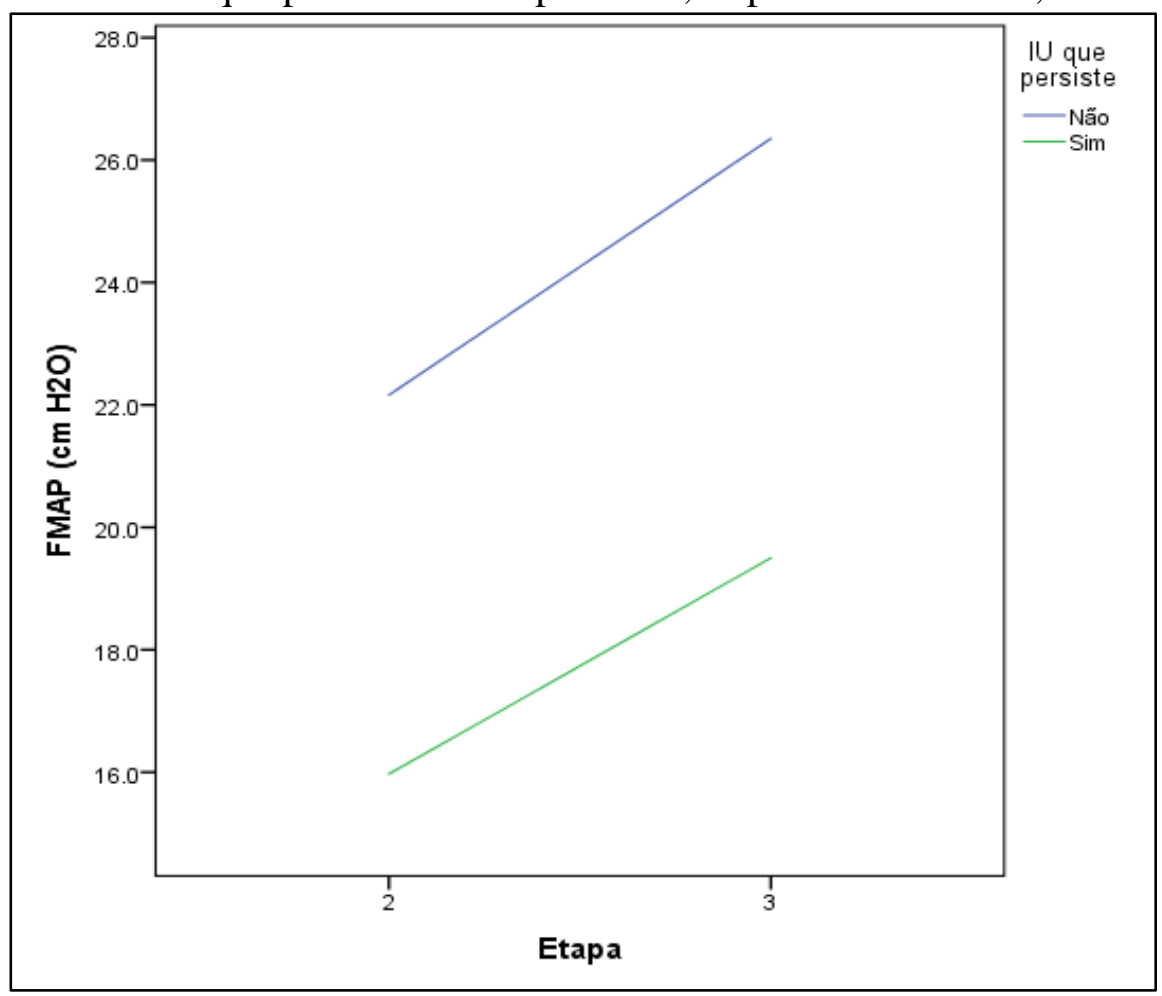

A Tabela 14 e a Figura 7 indicam que as mulheres que realizam exercícios perineais apresentam maior FMAP no limite da significância estatística, independente da etapa pósparto.

Tabela 14 - Comparação da força muscular do assoalho pélvico (FMAP) de acordo com o exercício perineal nas etapas 2 e 3, Itapecerica da Serra, SP - 2014 a 2016 (n=99)

\section{FMAP $\left(\mathrm{CmH}_{2} \mathbf{O}\right)$}

\begin{tabular}{|c|c|c|c|c|c|c|c|}
\hline \multirow{2}{*}{ Variável } & \multicolumn{2}{|c|}{ Etapa 2} & \multicolumn{2}{|c|}{ Etapa 3} & \multicolumn{3}{|c|}{ Valor-p } \\
\hline & $\mathbf{n}$ & $\begin{array}{c}\text { Média } \\
\text { (d.p.) }\end{array}$ & $\mathbf{n}$ & $\begin{array}{l}\text { Média } \\
\text { (d.p.) }\end{array}$ & $\begin{array}{c}\text { Efeito } \\
\text { de } \\
\text { Grupo }\end{array}$ & $\begin{array}{c}\text { Efeito } \\
\text { do } \\
\text { tempo }\end{array}$ & $\begin{array}{c}\text { Interação } \\
\text { Grupo x Tempo }\end{array}$ \\
\hline \multicolumn{8}{|c|}{ Exercício perineal } \\
\hline Sim & 9 & $23,910,5)$ & 43 & $26,8(13,7)$ & \multirow{2}{*}{0,054} & \multirow{2}{*}{0,085} & \multirow{2}{*}{0,730} \\
\hline Não & 90 & $21,5(13,6)$ & 56 & $25,8(13,2)$ & & & \\
\hline
\end{tabular}

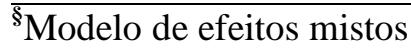


Figura 7 - Representação da associação da força muscular do assoalho pélvico (FMAP) com o exercício perineal nas etapas 2 e 3, Itapecerica da Serra, SP - 2014 a 2016

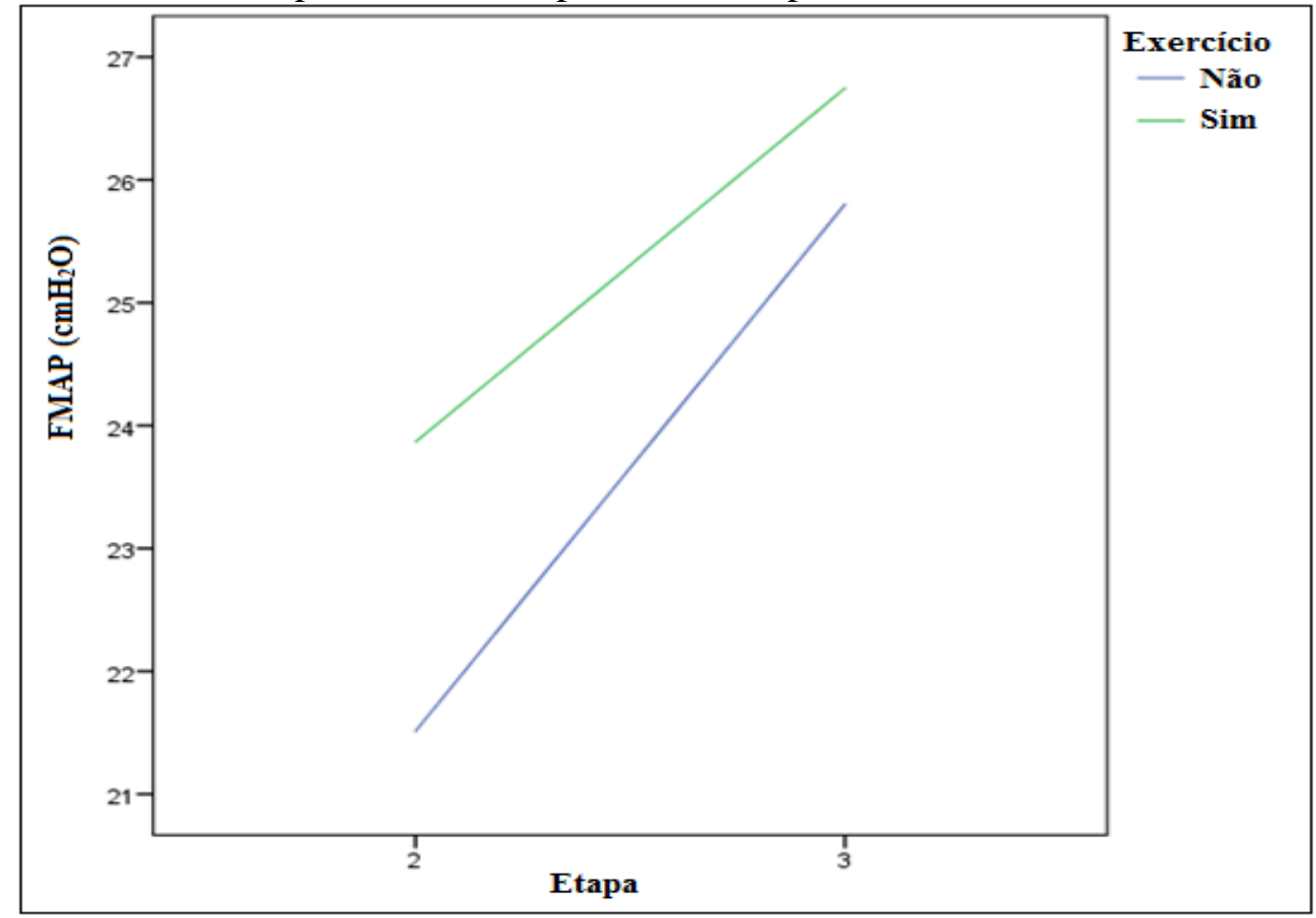

Entre as mulheres que tiveram parto normal, não houve diferença da FMAP em relação às medicações utilizadas durante o trabalho de parto, posição e intervenções adotadas no período expulsivo. As médias das FMAP, apesar de maiores na etapa 3, não apresentaram diferença estatisticamente significante (Tabela 15). 
Tabela 15 - Comparação da força muscular do assoalho pélvico (FMAP) após parto normal, de acordo com as intervenções no parto nas etapas 2 e 3, Itapecerica da Serra, SP -2014 a $2016(n=74)$

\section{FMAP $\left(\mathbf{C m H}_{2} \mathbf{O}\right)$}

\begin{tabular}{|c|c|c|c|c|c|c|}
\hline \multirow{2}{*}{ Variável } & \multicolumn{2}{|r|}{ Etapa 2} & \multicolumn{2}{|r|}{ Etapa 3} & \multirow[b]{2}{*}{$\begin{array}{c}\text { valor-p } \\
\text { Efeito } \\
\text { Principal }\end{array}$} & \multirow[b]{2}{*}{$\begin{array}{c}\text { valor-p }^{\S} \\
\text { Efeito de } \\
\text { Interação }\end{array}$} \\
\hline & $\mathbf{n}$ & $\begin{array}{l}\text { Média } \\
\text { (d.p.) }\end{array}$ & $\mathbf{n}$ & $\begin{array}{l}\text { Média } \\
\text { (d.p.) }\end{array}$ & & \\
\hline \multicolumn{7}{|l|}{$\begin{array}{l}\text { Medicação usada no } \\
\text { trabalho de parto }\end{array}$} \\
\hline Ocitocina/Misoprostol & 53 & $21,8(12,6)$ & 53 & $26,9(13,2)$ & \multirow{2}{*}{0,873} & \multirow{2}{*}{0,930} \\
\hline Nenhuma & 21 & $22,2(17,3)$ & 21 & $27,6(14,0)$ & & \\
\hline \multicolumn{7}{|l|}{ Posição no expulsivo } \\
\hline Semissentada & 64 & $21,4(14,0)$ & 64 & $26,1(13,0)$ & \multirow{2}{*}{0,182} & \multirow{2}{*}{0,273} \\
\hline Outras & 10 & $25,2(14,1)$ & 10 & $33,8(15,0)$ & & \\
\hline \multicolumn{7}{|c|}{ Puxo/manobra no expulsivo } \\
\hline Puxo espontâneo & 60 & $22,0(14,2)$ & 60 & $27,3(13,1)$ & \multirow{2}{*}{0,878} & \multirow{2}{*}{0,799} \\
\hline Puxo dirigido & 14 & $21,8(13,2)$ & 14 & $26,3(15,0)$ & & \\
\hline \multicolumn{7}{|l|}{ Kristeller } \\
\hline Sim & 4 & $23,9(11,1)$ & 4 & $25,5(1,9)$ & \multirow{2}{*}{0,977} & \multirow{2}{*}{0,496} \\
\hline Não & 70 & $21,8(14,2)$ & 70 & $27,2(13,7)$ & & \\
\hline
\end{tabular}

${ }^{\S}$ Modelo de efeitos mistos

Quando comparadas as médias da FMAP de acordo com as condições perineais, verificou-se que as médias foram similares nas duas etapas. No entanto, vale salientar que a FMAP das primíparas com períneo íntegro e laceração de primeiro grau foi maior em relação àquelas que tiveram laceração de segundo grau e episiotomia, porém sem diferença estatística. Em relação à anestesia, constatou-se que as mulheres sem anestesia apresentaram valores estatíticamente maiores da FMAP (efeito principal p=0,028) (Tabela 16 e Figura 8). 
Tabela 16 - Comparação da força muscular do assoalho pélvico (FMAP), de acordo com as condições do períneo após o parto normal nas etapas 2 e 3, Itapecerica da Serra, SP - 2014 a $2016(n=74)$

\section{FMAP $\left(\mathrm{cmH}_{2} \mathrm{O}\right)$}

Variável

\begin{tabular}{cccccc}
\hline \multicolumn{2}{c}{ Etapa 2 } & \multicolumn{2}{c}{ Etapa 3 } & & \\
n & $\begin{array}{c}\text { Média } \\
\text { (d.p.) }\end{array}$ & n & Média (d.p.) & $\begin{array}{c}\text { valor-p } \\
\text { Efeito } \\
\text { Principal }\end{array}$ & $\begin{array}{c}\text { valor-p } \\
\text { Efeito de } \\
\text { Interação }\end{array}$ \\
\hline
\end{tabular}

\section{Condições do períneo no parto normal}

Íntegro/ Laceração de $1^{\circ}$ grau

$$
35 \quad 22,8(14,6) \quad 35 \quad 27,3(14,5)
$$

0,790

0,611

Episiotomia/Laceração de $2^{\circ}$

grau

$3920,9(13,6) \quad 39 \quad 26,1(13,0)$

Reparo perineal sob anestesia

Local

$57 \quad 19,7(12,5) \quad 57$

$25,9(13,1)$

$\mathbf{0 , 0 2 8}$

0,496

Nenhuma

$17 \quad 29,6(16,1) \quad 17 \quad 31,2(13,7)$

${ }^{\S}$ Modelo de efeitos mistos

Figura 8 - Representação da associação da força muscular do assoalho pélvico (FMAP) e o reparo perineal sob anestesia nas etapas 2 e 3, Itapecerica da Serra, SP - 2014 a 2016

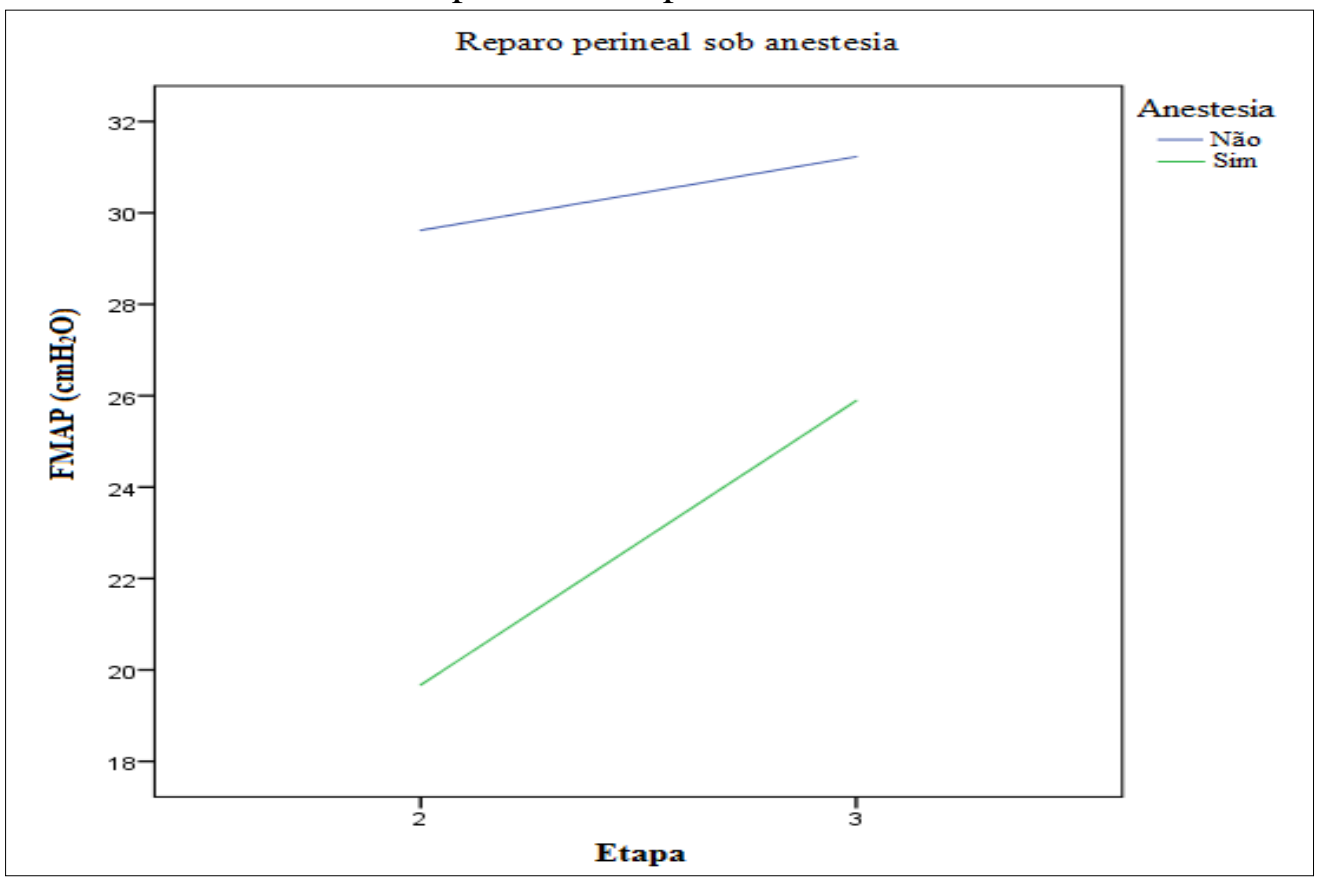

Não foram encontradas diferenças significativas entre as médias da FMAP com o peso e a circunferência cefálica do RN (Tabela 17). 
Tabela 17 - Comparação da força muscular do assoalho pélvico (FMAP) de primíparas de acordo com os dados do recém-nascido $(\mathrm{RN})$ nas etapas 2 e 3, Itapecerica da Serra, SP - 2014 a 2016

\begin{tabular}{|c|c|c|c|c|c|c|}
\hline \multirow{3}{*}{ Variável } & \multicolumn{4}{|c|}{ FMAP $\left(\mathbf{c m H}_{2} \mathbf{O}\right)$} & \multirow[b]{3}{*}{$\begin{array}{c}\text { valor-p } \\
\text { Efeito } \\
\text { Principal }\end{array}$} & \multirow[b]{3}{*}{$\begin{array}{l}\text { valor-p } \\
\text { Efeito de } \\
\text { Interação }\end{array}$} \\
\hline & \multicolumn{2}{|c|}{ Etapa 2} & \multicolumn{2}{|r|}{ Etapa 3} & & \\
\hline & $\mathbf{n}$ & $\begin{array}{c}\text { Média } \\
\text { (d.p.) }\end{array}$ & $\mathbf{n}$ & Média (d.p.) & & \\
\hline \multicolumn{7}{|c|}{ Peso do RN (g) } \\
\hline $\begin{array}{l}\leq 3.500 \\
>3.500\end{array}$ & $\begin{array}{l}80 \\
19\end{array}$ & $\begin{array}{l}22,0(13,1) \\
20,4(14,5)\end{array}$ & 80 & $\begin{array}{l}26,1(13,1) \\
26,8(14,7)\end{array}$ & 0,882 & 0,364 \\
\hline \multicolumn{7}{|c|}{ Circunferência cefálica $(\mathbf{c m})$} \\
\hline $\begin{array}{l}\leq 33 \\
>33\end{array}$ & 40 & $23,9(12,7)$ & 40 & $\begin{array}{l}27,9(14,8) \\
25,1(12,3)\end{array}$ & 0,206 & 0,709 \\
\hline
\end{tabular}

${ }^{\S}$ Modelo de efeitos mistos

A análise estatística da FMAP pelo modelo longitudinal preditivo mostra associação estatística com a idade, indicando que para cada ano a mais de vida materna a força diminui em 0,709. Além disso, houve associação significativa da FMAP com o exercício perineal, mostrando que a mulher que realiza exercício teve $3,359 \mathrm{cmH}_{2} \mathrm{O}$ a mais na média (Tabela 18 e Figura 9)

Tabela 18 - Modelo longitudinal preditivo para FMAP com base nas etapas 2 e 3, idade e exercício perineal, Itapecerica da Serra, SP - 2014 a 2016

\begin{tabular}{lccccc}
\hline & & & \multicolumn{2}{c}{ Intervalo de confiança 95\% } & \\
\cline { 5 - 6 } Variáveis & $\begin{array}{c}\text { Coeficiente } \\
\text { Regressão }\end{array}$ & $\begin{array}{c}\text { Erro- } \\
\text { padrão }\end{array}$ & $\begin{array}{c}\text { Limite } \\
\text { inferior }\end{array}$ & $\begin{array}{c}\text { Limite } \\
\text { superior }\end{array}$ & valor-p \\
\hline Etapa: 2 & $-3,333$ & 1,151 & $-5,615$ & $-1,051$ & $\mathbf{0 , 0 0 5}$ \\
\hline Idade & $-0,709$ & 0,241 & $-1,188$ & $-0,230$ & $\mathbf{0 , 0 0 4}$ \\
Exercício & 3,359 & 1,684 & 0,029 & 6,689 & 0,048 \\
\hline
\end{tabular}

${ }^{\S}$ Modelo de efeitos mistos 
Figura 9 - Representação da dispersão da idade, exercício perineal e força muscular do assoalho pélvico (FMAP), de acordo com as etapas 2 e 3, Itapecerica da Serra, SP - 2014 a 2016

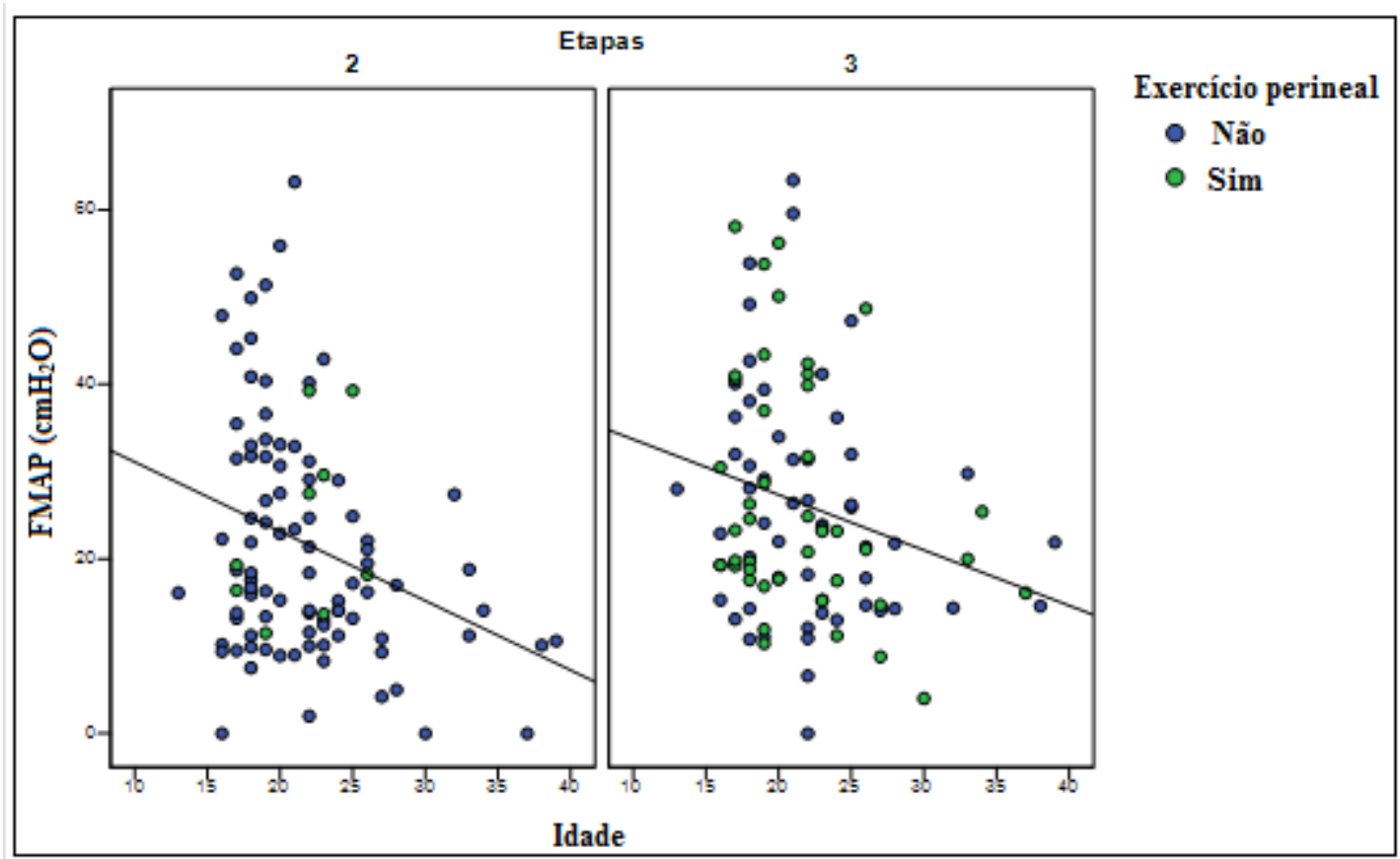


O presente estudo de coorte prospectiva analisou a FMAP, utilizando o método da perineometria de acordo com o tipo de parto, idade materna, escolaridade, cor da pele, situação conjugal, ocupação, IMC, ITU, IU, exercícios perineais, dispareunia, intervenções e condições do períneo e dados do RN em primíparas com 50 a 70 dias e com 170 a 190 dias após o parto. Inicialmente, pretendia-se verificar a existência de associação da FMAP com a IA, mas devido ao reduzido número encontrado dessa disfunção não foi possível efetuar a análise estatística.

Neste estudo, foram recrutadas 251 primíparas e ao final houve perda de 152 participantes $(60,5 \%)$. Como referido nos resultados, os grupos de perdas de seguimento e de mulheres que permaneceram na coorte foram homogêneos, exceto quanto ao estado marital. Contudo, por se tratar de uma coorte, durante o cálculo da amostra foi considerada a possibilidade de perda de seguimento dessas mulheres. Dessa forma, optou-se por ampliar em $30 \%$ o recrutamento com a previsão de analisar ao fim do estudo 96 mulheres entre 170 e 190 dias de pós-parto. Essa estratégia permitiu chegar a uma amostra final de 99 paticipantes.

A discussão dos resultados aborda, inicialmente, o perfil das mulheres; as prevalências de ITU, IU, IA; exercícios perineais; dispareunia e práticas adotadas no parto, seguidas pela análise comparativa das médias da FMAP quanto às características sociodemográficas, clínicas e do trato genito-urinário, exercício perineal, dados do parto, condições do períneo e dados do RN.

\subsection{CARACTERIZAÇÃo dAS PUÉRPERAS E DAS PRÁticAS AdOTAdAS NO PARTO}

O perfil das mulheres deste estudo mostra idade média jovem, com a maioria referindo ser de cor parda, ter realizado nove anos ou mais de estudo, viver com o companheiro, não possuir atividade remunerada e não consumir álcool, tabaco ou drogas ilícitas. As primíparas tinham idade gestacional a termo, a menarca ocorreu em média com 12,7 anos, iniciaram a atividade sexual com idade média de 16,6 anos e tinham tempo médio de vida sexual ativa de 5,4 anos. A maioria das características da amostra do estudo atual é similar àquelas encontradas na pesquisa Nascer no Brasil (d'Orsi et al., 2014; Domingues et al., 2014; Viellas et al., 2014). Na primeira consulta do pré-natal tinham, em média, IMC de 23,8, valor considerado como peso adequado (Atalah et al., 1997). O ganho de peso na gestação apresentou uma média de $11,7 \mathrm{~kg}$, que também indica ganho de peso adequado de acordo com o IMC (Institute of Medicine - IOM, 2009). 
Em relação às praticas adotadas no parto, neste estudo constatou-se que a maioria das parturientes fez uso de ocitocina intravenosa durante o trabalho de parto e parto, a totalidade delas utilizou posições verticalizadas no expulsivo, grande número referiu puxos espontâneos, mas poucas citaram a manobra de Kristeller. Verificou-se, também, que a maioria das mulheres de parto normal, apresentou algum trauma perineal, com cerca de um terço delas tendo sofrido episiotomia e as demais lacerações perineais de primeiro e de segundo graus. Praticamente a totalidade delas foi submetida à sutura perineal sob anestesia local.

Quanto aos dados do neonato, observou-se que embora tivesse valor máximo de peso correspondente à classificação grande para a idade gestacional (GIG), a média manteve-se dentro da normalidade, assim como a média da circunferência cefálica.

No presente estudo, vale considerar que nenhuma participante foi submetida ao parto instrumental, pois não é uma prática comum no local deste trabalho. A instituição também apoia as boas práticas obstétricas e muitos profissionais que assistem o parto seguem as orientações das publicações da OMS e do Ministério da Saúde do Brasil (OMS, 1996; Brasil, 2016). Talvez essa tenha sido a razão pela qual o parto normal não tenha causado lacerações de terceiro ou quarto graus nas mulheres do presente estudo e, consequentemente, menos morbidades no AP com maiores repercussões.

\subsection{PREVALÊNCIAS DE ITU, IU, IA, EXERCÍCIOS PERINEAIS E DISPAREUNIA NO PÓS-PARTO}

Quanto aos sintomas do trato genito-urinário, constatou-se elevada frequência de ITU na gestação comparada aos dois e seis meses pós-parto. A gestação é uma condição que aumenta o risco de ITU em razão das modificações fisiológicas que ocorrem no organismo da mulher, tais como, dilatação dos ureteres, levando à estagnação de urina. O próprio gênero feminino é um fator de risco em razão da uretra curta, da sua proximidade com a vagina e o ânus e pela dificuldade de esvaziar a bexiga totalmente (Parveen et al., 2011). A maioria das participantes deste estudo referiu ter feito tratamento para ITU. Convém comentar que essa variável foi obtida por autorrelato da mulher, e assim pode ser considerada um viés de informação. De acordo com Glaser e Schaeffer (2015), depois do tratamento da bacteriúria, as pacientes devem ser seguidas, de perto, em razão do risco de bacteriúria recorrente.

As DAP são citadas como um sério problema que afeta a saúde pública quanto à

prevalência, custo e impacto na qualidade de vida das mulheres (Torrisi et al., 2012). É conhecido que mais de um terço das mulheres apresentam DAP com graus variados de gravidade ao longo da vida (Kim, Harvey, Johnston, 2005). 
Em relação à IU, nossos dados mostraram que houve cerca de um décimo das mulheres que relataram IU anterior à gestação, praticamente, dobrando de frequência durante a gravidez $(23,3 \%)$, diminuindo para $15,2 \%$ logo após o parto e para $7,1 \%$ aos dois meses e permanecendo somente em duas delas aos seis meses, com baixa pontuação no ICIQ-SF. Com seis meses após o parto, taxas semelhantes foram observadas nas pesquisas de Valeton e Amaral (2011) e Zizzi et al. (2017).

Estudo prospectivo multicêntrico italiano, também constatou que entre as mulheres com IU, 53\% delas já desenvolviam esses sintomas durante a gravidez. Igualmente como em nossos achados, em termos de gravidade da IU, prevaleceram os sintomas referidos como leve, com impacto modesto sobre a qualidade de vida. Os autores constataram que o surgimento da IU na gestação, a história familiar positiva e o parto vaginal foram fatores de risco independentes para a persistência dos sintomas de IU com três meses após o parto (Torrisi et al., 2012).

Uma coorte encontrou risco maior $(\mathrm{OR}=3,3)$ de IU entre primíparas em comparação às nulíparas. Os sintomas e o impacto na qualidade de vida foram de leve a moderado em ambos os grupos (Hansen et al., 2012).

Em uma revisão da literatura que incluiu somente revisão sistemática e meta-análises, tendo por objetivo verificar a prevalência de IU com três meses após o parto, constatou-se variação entre $25 \%$ e $45 \%$ independente do tipo de parto. Quando os revisores associaram com o tipo de parto normal e cesariana, as médias das prevalências foram de $30 \%$ e de $15 \%$, respectivamente, porém essa diferença parece diminuir conforme a mulher aumenta de idade. (Rørtveit, Hannestad, 2014). Outra pesquisa, também, aponta menor frequência de IU entre as mulheres submetidas à cesariana $(9,1 \%)$ comparadas àquelas de parto vaginal $(16,9 \%)$, porém sem diferença estatística (Li et al., 2015). Dessa forma, nota-se, na literatura científica, uma ampla flutuação na prevalência de IU. Esse fato justifica-se, de certo modo, por diferenças no método, por populações diferentes com características clínicas e obstétricas específicas de cada casuística estudada (Zizzi et al., 2017).

Vale considerar que, além do tipo de parto, também existem práticas obstétricas que provocam lesões no AP, e isso pode aumentar a prevalência de muitas morbidades relacionadas aos MAP.

Nesse sentido, vários autores verificaram forte relação de lesões obstétricas, sobretudo do esfíncter anal, com IU, IA, dispareunia, disfunção sexual e prejuízo na qualidade de vida de mulheres no período pós-natal (Samuelsson et al., 2002; Brubaker et al., 2008; Boran et al., 2013; Obioha et al., 2015; Sut, kaplan 2016). 
Um estudo investigou a ocorrência de IU e POP em 83 primíparas que tiveram parto vaginal e 66 submetidas à cesariana. A análise da IU no pós-parto, o exame pélvico e a avaliação da FMAP foi realizada, entre 8 e 12 semanas após o parto, utilizando o questionário ICIQ-SF. Também foi mensurada a FMAP e realizado o exame eletrofisiológico dos MAP, introduzindo, na vagina, uma sonda (Guangzhou Shanshan Company ${ }^{\mathrm{TM}}$, China) que era conectada ao instrumento de terapia neuromuscular (PHENIX, Electronic Concept Lignon Innovation, France). Os pesquisadores concluíram que a cesariana tem um efeito protetor quanto aos POPs, mas não em relação à IU e a FMAP (Li et al., 2015).

Uma revisão da literatura que tinha por objetivo verificar a associação entre o tipo de parto e os fatores de risco que podem causar as disfunções que ocorrem no AP, os resultados parecem mostrar que a cesariana é um fator protetor contra a IU, mas esse efeito diminui quando a mulher se aproxima dos 50 anos de idade. As mulheres que tiveram lesão obstétrica do esfíncter anal no parto têm elevado risco para IA. Em conclusão, a prevalência de IU é menor entre as mulheres que tiveram cesariana do que naquelas de parto vaginal, porém essa diferença parece diminuir conforme a mulher aumenta de idade. Os autores consideram que existem poucos estudos confiáveis sobre a associação entre o tipo de parto e a incontinência anal, mas as meta-análises indicam que a cesariana não oferece proteção no período pós-parto (Rørtveit, Hannestad, 2014).

Apesar da menor incidência da IA comparada à IU, os desconfortos e constrangimentos provocados por essa disfunção são enormes (Hay-Smith et al., 2011).

Neste estudo houve baixa frequência de IA com dois meses de pós-parto, a qual, praticamente, desapareceu aos seis meses. Resultados semelhantes foram, também, observados por Zizzi et al. (2017) que encontrou prevalência de 5,5\% aos seis meses de pósparto. Em contrapartida, taxas mais elevadas foram constatadas pelos estudos italiano e australiano com nulíparas, com valores de $16,3 \%$ e 17\%, aos três e 12 meses depois do parto, respectivamente (Torrisi et al., 2012; Brown et al., 2014). As frequências da IA pós-parto fornecidas por diferentes autores, também, são muito variadas, independente da paridade (1,2\% a 49\%) (Torrisi et al., 2012; Rajeshkannan, Pathmeswaran, 2013; Rojas et al., 2013; Johannessen et al., 2015; Richter et al., 2015). A justificativa para tal fato deve-se ao emprego de definições não padronizadas, pela falta de questionamento dos profissionais de saúde e, também, por constrangimento das próprias mulheres que não relatam a queixa aos profissionais (Brown et al., 2014; Trevisan, 2015).

Embora nos últimos 10 anos o interesse por essa disfunção tenha aumentado, os fatores de risco para a IA, na literatura, não estão muito esclarecidos. Existem, ainda, áreas 
controversas sobre os fatores de risco obstétrico de parto vaginal, incluindo a infusão de ocitocina, o período expulsivo prolongado, o tipo de parto e a gravidade das lacerações perineais. A utilização crescente de parto fórcipe e vácuo extrator e a introdução de analgesia peridural dificultam tirar conclusões confiáveis (Torrisi et al., 2012), no entanto, no atual estudo, os fatores associados à IA não foram investigados em razão do pequeno número de casos observado.

No tocante aos exercícios perineais, sete mulheres deste trabalho relataram fazer algum tipo de exercício na gestação, sendo o mais executado segurar o jato urinário. No pósparto, houve um aumento expressivo do número de mulheres que realizaram exercícios perineais. A justificativa para esse resultado está relacionada às orientações verbais e, também, à entrega de um folheto de exercícios perineais pela pesquisadora à participante.

Alguns autores consideram que é importante conscientizar as mulheres sobre o PTMAP, pois isso reduzirá a IU no pós-parto e aumentará a sua QV (Özdemir et al., 2015).

Nossos achados apontam que a maioria das mulheres havia retomado à atividade sexual com dois meses e, praticamente, a totalidade delas, aos seis meses depois do parto. Aproximadamente metade das puérperas referiu dispareunia aos dois meses, reduzindo para cerca de um décimo delas aos seis meses após o parto. Esses resultados são similares aos de outros autores que também identificaram uma melhora quanto à queixa de dispareunia pósparto em diferentes períodos (Buhling et al., 2006; Elenskaia et al., 2011; Blomquist, McDermott, Handa, 2014; Caroci et al., 2014; Rogers et al., 2014; McDonald et al., 2016). Frequências mais elevadas de dispareunia nesses períodos foram observadas por outro estudo brasileiro que aponta 69,7\% e 29,2\% com dois e seis meses de pós-parto, respectivamente (Silva et al., 2013).

Dados semelhantes também foram encontrados aos cinco meses depois do parto. Uma coorte com 320 primíparas analisou a prevalência de lesão obstétrica do esfíncter anal. A avaliação foi feita analisando os exames de imagens com e algumas variáveis antes do parto. Aproximadamente um quarto dessas mulheres foi submetida à cesariana, 54,1\% tiveram PN, $16,3 \%$ parto a vácuo extrator e $6,9 \%$ fórcipe. Cerca de metade daquelas de parto vaginal sofreram trauma perineal, sendo 13,4\% lacerações de primeiro grau, 30,8\% lacerações de segundo grau, 4,9\% lacerações de terceiro grau e episiotomia em 26,3\%. Na avaliação realizada no pós-parto, 3,4\% referiram IA, 4,7\% sintomas de POP, 28,8\% de IUE e 21,6\% de dispareunia (Rojas et al., 2013).

Estudo de coorte observou que entre as mulheres que tiveram parto vaginal, aquelas com pelo menos um fórcipe e as com pelo menos um $\mathrm{RN}$ igual ou acima de quatro 
quilogramas, relataram uma maior taxa de dispareunia (Blomquist, McDermott, Handa, 2014).

Uma revisão da literatura avaliou o efeito da gravidez e do tipo de parto na função sexual no pós-parto. Os revisores referem que a função sexual diminui na gravidez, agravando-se à medida que ela progride. Nos primeiros 3 meses depois do parto, ocorre diminuição do desejo e do orgasmo, aumento da dor perineal e outros problemas de disfunção sexual que melhoraram, gradualmente, com 6 meses após o parto. Esse processo é afetado por muitos fatores, tais como: socioculturais, idade, paridade, amamentação, depressão, cansaço, imagem corporal pós-parto, preocupações sobre engravidar novamente e infecções concomitantes do trato urinário são relatados como fatores de risco independentes para a disfunção sexual. Não houve evidências relacionando o tipo de parto e alterações na função sexual (Yeniel, Petri, 2014).

Os estudos indicam que entre as mulheres que tiveram lesão obstétrica do esfíncter anal houve maior demora para se retornar à atividade sexual e elas apresentaram POP, IU, IA, dispareunia, dor pélvica e outras morbidades (Blomquist, McDermontt, Handa, 2014; Brown et al., 2014; Petricelli et al., 2014; Yeniel, Petri, 2014; Bø et al., 2015; Dumoulin et al., 2015; Sut, Kaplan, 2016).

\subsection{ASSOCIAÇÃO DA FORÇA MUSCULAR DO ASSOALHO PÉLVICO NO PÓS- PARTO COM AS VARIÁVEIS ESTUDADAS}

Para Vanconcelos e Ribeiro (2013), a avaliação da FMAP proporciona o reconhecimento da capacidade, eficácia, tonicidade e resistência dessa musculatura e isso pode permitir o planejamento de um tratamento adequado de acordo com a função que cada mulher tem em relação aos músculos do AP. Por outro lado, eles concluem que existem diversos instrumentos para avaliar a FMAP, porém nem todos são acessíveis devido ao custo elevado ou pela falta de profissionais especializados no seu manuseio. Esses autores ressaltam ainda a importância de observar que algumas variáveis podem interferir na avaliação da FMAP, como por exemplo, o posicionamento da mulher, o tipo de sonda utilizada e a mulher utilizar a musculatura acessória.

Riesco et al. (2010) consideram que é importante a realização de mais estudos que mensure a FMAP com o objetivo de estabelecer o seu perfil durante a gestação e o puerpério uma vez que existe uma diversidade de aparelhos e métodos de avaliação, além da falta de medidas padronizadas para a classificação funcional da FMAP. Essas autoras destacam, 
também, que os profissionais que assistem as mulheres não só devam identificar os fatores que possam diminuir a FMAP, mas que estimulem a mulher para realizar PTMAP e para abordar as queixas do trato genito-urinário. Elas consideram, ainda, que a avaliação da FMAP no pós-parto pode auxiliar como referência para a orientação e prevenção de transtornos ou agravamentos do AP em longo prazo.

Ao comparar nossas médias da FMAP aos dois e seis meses pós-parto $\left(21,7 \mathrm{cmH}_{2} \mathrm{O}\right.$ e 26,3 $\mathrm{cmH}_{2} \mathrm{O}$, respectivamente), constatou-se uma tendência de aumento da força muscular perineal, com o passar do tempo, após o parto. Reforçando esses achados, médias inferiores de FMAP às atuais, foram obtidas por Gameiro et al. (2011), sendo $8,3 \mathrm{cmH}_{2} \mathrm{O}$ após o parto normal e 13,7 $\mathrm{cmH}_{2} \mathrm{O}$ após a cesariana com 45 dias de pós-parto. Resultados diferentes dos atuais foram encontrados por Elenskaia et al. (2011) que verificaram maiores valores aos 98 dias $\left(54,1 \mathrm{cmH}_{2} \mathrm{O}\right)$ e com 1 ano $\left(59,9 \mathrm{cmH}_{2} \mathrm{O}\right)$ após o parto, independente do tipo de parto.

Embora exista, na literatura, muitos estudos indicando relação entre o tipo de parto e a FMAP (Hilde et al., 2013; Sut, Kaplan, 2016; Zizzi et al., 2017), no presente estudo, os resultados revelam que as médias da FMAP das mulheres pós-parto foram, discretamente, inferiores entre aquelas submetidas à cesariana comparadas às de parto normal, porém sem diferença estatística. Em contrapartida, estudos transversais observaram que as médias da FMAP foram 8,92 $\mathrm{cmH}_{2} \mathrm{O}$ e $14 \mathrm{cmH}_{2} \mathrm{O}$ menor no $\mathrm{PN}$ comparadas à cesariana (Zizzi et al., 2017; Batista et al., 2011, respectivamente).

Outros autores, também, não encontraram diferença, estatisticamente, significante entre o tipo de parto e a diminuição da FMAP (Caroci et al., 2010; Yeniel, Petri, 2014; Li et al., 2015; Mendes et al., 2016). Por outro lado, diversos estudos observaram menor FMAP após o parto normal ou instrumental comparada à cesariana (Gameiro et al., 2011; Friedman et al., 2012; Hansen et al., 2012; Blomquist, McDermott, Handa, 2014; Caroci et al., 2014; Rikard-Bell, Iyer, Rane, 2014; Rørtveit, Hannestad, 2014).

Foram encontrados na literatura alguns trabalhos de mensuração da FMAP citados a seguir. O primeiro deles empregou a escala de Oxford (palpação digital vaginal) e a perineometria (em $\mathrm{mmHg}$ ), a coorte que incluiu 110 primigestas com até 12 semanas de gestação, entre 36 e 40 semanas e 42 a 60 dias após o parto, não verificou mudança da FMAP durante a gestação ou depois do parto $(\mathrm{p}=0,78)$. Os dois métodos utilizados para avaliar a FMAP foram bem aceitos entre as mulheres e são efetivos para ajudar no diagnóstico de IU, IA e disfunções sexuais (Caroci et al., 2010). O segundo estudo, já citado anteriormente, analisou a FMAP entre primíparas de parto normal e cesariana, e os resultados foram de 14,3 microvolts $(\mu \mathrm{V})$ dentre as que tiveram parto normal e 13,3 $\mu \mathrm{V}$ entre aquelas de cesariana, 
contudo sem diferença estatística significante. Nesse sentido, os pesquisadores constatam que a cesariana não teve efeito protetor sobre a FMAP (Li et al., 2015).

Nossos achados mostram que houve diferença significativa na média da FMAP segundo a idade materna na análise bivariada, ou seja, quanto maior a idade da mulher menor a FMAP. Ao analisar a FMAP pelo modelo longuitudinal preditivo a associação estatística com a idade se manteve, indicando que para cada ano a mais de vida da mulher a FMAP diminui em 0,709. Vale comentar que a amostra desse estudo era composta de mulheres jovem com idade média de 21,7 anos. Esses resultados são similares aos de outros trabalhos que também encontraram uma diminuição da FMAP em relação à maior idade (Rørtveit, Hannestad, 2014; Obioha et al., 2015; Zizzi et al., 2017).

Resultados divergentes dos atuais foram observados nos estudos de Mendes et al. (2016), Gameiro et al. (2011) e Caroci et al. (2010) que não constataram diferença estatística quanto à idade materna e a FMAP, apesar da amostra de participantes jovens.

Ao comparar a FMAP com a escolaridade, não houve diferença estatística significante. Achados semelhantes foram verificados no estudo transversal de Zizzi et al. (2017). Em contrapartida, resultados diferentes foram observados no estudo de Mendes et al. (2016), que apontam maior FMAP entre as mulheres com maior escolaridade ( $\geq$ a 12 anos de estudo).

No presente estudo, a cor da pele não teve associação com a FMAP, embora as médias das mulheres de cor parda apresentassem os maiores valores; no entanto destaca-se que poucas participantes se classificaram como negras. É importante comentar que essa variável foi autorreferida pelas participantes e assim, pode-se não considerar características físicas semelhantes às dos grupos raciais. Além disso, é conhecido que nossa população possui elevada miscigenação racial. Achados divergentes dos atuais foram observados no estudo transversal que comparou a FMAP nas mulheres da África do Sul. Os valores da FMAP foram, significativamente, maiores entre as negras do que entre as brancas e pardas (Walt et al., 2014). Por outro lado, nas coortes de Caroci et al. (2010) e de Rogers et al. (2014), a cor da pele não esteve relacionada com a alteração da FMAP e com o tipo de parto.

Nossos dados apontam que a situação conjugal e a atividade remunerada, também, não estiveram associadas à FMAP. Os resultados de pesquisas citadas anteriormente, que avaliaram a FMAP, igualmente, não mostraram diferença significativa em relação ao estado marital (Caroci et al., 2010). Contrariamente Zizzi et al. (2017) verificaram que a FMAP foi estatisticamente menor quanto maior foi o tempo de coabitação e esta associação permaneceu na análise multivariada. 
Esse estudo, também, não revelou associação entre o IMC e a FMAP em nenhuma das etapas analisadas. A justificativa para esse achado pode ser que a maioria das participantes apresentasse ganho de peso adequado. Outrossim, uma coorte não encontrou associação entre o IMC da mulher e a FMAP (p=0,04) (Caroci et al., 2010). Emcontrapartida, pesquisas indicam que a obesidade pode diminuir a FMAP e causar morbidades no AP (Brubaker et al., 2008; Subak, Richter, Hunskaar, 2009; Baracho et al., 2012; Blomquist, McDermott, Handa, 2014; Riesco et al., 2014; Obioha et al., 2015).

Os resultados do atual estudo demonstraram relação entre a presença de ITU e maior FMAP, mas esses dados divergem de outros autores (Caroci et al., 2014). Esses achados, contudo, podem ser questionados uma vez que a mulher referiu ter tido ITU no pós-parto, porém eles não foram confirmados por exames laboratoriais.

Várias pesquisas indicam diminuição da FMAP e, consequente aumento dos sintomas do trato genito-urinário conforme aumenta o número de gestações ou partos, reforçando a hipótese de que a gestação e o parto causam morbidades nos MAP (Barbosa et al., 2005; Scarpa et al., 2008; Caroci et al., 2010; Gameiro et al., 2011; Chamochumbi et al., 2012; Hansen et al., 2012; Caroci et al., 2014).

$\mathrm{Na}$ literatura, existe evidência de que a paridade influencia a FMAP (Caroci et al., 2010; Elenskaia et a., 2011; Petricelli et al., 2014). No atual estudo, a variável paridade não foi avaliada, pois o critério de inclusão foi que as participantes fossem primíparas; entretanto Özdemir et al. (2015) analisaram a FMAP depois do parto vaginal e o efeito da paridade na FMAP e na QV de 233 mulheres com IU. Essas mulheres foram divididas em três grupos: grupo 1, elas tinham de um a três filhos; grupo 2, de quatro a seis e grupo 3, acima de seis filhos. A FMAP entre as mulheres do grupo 1 foi, estatisticamente, maior do que as do grupo 2 e 3 , indicando que os problemas de IU aumentam de acordo com o número maior de partos.

No estudo atual, a FMAP foi, estatíticamente, maior entre as mulheres que não referiram IU, resultado que corrobora os achados de Riesco et al. (2014). Da mesma forma, Chamochumbi et al. (2012) encontraram que a redução da FMAP é a principal causa de IUE. Ao compararar a FMAP na contração com a FMAP em situação de repouso nas mulheres continentes e incontinentes ao esforço, foi constatado que a FMAP na contração foi maior nas mulheres continentes, com diferença estatística.

Dados contraditórios aos resultados do presente estudo foram observados por outros trabalhos (Li et al., 2015; Bø et al., 2016).

A revisão sistemática que avaliou a atividade muscular e os componentes da FMAP influentes na continência urinária feminina e na IUE, concluiu que nas mulheres que 
realizaram um PTMAP houve melhora na ativação e na sustentação da FMAP e uma diminuição na perda urinária nas mulheres que tinham IUE. As mulheres que possuíam maior atividade e FMAP eram mais continentes (Luginbuehl et al., 2015).

Estudo observacional e analítico com 218 mulheres que tinham entre 28 e 85 anos as quais foram entrevistadas utilizando-se de um questionário sobre IU e QV. Elas apresentaram IUE nos últimos seis meses e quanto ao exame urodinâmico não mostraram nenhuma atividade excessiva do detrusor. Essas mulheres revelaram IU por tosse e perda de urina menor que três gramas, avaliada pelo absorvente, com um volume de bexiga padronizado de 200 mililitros. A FMAP foi estimada pela palpação digital vaginal e pelo perineômetro Peritron $^{\mathrm{TM}}$ e não foi encontrada relação significante entre a FMAP e a QV das mulheres. Os valores médios da FMAP foram classificados como moderadas por ambos os métodos de avaliação (Chevalier et al., 2014).

Embora no estudo atual não tenha sido realizado análise entre o tipo de parto e a IU, MacArthur et al. (2016) em estudo longitudinal que investigou a ocorrência da IU depois de 12 anos após o parto normal ou cesariana concluíram que a IU persistiu por 12 anos após o parto em três-quartos das mulheres e que o risco reduziu apenas para a cesariana, se a mulher não teve nenhum outro tipo de parto.

Quanto à IA, como referido anteriormente, foram encontradas poucas mulheres (seis e uma, respectivamente aos dois e seis meses) que não nos permitiu realizar análise comparativa com a FMAP.

Um estudo analisou a associação da FMAP com IA e com histórico de lesão obstétrica do esfíncter anal, selecionando mulheres que foram submetidas ao reparo do esfíncter anal intraparto e 95 foram avaliadas aos seis meses após o parto. As mulheres que tiveram lacerações do esfíncter anal de maior gravidade, foram as que apresentaram maior correlação com à IA. As mulheres que apresentaram maior FMAP estiveram associadas com menores sintomas de IA no período após o parto (Cerro et al., 2016).

Estudo aponta como maior fator de risco para IA a lesão obstétrica do esfíncter anal seguido por episiotomia, parto instrumental, RN acima de 4.000 gramas, período expulsivo prolongado e o primeiro parto. Outros fatores foram considerados de riscos menores como a apresentação fetal em OS, analgesia epidural, edema perineal, proteção perineal inadequada, parto induzido e manobra de kristeller (Rodríguez et al., 2015). Por outro lado, a laceração de quarto grau, a cor branca e a menor duração do período expulsivo foram associadas com a IA aos seis meses depois do parto (Richter et al., 2015). 
Da mesma maneira, outra pesquisa, também, encontrou que a episiotomia esteve fortemente associada à IA, mas não o peso do RN. Conclui-se que a IA é uma morbidade comum entre as mulheres no pós-parto, porém a maioria não percebe essa morbidade como severa e várias delas não referem os sintomas de IA, a menos que o profissional questione especificamente. Diante disso, recomenda-se que os profissionais da saúde façam perguntas específicas sobre os sintomas de IA nas consultas de rotina do puerpério (Rajeshkannan, Pathmeswaran, 2013).

A coorte com 747 mulheres que tinham IU com três meses depois do parto distribuiuas em dois grupos: o de intervenção (realizou-se o PTMAP e o treinamento da bexiga) e o de controle (cuidado padrão). A intervenção foi realizada com cinco, sete e nove meses depois do parto e concluiu-se que a prevalência de IU e IA foi menor com um ano depois do parto, porém não foi observada essa diferença aos seis ou 12 anos após o parto. Quatro-quintos das mulheres que tinham IU com três meses depois do parto permaneceram com esse sintoma depois de 12 anos. Desse modo considera-se que houve efeito moderado a curto prazo no grupo intervenção, mas que não persistiu a longo prazo, provavelmente, pela sua descontinuidade (Glazener et al., 2014).

Os autores consideram que as ocorrências de IA causadas por lesão obstétrica do esfíncter anal podem ser minimizadas se forem feitos os reparos perineais por profissionais devidamente treinados (Andrews et al., 2013).

Quanto à variável exercícios perineais, a análise bivariada evidenciou que a média da FMAP esteve próxima da significância estatística, mas no modelo longitudinal preditivo a associação da FMAP com o exercício aparece indicando que a mulher que pratica exercício perineais teve 3,359 $\mathrm{cmH}_{2} \mathrm{O}$ a mais na média da FMAP. Merece comentar que a regularidade dessa prática não foi questionada com as mulheres e tampouco supervisionada. Contrariamente, Zizzi et al. (2017) não encontraram diferença significativa na FMAP entre as mulheres que realizaram ou não exercícios perineais, pelo menos duas vezes por semana, na gravidez ou no pós-parto, sendo essa variável obtida por autorrelato como na atual pesquisa.

Para avaliar o impacto do PTMAP na FMAP foi realizada uma coorte prospectiva utilizando vários questionários validados sobre QV, IU, disfunções dos MAP e a palpação digital vaginal. Foram atendidas 218 mulheres que referiram ou não IU no pós-parto, sendo que $75 \%$ delas realizaram o PTMAP em oficina e 25\% fizeram o PTMAP na oficina e depois individualmente. Todas foram acompanhadas, no mínimo, durante três meses depois do parto por um fisioterapeuta. Os resultados sugerem que a abordagem da auto-seleção para a realização do PTMAP, no período pós-parto, contribuiu, significantemente, para a melhoria 
das funções dos MAP, da FMAP, da satisfação da mulher e da QV (Gagnon, Boucher, Robert, 2016).

Estudo que teve por objetivo verificar o impacto dos exercícios extenuantes nos MAP em comparação com exercícios de caminhadas realizadas por nulíparas maiores de 18 anos até 35 anos. Os exercícios extenuantes (Crossfit) eram caracterizados por alta intensidade e atividades físicas variadas, sendo realizados três vezes por semana e nos últimos seis meses. A primeira avaliação foi feita antes de designar as mulheres para o grupo de exercícios extenuantes ou não, e a segunda foi feita depois de concluir 15 minutos de exercícios. Antes e depois da realização dos exercícios não houve diferenças significantes na FMAP entre os grupos, sugerindo que sejam realizados exercícios específicos com os MAP em vez de exercícios envolvendo vários músculos (Middlekauff et al., 2016).

Ensaio clínico que avaliou o efeito do PTMAP na FMAP de 116 mulheres que tinham IU. 65 delas foram randomizadas no grupo que realizou o PTMAP e 51 no controle. O PTMAP foi executado duas vezes por semana durante três meses, sendo acompanhado por um fisioterapeuta nas três primeiras semanas. A FMAP, em ambos os grupos, foi avaliada antes e depois de 12 semanas por meio da palpação digital vaginal, perineometria e ultrassonografia transabdominal. Houve significante melhora na FMAP e nos sintomas de IU no grupo que realizou o PTMAP e nenhuma diferença foi encontrada no grupo controle (Tosun et al., 2016).

Vários estudos citados anteriormente mostraram que o tipo de parto pode ser um fator de risco para a diminuição FMAP e, consequentemente, causar alterações aos MAP, porém referem que essas alterações podem ser evitadas, reduzidas ou melhoradas realizando exercícios de fortalecimento dos MAP (Menta, Schirmer, 2006; Oliveira et al, 2007; Zanetti et al., 2007; Fitz et al., 2012; Pelaez et al., 2014; Dumoulin et al., 2015; Gagnon, Boucher, Robert, 2016; Sut, Kaplan, 2016; Yohay et al, 2016).

Coorte prospectiva teve por objetivo analisar o efeito das lacerações perineais na função e anatomia dos MAP com seis meses depois do parto. Essa avaliação foi realizada pelo exame físico e por questionário validado. Foram incluídas 448 mulheres que tiveram PN atendidas por obstetrizes. Entre essas, 297 tiveram períneo íntegro ou lacerações perineais de primeiro grau e 151 tiveram lacerações de segundo grau ou de maior gravidade. Essas mulheres foram seguidas desde a gestação e cerca de três quartos delas retornaram para avaliação com seis meses. Os resultados não mostraram associação entre o grau de laceração perineal e IU, IA, diminuição da atividade sexual, dor perineal ou POP. A avaliação da FMAP, do tônus retal, da IU e da anatomia foram equivalentes entre as lacerações perineais 
espontâneas; portanto as lacerações perineais espontâneas não estavam relacionadas com o aumento do risco das disfunções dos MAP (Leeman et al., 2016).

Apesar de quase a metade das participantes do atual estudo referir dispareunia, essa variável não mostrou associação com as médias da FMAP. Na literatura, foram encontrados poucos estudos que associam a dispareunia com a FMAP. Dados semelhantes foram observados por Caroci et al., 2010 e Caroci et al., 2014.

Em contraste, estudo transversal que avaliou o desempenho sexual e incluiu 40 multíparas entre 20 e 28 anos sem disfunções no assoalho pélvico verificou que as participantes com maior FMAP apresentaram escore elevado em relação ao desejo sexual, excitação, orgasmo e pontuação geral do questionário ( $\mathrm{p}<0,001)$. Observou-se, também, uma correlação entre a pressão dos músculos do AP e a satisfação sexual ( $r=0,47, p=0,03)$ e lubrificação $(r=-0,69, p=0,001)$. Os autores concluíram que as mulheres que apresentaram maior FMAP possuem melhor função sexual (Martinez et al., 2014).

Em relação às condições do períneo, no estudo atual e no de Mendes et al. (2016) não foram observadas lacerações perineais de maior gravidade, e as médias da FMAP de acordo com ter ou não trauma perineal foram similares nas duas etapas. Em contraste, a FMAP observada entre as mulheres sem anestesia local apresentaram média estatisticamente maior. Tal fato leva-nos a pressupor que as participantes tinham integridade da região ou no máximo laceração de primeiro grau e que não houve necessidade de sutura. Convém destacar que como a variável condições do períneo no parto normal estava classificada em quatro categorias, e por isso com um número pequenos de casos em cada categoria, isto dificultou a análise apontar diferença estatística; o que não ocorreu na variável reparo perineal sob anestesia. Reforçando essa suposição, o estudo transversal também constatou que as mulheres com trauma perineal, apresentaram média estatisticamente menor de FMAP comparadas aquelas com integridade perineal (26,6 $\mathrm{cmH}_{2} \mathrm{O}$ vs 35,2 $\mathrm{cmH}_{2} \mathrm{O}$ ) (Zizzi et al., 2017).

Pesquisa já citada na introdução, também não encontrou diferença, estatisticamente, significativa na função da FMAP (resistência, repouso e contração) entre as mulheres com ou sem episiotomia (Bø et al., 2017). Resultados opostos foram apontados na coorte que verificou, nas mulheres com episiotomia, valores de FMAP, estatisticamente, maiores comparadas àquelas sem esse procedimeto (Caroci et al., 2014). 


\subsection{LIMITAÇÕES DO ESTUDO}

Considera-se que o tamanho da amostra foi uma limitação do estudo, considerando a quantidade de variáveis avaliadas. Por outro lado, por ser um estudo longuitudinal houve muitas perdas de seguimento que a pesquisadora precisou compensar recrutando mais participantes.

O fato de não se perguntar a frequência da realização dos exercícios perineais e físicos, também, pode ser considerado uma limitação desse estudo, uma vez que a repercussão de frequências variadas é muito diversa.

Vários estudos apontam para a falta de padronização dos procedimentos e a grande variabilidade dos métodos e instrumentos utilizados para avaliação da FMAP, dificultando a comparação dos resultados (Riesco et al., 2010; Vanconcelos e Ribeiro, 2013; Luginbuehl et al., 2015).

Outra limitação é que em razão de pouca frequência dos distúrbios encontrados no assoalho pélvico, a análise estatística foi realizada apenas no curto prazo após o parto portanto, nossos resultados sobre a associação entre a FMAP e IU deve ser interpretada com cautela, pois podem refletir um poder de estudo limitado para comparações destes subgrupos.

Também consideramos como limitação a não utilização de questionários validados para a investigação da atividade sexual, tais como o Oxfordshire women's Health Study Questionnaire e o Female Sexual Function Index (FSFI).

\subsection{IMPLICAÇÕES PARA A PESQUISA E A PRÁTICA}

Nossos resultados contribuem com informações sobre a avaliação funcional da FMAP e suas disfunções após o parto, e a importância do acompanhamento das mulheres a longo prazo. Eles, também, colaboram na construção de um perfil da FMAP e fornecem dados para a elaboração de PFMAP, buscando a prevenção e redução de morbidades no trato genitourinário, em especial a IU, além de melhorar a avaliação do MAP.

Para a prática assistencial, este estudo pode favorecer aos profissionais atuantes na assistência em qualquer período do ciclo gravídico-puerperal na conscientização de que precisam identificar as mulheres que possuem ou aquelas com predisposição de desenvolver as disfunções IU, IA e dispareunia para contribuir com a prevenção ou implementar o tratamento. 
Os resultados desta coorte permitiram concluir que:

A FMAP avaliada aos dois e seis meses depois do parto, não está associada ao tipo de parto. Apesar das médias da FMAP terem sido mais elevadas entre as mulheres com parto normal comparadas àquelas de cesariana, não houve diferença estatística.

A análise aos dois e seis meses mostra um discreto aumento da FMAP, independente do tipo de parto, mas sem diferença estatística.

A FMAP está relacionada à idade (efeito principal p=0,001), não sendo observadas interações entre idade e etapas $(\mathrm{p}=0,756)$. Além do mais, constata-se que à medida que aumenta a idade materna, diminui a FMAP em 0,709 a cada ano de vida.

As mulheres com ITU revelaram FMAP, estatisticamente, maior (efeito principal $\mathrm{p}=0,012$ ), independente do período pós-parto. Observou-se, também, que a FMAP é, estatisticamente, maior naquelas sem IU (efeito principal p=0,021).

Houve associação entre as puérperas que praticaram exercícios perineais, indicando que aquelas que realizam exercícios perineais apresentam um aumento na média da FMAP em 3,359, independente da etapa pós-parto.

Média estatisticamente maior da FMAP (efeito principal p=0,028) é observada entre as mulheres sem anestesia local para sutura do períneo.

Não houve associação entre a FMAP e as demais variáveis analisadas.

Quanto à prevalência de IU, considerando o período anterior à gestação, verifica-se que houve um aumento de 13,1 (p.p.) na gravidez e uma redução de 16,1(p.p.) e de 21,2 (p.p.) aos dois e seis meses pós-parto, respectivamente.

Em relação à prevalência de IA, está presente em 6,1\% das puérperas aos dois meses após o parto, mas apenas duas delas reportaram incontinência de fezes. Com seis meses pós-parto, somente uma mulher persistiu com incontinência de flatos.

Aos dois e seis meses pós-parto, a prevalência de dispareunia foi referida por $44,3 \%$ e $9,5 \%$ das mulheres, respectivamente.

Os resultados sugerem que ocorreu uma recuperação espontânea dos MAP, visto que houve uma reducão da frequência das DAPs aos seis meses pós-parto.

Considerando os achados deste estudo é importante destacar o papel fundamental da enfermeira obstetra na orientação dos exercícios perineais para a puérpera, visto que a sua realização, independente da regularidade e da supervisão de um profissional, aumentou a FMAP, podendo auxiliar na prevenção e no tratamento das DAP. 
Abrams P, Andersson KE, Birder L, Brubaker L, Cardozo L, Chapple C, et al. Fourth International Consultation on Incontinence Recommendations of the International Scientific Committee: Evaluation and treatment of urinary incontinence, pelvic organ prolapse, and fecal incontinence. Neurourol Urodyn. 2010;29(1):213-40.

Axelsson D, B Lomberg M. Prevalence of postpartum infections: a population-based observational Study. Acta Obstet Gynecol Scand. 2014;93(10):1065-8.

Andrews V, Shelmeridine S, Sultan AH, Takar R. Anal and urinary incontinence 4 years after a vaginal delivery. Int Urogynecol J. 2013;24(1):55-60.

Andrews V, Sultan AH, Thakar R, Jones PW. Occult anal sphincter injuries myth or reality? BJOG. 2006;113(2):195-200.

Arroyo A, Parra P, Lopez A, Peña E, Ruiz-Tovar J, Benavides J, et al. Percutaneous posterior tibial nerve stimulation (PTNS) in faecal incontinence associated with an anal sphincter lesion: Results of a prospective study. Int J Surg. 2014;12(2):146-9.

Atalah E, Castillo C, Castro R, Aldea A, et al. Propuesta de un nuevo estándar de evaluación nutricional en embarazadas. Rev Med Chile. 1997;125(12):1429-36.

Avery K, Donovan J, Peters TJ, Shaw C, Gotoh M, Abrams, P. ICIQ: a brief and robust measure for evaluating the symptoms and impact of urinary incontinence. Neurourol Urodyn. 2004;23(4):322-30.

Baracho SM, Silva LB, Baracho E, Filho ALS, Sampaio RF, Figueiredo EM. Pelvic floor muscle strength predicts stress urinary incontinence in primiparous women after vaginal delivery. Int Urogynecol J. 2012;23(7):899-906.

Barbosa AMP, Carvalho LRD, Martins AMVC, Calderon IDMP, Rudge MVC. Efeito da via de parto sobre a força muscular do assoalho pélvico. Rev Bras Ginecol Obstet. 2005;27(11): $677-82$.

Barbosa AMP, Marini G, Piculo F, Rudge CVC, Calderon IDMP, Rudge MVC. Prevalência de incontinência urinária e disfunção muscular do assoalho pélvico em primíparas dois anos após parto cesárea: Estudo transversal. São Paulo Med J. 2013;131(2):95-9.

Barbosa PB, Franco MM, Souza FDO, Antônio FI, Montezuma T, Ferreira CHJ. Comparison between measurements obtained with three different perineometers. Clinics. 2009;64(6):52733.

Blomquist JL, McDermott K, Handa VL. Pelvic pain and mode of delivery. Am J Obstet Gynecol. 2014;210(5):423.e1-6.

$\mathrm{B} \emptyset \mathrm{K}$, Finckenhagen HB. Vaginal palpation of pelvic floor muscle strength: Inter-test reproducibility and comparison between palpation and vaginal squeeze pressure. Acta Obstet Gynecol Scand. 2001;80(10):883-7. 
$\mathrm{B} \emptyset \mathrm{K}$, Hilde G, Jensen JS, Siafarikas F, Engh ME. Too tight to give birth? Assessment of pelvic floor muscle function in 277 nulliparous pregnant women. Int Urogynecol J. 2013;24(12):2065-70.

Bø K, Hilde G, Stær-Jensen J, Siafarikas F, Tennfjord MK, Engh ME. Postpartum pelvic floor muscle training and pelvic organ prolapse a randomized trial of primiparous women. Am J Obstet Gynecol. 2015;212(1):38-e1-7.

$\mathrm{B} \emptyset \mathrm{K}$, Hilde G, Tennfjord MK. Pelvic floor muscle function, pelvic floor dysfunction and diastasis recti abdominis: prospective cohort study. Neurourol Urodyn. 2016;36(3):716-21.

Bø K, Hilde G, Tennfjord MK, Engh ME. Does episiotomy influence vaginal resting pressure, pelvic floor muscle strength and endurance, and prevalence of urinary incontinence 6 weeks postpartum? Neurourol Urodyn. 2017;36(3):683-6.

Boran SU, Cengiz H, Erman O, Erkaya S. Episiotomy and the development of postpartum dyspareunia and anal incontinence in nulliparous females. Eurasian J Med. 2013;45(3):17680.

Boyle R, Hay-Smith EJC, Cody JD, Mørkved S. Pelvic floor muscle training for prevention and treatment of urinary and faecal incontinence in antenatal and postnatal women. Cochrane Database Syst Rev. 2012;10:CD007471.

Brækken IH, Majida M, Engh ME, Bø K. Morphological changes after pelvic floor muscle training measured by 3-dimensional ultrasonography: a randomized controlled trial. Obstet Gynecol. 2010;115(2):317-24.

Brækken IH, Majida M, Engh ME, Bø K. Test-retest reliability of pelvic floor muscle contraction measured by 4D ultrasound. Neurourol Urodyn. 2009;28(1):68-73.

Brasil. Ministério da Saúde-MS (BR). Secretaria de Políticas de Saúde. Área Técnica de Saúde da Mulher. Parto, aborto e puerpério: assistência humanizada à mulher. Brasília (DF); 2001.

Brasil. Ministério da Saúde: Conselho Nacional de Saúde. Resolução n. 422, de 12 de dezembro de 2012. Dispõe sobre as diretrizes e normas regulamentadoras de pesquisas envolvendo seres humanos [Internet]. Brasília; 2012 [citado 2013 set. 4]. Disponível em: http://conselho.saude.gov.br/resolucoes/2012/Reso466.pdf

Brasil. Ministério da Saúde. Secretaria de Atenção à Saúde. Departamento de Ações Programáticas Estratégicas. Gestação de alto risco: manuel técnico. $5^{\mathrm{a}}$ ed. Brasília (DF): Editora do Ministério da Saúde; 2012. Infecção urinária; p. 111-2.

Brasil. Ministério da Saúde. Comissão Nacional de Incorporação de Tecnologias no SUS. Diretriz nacional de assistência ao parto normal: relatório de recomendação. Brasilia; 2016.

Brincat C, Crosby E, McLeod A, Fenner DE. Experiences during the first four years of a postpartum perineal clinic in the USA. Int J Gynecol Obstet. 2015;128(1):68-71. 
Brouwer R, Duthie G. Sacral nerve neuromodulation is effective treatment for fecal incontinence in the presence of a sphincter defect, pudendal neuropathy, or previous sphincter repair. Dis Colon Rectum. 2010;53(3):273-8.

Brown S, Gartland D, Perlen S, McDonald E, MacArthur C. Consultation about urinary and faecal incontinence in the year after childbirth: a cohort study. BJOG. 2014;122(7):954-62.

Brubaker L, Handa VL, Bradley CS, Connolly A, Moalli P, Brown MB \& Weber A. Sexual function 6 months after first delivery. Obstet Gynecol. 2008;111(5):1040-4.

Buhling KJ, Schmidt S, Robinson JN, Klapp C, Siebert G, Dudenhausen JW. Rate of dyspareunia after delivery in primiparae according to mode of delivery. Eur J Obstet Gynecol Reprod Biol. 2006;124(1):42-6.

Bunduki V, Cabar FR, Nomura RMY. Anatomia da Pelve Feminina. In: Zugaibe M. Zugaibe Obstetrícia. Barueri, SP: Manole; 2012.p.45-7.

Burrell M, Dilgir S, Patton V, Parkin K, Karantanis E. Risk factors for obstetric anal sphincter injuries and postpartum anal and urinary incontinence: a case-control trial. Int Urogynecol. J. 2015;26(3):383-9.

Cabar FR, Codarin RR, Bunduki V. Anatomia da pelve feminina. In: Zugaib M, Francisco RPV. Zugaib Obstetrícia. $3^{\text {a }}$ ed. Barueri, SP: Manole; 2016.p. 34-49.

Calais-Germain B. O períneo feminino e o parto: elementos de anatomia e exercícios práticos. Barueri: Manole; 2005. 160p.

Caroci AS, Riesco MLG, Sousa WS, Cotrim AC, Sena EM, Rocha NL,et al. Analysis of pelvic floor musculature function during pregnancy and postpartum: A cohort study. J Clin Nurs. 2010;10:2424-33.

Caroci AS, Riesco MLG, Rocha BMC, Ventura LJ, Oliveira SG. Avaliação da força muscular do assoalho pélvico no primeiro trimestre da gestação. Rev Latino Am-Enferm. 2014;22(5):874-82.

Cerro CR, Franco EM, Santoro GA, Palau MJ, Wieczorek P, Espuña-Pons M. Residual defects after repair of obstetric anal sphincter injuries and pelvic floor muscle strength are related to anal incontinence symptoms. Int Urogynecol J. 2016;28(3):455-60.

Chamochumbi C, Nunes FR, Guirro RR, Guirro EC. Comparison of active and passive forces of the pelvic floor muscles in women with and without stress urinary incontinence. Rev Bras Fisioter. 2012;16(4): 314-9.

Chang SR, Chen KH, Lin HH, Lin MI, Chang TC, Lin WA. Association of mode of delivery with urinary incontinence and changes in urinary incontinence over the first year postpartum. Obstet Gynecol. 2014;123(3):568-77. 
Chevalier F, Fernandez-Lao C, Cuesta-Vargas AI. Normal reference values of strength in pelvic floor muscle of women: a descriptive and inferential study. BMC Women's Health. 2014;25;14:143.

Chow SC, Shao J, Wang H. A note on sample size calculation for mean comparisons based on noncentral t-statistics. J Biopharm Stat. 2002;12(4):441-56.

Clarkson J, Newton C, Bick D, Gyte G, Kettle C, Newburn M, et al. Achieving sustainable quality in maternity services-using audit of incontinence and dyspareunia to identify shortfalls in meeting standards. BMC Pregnancy Childbirth. 2001;1(1):4.

Costa ASC. Análise da força muscular perineal na gestação e no puerpério [tese] São Paulo: Escola de Enfermagem, Universidade de São Paulo, 2008.

Costa ASC, Riesco MLG, Rocha BMC, Oliveira SG, Ventura LJ. Avaliação da força muscular perineal no primeiro trimestre da gestação. Rev Latino Am-Enferm. 2014;22(6):893-901.

Dietz HP, Simpson JM. Levator trauma is associated with pelvic organ prolapse. BJOG: 2008;115(8):979-84.

Dinc A, Beji NK, Yalcin O. Effect of pelvic floor muscle exercises in the treatment of urinary incontinence during pregnancy and the postpartum period. Int Urogynecol $\mathrm{J}$. 2009;20(10):1223-31.

Domingues RMSM, Dias MAB, Nakamura PM, Torres JA, d'Orsi E, Pereira APEs et al . Processo de decisão pelo tipo de parto no Brasil: da preferência inicial das mulheres à via de parto final. Cad. Saúde Pública [Internet]. 2014 [citado 2016 Nov 09]. Disponível em: http://dx.doi.org/10.1590/0102-311X00105113.

d'Orsi E, Brüggemann OM, Diniz CSG, Aguiar JM, Gusman CR, Torres JA et al . Desigualdades sociais e satisfação das mulheres com o atendimento ao parto no Brasil: estudo nacional de base hospitalar. Cad. Saúde Pública [Internet]. 2014 [citado 2016 Nov 09] Disponível em: http://dx.doi.org/10.1590/0102-311X00087813.

Dumoulin C, Hay-Smith J. Pelvic floor muscle training versus no treatment, or inactive control treatments, for urinary incontinence in women. Cochrane Database Syst Rev. 2010; 1(1):CD005654.

Dumoulin C, Hay-Smith EJC, Mac Habée-Séguin G, Mercier J. Pelvic floor muscle training versus no treatment, or inactive control treatments, for urinary incontinence in women: A short version Cochrane Systematic Reviews with Meta-Analysis. Neurourol Urodyn. 2015;34(4):300-8.

Elenskaia K, Thakar R, Sultan AH, Scheer I, Beggs A. The effect of pregnancy and childbirth on pelvic floor muscle function. Int Uroginecol J. 2011;22(11):1421-7. 
Evans C, Archer R, Forrest A, Barrington J. Management of obstetric anal sphincter injuries (OASIS) in subsequent pregnancy. J Obstet Gynaecol. 2014;34(6): 486-8.

Faul F, Erdfelder E, Lang AG, Buchner A. G* Power 3: A flexible statistical power analysis program for the social, behavioral, and biomedical sciences. Behav Res Meth. 2007;39(2): 175-91.

Findik RB, Unluer AN, Sahin E, Bozkurt OF, Karakaya J, Unsal A. Urinary incontinence in women and its relation with pregnancy, mode of delivery, connective tissue disease and other factors. Adv Clin Exp Med.2012;21(2):207-13.

Fitz FF, Costa TF, Yamamoto DM, Resende APM, Stüpp L, Sartori MGF, et al. Impacto do treinamento dos músculos do assoalho pélvico na qualidade de vida em mulheres com incontinência urinária. Rev Assoc Méd Bras. 2012;58(2):155-9.

Fitzpatrick M, Herlihy CO. The effects of labour and delivery on the pelvic floor. Best Pract Rev Clin Obstet Gynaecol. 2001;15(1):63-79.

Fleming N, Newton ER \& Roberts J. Changes in postpartum perineal muscle function in women with and without episiotomies. J Midwifery Womens Health. 2003;48(1):53-9.

Flores-Mireles AL, Walker JN, Caparon M, Hultgren SJ. Urinary tract infections: epidemiology, mechanisms of infection and treatment options. Nat Rev Microbiol. 2015;13(5):269-84.

Friedman S, Blomquist JL, Nugent JM, McDermott KC, Muñoz A, Handa VL. Pelvic muscle strength after childbirth. Obstet Gynecol. 2012;120(5):1021-8.

Gameiro MO, Sousa VO, Gameiro LF, Muchailh RC, Padovani CR, Amaro JL. Comparison of pelvic floor muscle strength evaluations in nulliparous and primiparous women: a prospective study. Clinics. 2011;66(8):1389-94.

Gagnon LH, Boucher J, Robert M. Impact of pelvic floor muscle training in the postpartum period. Int Urogynecol J. 2016;27(2):255-60.

Garcia-Burguillo MP, Aguila-Maturana AM. Energy-saving strategies in the treatment of fatigue in patients with multiple sclerosis. A pilot study. Rev Neurol. 2009;49:181-5.

Glazener C, Cooper K. Anterior vaginal repair for urinary incontinence in women. Cochrane Database Syst Rev. 2001;(1):CD001755.

Glazener CM, MacArthur C, Hagen S, Elders A, Lancashire R, Herbison GP, et al. Twelveyear follow-up of conservative management of postnatal urinary and faecal incontinence and prolapse outcomes: randomised controlled trial. BJOG: An J Obstet Gynaecol. 2014;121(1): 112-20.

Glaser AP, Schaeffer AJ. Urinary tract infection and bacteriuria in pregnancy. Urol Clin North Am. 2015;42(4):547-60. 
Grant A, Sleep J. Dor e desconforto perineais. In: Enkin M, Keirse MJNC, Renfrew M, Neilson J. Guia para atenção efetiva na gravidez e no parto. $3^{a}$ ed. Rio de Janeiro: Guanabara Koogan; 2002. p.243-7.

Guimarães LSP, Hirakata VN. Uso de modelo de equações de estimações generalizadas na análise de dados longitudinais. Rev HCPA. 2012;32(4):503-11.

Hadi E, Groutz A, Gold R, Lessing J, Gordon D. Pregnancy, labor and delivery: the pelvic floor injury. Harefuah. 2004;143(7):525-9, 548, 547.

Hagen S, Stark D. Conservative prevention and management of pelvic organ prolapse in women. Cochrane Database Syst Rev. 2011;7;(12):CD003882.

Hagen S, Stark D, Glazener C, Dickson S, Barry S, Elders A et al. Individualised pelvic floor muscle training in women with pelvic organ prolapse (POPPY): a multicentre randomised controlled trial. Lancet. 2014;383(9919):796-806.

Hansen BB, Svare J, Viktrup L, Jørgensen T, Lose G. Urinary incontinence during pregnancy and 1 year after delivery in primiparous women compared with a control group of nulliparous women. Neurourol urodyn. 2012;31(4):475-80.

Hay-Smith J, Mørkved S, Fairbrother KA, Herbison GP. Pelvic floor muscle training for prevention and treatment of urinary and faecal incontinence in antenatal and postnatal women. Cochrane Database Syst Rev. 2011;(4):CD007471.

Hilde G, Stær-Jensen J, Engh ME, Brækken IH, Bø K. Continence and pelvic floor status in nulliparous women at midterm pregnancy. Int urogynecol J .2012;23(9):1257-63.

Hilde G, Stær-Jensen J, Siafarikas F, Engh ME, Bø K. Postpartum pelvic floor muscle training and urinary incontinence: a randomized controlled trial. Obst Gynecol. 2013a;122(6):1231-38.

Hilde G, Staer-Jensen J, Siafarikas F, Engh ME, Braekken IH, Bø K. Impact of childbirth and mode of delivery on vaginal resting pressure and on pelvic floor muscle strength and endurance. Am J Obstet Gynecol. 2013b;208(1):50.e1-7.

Hotouras A, Thaha MA, Allison ME, Currie A, Scott SM, Chan CLH. Percutaneous tibial nerve stimulation (PTNS) in females with faecal incontinence: the impact of sphincter morphology and rectal sensation on the clinical outcome. Int J Colorectal Dis. 2012;27(7): 927-30.

Johannessen HH, Wibe A, Stordahl A, Sandvik L, Mørkved S. Anal incontinence among first time mothers-What happens in pregnancy and the first year after delivery? Acta obst Gynecol Scand. 2015;94(9):1005-13.

Jones, KD. Incedence and risk factors for third degree perineal tears. Int J GynecolObstet 2000;71(3):227-9. 
Kabakian-Khasholian T, Ataya A, Shayboub R, El-Kak F. Mode of delivery and pain during intercourse in the postpartum period: Findings from a developing country. Sex Reprod Healthc. 2015;6(1):44-7.

Kearney R, Miller JM, Ashton-Miller JA, DeLancey JO. Obstetrical factors associated with levator ani muscle injury after vaginal birth. Obst Gynecol. 2006;107(1):144.

Kim S, Harvey MA, Johnston S. A review of the epidemiology and pathophysiology of pelvic floor dysfunction: do racial differences matter? Obstet Gynaecol Can. 2005;27(3):251-9.

Kramer MS, McDonald SW. Aerobic exercise for women during pregnancy. Cochrane Database Syst Rev. 2006;19(3):CD000180.

Laine K, Skjeldestad FE, Sandvik L, Staff AC. Prevalence and risk indicators for anal incontinence among pregnant women. ISRN obstet Gynecol. 2013 Article ID 947572.

Laine K, Skjeldestad FE, Sanda B, Horne H, Spydslaug A, Staff AC. Prevalence and risk factors for anal incontinence after obstetric anal sphincter rupture. Acta obstetGynecol Scand. 201;90(4):319-24.

Laine K, Skjeldestad FE, Sandvik L \& Staff AC. Incidence of obstetric anal sphincter injuries after training to protect the perineum: cohort study. BMJ Open. 2012;17;2(5). pii: e001649.

Lavy Y, Sand PK, Kaniel CI, Hochner-Celnikier D. Can pelvic floor injury secondary to delivery be prevented?. Int urogynecol J.2012;23(2):165-73.

Leeman L, Rogers R, Borders N, Teaf D, Qualls. The effect of perineal lacerations on pelvic floor function and anatomy at 6 moths postpartum in a prospective cohort of nulliparous womens. Bitth. 2016;43(4):293-302.

Leroy LS, Lopes MHBM. A incontinência urinária no puerpério e o impacto na qualidade de vida relacionada à saúde. Rev Latino-Am Enferm. 2012;20(2):E1-E8.

Li H, Wu RF, Qi F, Xiao AM, Ma Z, Hu Y, et al. Postpartum pelvic floor function performance after two different modes of delivery. Genet Mol Res. 2015;14(2):2994-3001.

Lopes DBM, Praça NDS. Incontinência urinária autorreferida no pós-parto: características clínicas. Rev Esc Enferm USP. 2012b;46(3):559-64.

Luginbuehl H, Baeyens JP, Taeymans, Maeder IM, Kul A, Radlinger L. Pelvic floor muscle activation and strength components influencing female urinary continence and stress incontinence: a systematic review. Neurol Urodyn. 2015;34:498-506.

Lukacz ES, Lawrence JM, Contreras R, Nager CW, Luber KM. Parity, mode of delivery, and pelvic floor disorders. Obstet Gynecol. 2006;107(6):1253-60.

Luthander C, Emilsson T, Ljunggren G, Hammarström M. A questionnaire on pelvic floor dysfunction postpartum. Int urogynecol J. 2011;22(1):105-13. 
MacArthur C, Wilson D, Herbison P, Lancashire RJ, Hagen S, Toozs-Hobson P, et al. Urinary incontinence persisting after childbirth: extent, delivery history, and effects in a 12year longitudinal cohort study. BJOG. 2016;123(6):1022-29.

McDonald EA, Gartland D, Small R, Brown SJ. Frequency, severity and persistence of postnatal dyspareunia to 18 months post partum: A cohort study. Midwifery. 2016;34:15-20.

Martinez CS, Ferreira FV, Castro AA, Gomide LB. "Women with greater pelvic floor muscle strength have better sexual function. Acta obstet gynecol Scand. 2014;93(5):497-502.

Martinho NM, Silva VR, Marques J, Carvalho LC, Lunes DH, Botelho S. The effects of training by virtual reality or gym ball on pelvic floor muscle strength in postmenopausal women: a randomized controlled trial. Braz J Phys Ther. 2016;20(3):248-57.

Mathé M, Valancogne G, Atallah A, Sciard C, Doret M, Gaucherand P, et al. Early pelvic floor muscle training after obstetrical anal sphincter injuries for the reduction of anal incontinence. Eur J Obstet Gynecol Reprod Biol. 2016;199:201-06.

Mendes EPB, Oliveira SMJV, Caroci AS, Francisco AA, Oliveira SG, Silva RL. Pelvic floor muscle strength in primiparous women according to the delivery type: cross-sectional study. Rev Lat-Am Enferm. 2016;24:e2758.

Menta SS, Schirmer J. Relação entre a pressão muscular perineal no puerpério e o tipo de parto. Rev Bras Ginecol Obstet. 2006;28(9):523-9.

Middlekauff ML, Egger MJ, Nygaard IE, et al. The impact of acute and chronic strenuous exercise on pelvic floor muscle strength and support in nulliparous healthly women. Am J Obstet Gynecol. 2016;215:316-17.

Montenegro CAB, Rezende Filho J. Obstetrícia fundamental. $13^{\mathrm{a}}$ ed. Rio de Janeiro: Guanabara Koogan; 2014. Modificações do organismo materno; p. 88-94.

Moore K, Dumoulin C, Bradley C, Burgio K, Chambers T, Hagen S, et al. Adult conservative management. Abrams P, Cardozo L Khouy S, Wein A (eds): Incontinence $5^{\text {th }}$ edn Commitee. 2013;12:1101-227.

Mørkved S, Bø K, Schei B, Salvesen, K. Å. Pelvic floor muscle training during pregnancy to prevent urinary incontinence: a single-blind randomized controlled trial. Obstet Gynecol. 2003;101(2):313-19.

Obioha KC, Ugwu EO, Obi SN, Dim CC, Oguanuo TC. Prevalence and predictors of urinary/anal incontinence after vaginal delivery: prospective study of Nigerian women. Int Urogynecol J. 2015;26(9):1347-54.

Oliveira $\mathrm{CD}$, Lopes $\mathrm{MAB}$, Zugaib $\mathrm{M}$. Effects of pelvic floor muscle training during pregnancy. Clinics. 2007;62(4):439-46.

Oliveira C. Efeitos da cinesioterapia no assoalho pélvico durante o ciclo gravídico puerperal [dissertação]. São Paulo: Faculdade de Medicina da Universidade de São Paulo, 2006. 
Organização Mundial da Saúde-OMS. Assistência ao parto normal: um guia prático. Brasília (DF): OPAS/USAID: 1996. [OMS/SRF/MSM/96.24].

Örnö AK, Marsál K, Herbst A. Ultrasonographic anatomy of perineal structures during pregnancy and immediately following obstetric injury. Ultrasound Obstet Gynecol. 2008; 32(4):527-34.

Özdemır ÖÇ, Bakar Y, Özengın N, Duran B. The effect of parity on pelvic floor muscle strength and quality of life in women with urinary incontinence: a cross sectional study. $\mathrm{J}$ Phys Ther Scie. 2015;27(7): 2133.

Palmezoni VP, Santos MD, Pereira JM, Bernardes BT, Pereira-Baldon VS, Resende APM. Pelvic floor muscle strength in primigravidae and non-pregnant nulliparous women: a comparative study. Int Urogynecol J. 2016;28(1):131-137.

Parveen K, Momen A, Begum AA, Begum M. Prevalence of urinary tract infection during pregnancy. J Dhaka National Med Coll Hos. 2011;17(2):8-12.

Pedraza R, Nieto J, Ibarra S, Haas EM. Pelvic muscle rehabilitation: a standardized protocol for pelvic floor dysfunction. Adv Urol. 2014;487436.

Pelaez M, Gonzalez-Cerron S, Montejo R, Barakat R. Pelvic floor muscle training included in a pregnancy exercise program is effective in primary prevention of urinary incontinence: a randomized controlled trial. Neurourol Urodyn. 2014;33(1):67-71.

Petricelli CD, Resende APM, Elito Junior J, Araujo Junior E, Alexandre SM, Zanetti MRD et al. Distensibility and strength of the pelvic floor muscles of women in the third trimester of pregnancy. BioMed Res Int. 2014;437867.

Pretlove SJ, Thompson PJ, Toozs-Hobson PM, Radley S, Khan KS. Does the mode of delivery predispose women to anal incontinence in the first year postpartum? A comparative systematic review. BJOG. 2008;115(4):421-34.

Rahmani N, Mohseni-Bandpei MA. Application of perineometer in the assessment of pelvic floor muscle strength and endurance: a reliability study. J Bodyw MovTher. 2011;15(2):20914.

Rajeshkannan N, Pathmeswaran A. Prevalence of postpartum anal incontinence: a cross sectional study in Northern Sri Lanka. Ceylon Med J. 2013;58(2):76-9.

Rasmussen KM, Yaktine AL, editors; Institute of Medicine and National Research Council. Weight gain during pregnancy: reexamining the guidelines. Washington, D.C.: The National Academies Press; (c) 2009.

Ratto C, Litta F, ParelloA, Donisi L, De Simone V, Zaccone G. Sacral nerve stimulation in faecal incontinence associated with an anal sphincter lesion: a systematic review. Colorectal Dis. 2012;14(6):297-304. 
Reilly ETC, Freeman RM, Waterfield MR, Waterfield AE, Steggles P, Pedlar F. Prevention of postpartum stress incontinence in primigravidae with increased bladder neck mobility: a randomised controlled trial of antenatal pelvic floor exercises. BJOG. 2014;121(7):58-66.

Resende APM, Nakamura MU, Ferreira EAG, Petricelli CD, Alexandre SM, Zanetti MRD. Eletromiografia de superfície para avaliação dos músculos do assoalho pélvico feminino: revisão de literatura [internet]. Fisioterapia e Pesquisa; 2011;18(3):292-297. Disponível em: http://www.revistasusp.sibi.usp.br/pdf/fpusp/v18n3/16.pdf

Richter HE, Nager CW, Burgio KL, Whitworth R, Weidner AC, et al. Incidence and predictors of anal incontinence after obstetric anal sphincter injury in primiparous women. Female Pelvic Med Reconstr Surg. 2015;21(4):182-9.

Riesco MLG, Caroci ADS, Oliveira SMJVD, Lopes MHBDM. Perineal muscle strength during pregnancy and postpartum: the correlation between perineometry and digital vaginal palpation. Rev Lat-Am Enferm. 2010;18(6):1138-44.

Riesco MLG, Fernandes-Trevisan K, Leister N, Cruz CDS, Caroci ADS, Zanetti MRD. Incontinência urinária relacionada à força muscular perineal no primeiro trimestre da gestação: estudo transversal. Rev Esc Enferm USP. 2014;48(Esp):32-8.

Riesco MLG, Costa ASC, Almeida SFSD, Basile ALDO, Oliveira SMJVD. Episiotomia, laceração e integridade perineal em partos normais: análise de fatores associados. Rev Enferm. UERJ. 2011;19(1):77-83.

Rikard-Bell J, Iyer J, Rane A. Perineal outcome and the risk of pelvic floor dysfunction: a cohort study of primiparous women. Aust N Z J Obstet Gynaecol. 2014;54(4):371-6.

Rodríguez R, Alós R, Carceller MS, Solana A, Frangi A, Ruiz MD. et al. Incontinencia fecal posparto. Revisión de conjunto. Cir Esp. 2015;93(6):359-67.

Rogers RG, Leeman LM, Borders N, Qualls C, Fullilove AM, Teaf D. et al. Contribution of the second stage of labour to pelvic floor dysfunction: a prospective cohort comparison of nulliparous women. BJOG. 2014;121(9):1145-53.

Rojas RAG, Shek KL, Langer SM, Dietz HP. Prevalence of anal sphincter injury in primiparous women. Ultras Obstet Gynecol. 2013;42(4):461-66.

Romero-Cullerés G, Peña-Pitarch E, Jané-Feixas C, Arnau A, Montesinos J, AbenozaGuardiola M. Intra-rater reliability and diagnostic accuracy of a new vaginal dynamometer to measure pelvic floor muscle strength in women with urinary incontinence. Neurourol Urodyn. 2015;36(2):333-7.

Rørtveit G, Hannestad YS. Association between mode of delivery and pelvic floor dysfunction. Tidsskr Nor Laegeforen. 2014;134(19):1848-52.

Rortveit G, Daltveit AK, Hannestad YS, Hunskaar S. Urinary incontinence after vaginal delivery or cesarean section. N Engl J Med. 2003;348(10):900-7. 
Safarinejad, Kolahi, Hosseini. The effect of the mode of delivery on the quality of life, sexual function, and sexual satisfaction in primiparous women and their husbands. J Sex Med. 2009;6(6):1645-67.

Scarpa KP, Herrmannn V, Palma PCR, Rivetto CLZ, Morais S. Sintomas do trato urinário inferior três anos após o parto: estudo prospectivo. Rev Bras Ginecol Obstet. 2008;30(7):3559.

Singh N, Rashid M, Bayliss L, Graham P. Pelvic floor muscle training for female urinary incontinence: Does it work? Arch Gynecol Obstet, 2016;293(6):1263-9.

Silva NLS, Oliveira SMJVD, Silva FMBD \& Santos JD. O. Dispareunia, dor perineal e cicatrização após episiotomia. Rev Enferm UERJ. 2013;21(2):216-20.

Cohain JS. Perineal outcomes after practising with a perineal dilator. MIDIRS Midwifery Digest 2004;14(1):37-44.

Stephenson RG, O'Connor LJ. Fisioterapia aplicada à ginecologia e obstetrícia. 9a ed. Barueri, SP: Manole; 2004. Fisioterapia e pacientes do sexo feminino: Avaliação e tratamento; p.65-150.

Subak LL, Richter HE, Hunskaar S. Obesity and urinary incontinence: epidemiology and clinical research update. J Urol. 2009;182(6Suppl):S2-7.

Sultan AH. Obstetric perineal injury and anal incontinence. Clin Risk. 1999;5:193-6.

Sut HK, Kaplan PB. Effect of pelvic floor muscle exercise on pelvic floor muscle activity and voiding functions during pregnancy and the postpartum period. Neurourol Urodyn. 2016;35:417-22.

Suzuki T, Yasuda K, Yamanishi T, Kitahara S, Nakai H, Yamashita T et al. A cross-over study for evaluation of functional continuous magnetic stimulation (FCMS) in patients with urinary incontinence on pelvic floor muscle exercise (PFME). ICS and IUGA, 574-5; 2004. Available from: https://www.ics.org/2004/slot/3965

Tamanini JT, Dambros M, D’Ancona CA, Palma PC, Rodrigues Netto Jr. N, Validação para o português do "International Consultation on Incontinence Questionnaire - Short Form" (ICIQSF). Rev Saude Publica. 2004;38(3):438-44.

Tennfjord MK, Hilde G, Stær-Jensen J, Engh ME, Bø K. Dyspareunia and pelvic floor muscle function before and during pregnancy and after childbirth. Inter Urogynecol J. 2014;25(9):1227-35.

Thompson JA, O'Sullivan PB, Briffa NK \& Neumann P. Differences in muscle activation patterns during pelvic floor muscle contraction and Valsalva manouevre. Neurourol Urodyn. 2006;25(2):148-55. 
Torrisi G, Minini G, Bernasconi F, Perrone A, Trezza G, Guardabasso V, et al. A prospective study of pelvic floor dysfunctions related to delivery. Eur J Obstet Gynecol Reprod Biol. 2012;160(1):110-5.

Tosun OC, Solmaz U, Ekin A, Tosun G, Gezer C, Ergenoglu AM, et al. Assessment of the effect of pelvic floor exercises on pelvic floor muscle strength using ultrasonography in patients with urinary incontinence: a prospective randomized controlled trial. T Physical Therapy Science. [internet]. 2016. Disponível em: http://creativecommons.org/licenses/by-nc$\underline{\mathrm{nd} / 4.0 /}$.

Trevisan KF. Força muscular perineal e incontinencia urinária e anal na gestação: estudo de corte. [tese] São Paulo: Escola de Enfermagem, Universidade de São Paulo, 2015.

Valeton CT, Amaral VFD. Evaluation of urinary incontinence in pregnancy and postpartum in Curitiba Mothers Program: a prospective study. Int Urogynecol J. 2011;22(7):813-18.

Vasconcelos ECLM, Ribeiro AM. Força e função muscular do assoalho pélvico: como avaliar? Fisiot Bras. 2013;14(6):469-73.

Viellas EF, Domingues RMSM, Dias MAB, Gama SN, Theme Filha MM, Costa JV, et al. Assistência pré-natal no Brasil. Cad. Saúde Pública. 2014;30 Supp11:85-100.

Walt IVD, Bø K, Hanekom S, Rienhardt G. Ethnic differences in pelvic floor muscle strength and endurance in South African women. Int Urogynecol J. 2014;25(6):799-805.

Wang X, Li GY, Deng ML. Pelvic floor muscle training as a persistent nursing intervention: effect on delivery outcome and pelvic floor myodynamia. Int J Nurs Sci. 2014;1(1):48-52.

Wood J, Amos L, Rieger N. Third degree anal sphincter tears: risk factors and outcome. J Obstet Gynaecol. 1998;38(4):414-17.

World Health Organization(WHO). Preventing and managing the global epidemic: report of Consultation. World Health Organization Tech Rep Ser. 1998;894..

Yeniel AO, Petri E. Pregnancy, childbirth, and sexual function: perceptions and facts. Int Urogynecol J. 2014;25(1):5-14.

Yohay D, Weintraub AY, Mauer-Perry N, Peri C, Kafri R, Yohay Z, et al. Prevalence and trends of pelvic floor disorders in late pregnancy and after delivery in a cohort of Israeli women using the PFDI-20. Eur J Obstet Gynecol Reprod Biol. 2016;200:35-39.

Zanetti MRD, Castro RDA, Rotta AL, Santos PDD, Sartori M, Girão MJBC. Impact of supervised physiotherapeutic pelvic floor exercises for treating female stress urinary incontinence. Sao Paulo Med J. 2007;125(5):265-9.

Zizzi PT, Trevisan KF, Leister N, Cruz CS, Riesco MLG. Women's pelvic floor muscle strength and urinary and anal incontinence after childbirth: a crosssectional study. Rev Esc Enferm USP. 2017;51:e03214. 


\section{APÊNDICE 1}

\section{FORMULÁRIO}

DADOS DA MATERNIDADE - ETAPA 1 -

Data entrevista:

1. Registro Hospitalar:

3. UBS de Origem:
2. Nome Endereço:

Ponto de referência:

Telefone residencial: Telefone celular:

Telefone de recado: Falar com:

e-mail/Facebook:

4. Idade materna: anos

\section{Situação conjugal:}

0 ( ) não tem parceiro

1 ( ) tem parceiro

6. Ocupação:

0 ( ) Estudante

1 ( ) Do lar

2 ( ) Trabalho remunerado

Especificar o trabalho:

7. Escolaridade: anos de estudo

0 ( ) nenhuma

1 ( ) ensino fundamental incompleto

2 ( ) ensino fundamental completo

3 ( ) ensino médio incompleto

4 ( ) ensino médio completo

5 ( ) ensino superior incompleto

6 ( ) ensino superior completo

7 ( ) pós-graduação incompleta

8 ( ) pós-graduação completa

8. Cor/raça:

0 ( ) preta

1( ) parda

2 ( ) branca

\section{DADOS DO PARTO}

9. Internação: __ _

10. Idade gestacional:

11. Peso na internação:

12.Tipo de parto:

I__ $; \ldots$ dias g;

12a. Normal:

0 ( ) não

1 ( ) $\operatorname{sim}$

12b - Posição materna durante o parto

13 - Anestesia:

13a - Local:

0 ( ) não

1 ( ) $\operatorname{sim}$

13b - Peridural: 
0 ( ) não

1 ( ) sim

13c - Raquidiana:

0 ( ) não

1 ( ) $\operatorname{sim}$

14. Intervenções:

14a. Ocitocina:

0 ( ) não 1( ) sim

14b - Misoprostol:

0 ( ) não 1( ) sim

14d - Puxo involuntário:

0 ( ) não referido 1( ) não registrado

2 ( ) sim referido 3( ) sim registrado

14e - Puxo dirigido:

0 ( ) não referido 1( ) não registrado

2( ) sim referido 3( ) sim registrado

14f - Manobra de Kristeller:

0 ( ) não referido 1( ) não registrado

2 ( ) sim referido 3( ) sim registrado

15. Condições do períneo:

0 ( ) - Íntegro:

1( ) -Laceração de $1^{0}$ grau:

2( ) - Laceração de $2^{0}$ grau:

3( ) - Laceração de $3^{0}$ grau:

4( ) - Laceração de $4^{0}$ grau:

5( ) - Episiotomia médio-lateral direita:

15a - Sutura das lacerações:

0 ( ) não

1 ( ) sim Outra:

16. Características do recém-nascido:

16a. Ápgar $1^{0}$ minuto:

16b. Ápgar $5^{0}$ minuto:

16c. Peso do RN:

16d. Circunferência cefálica: cm

ENTREVISTA APÓS O PARTO ETAPA 2

Data ________ Dias após o parto:

\section{DADOS DO PN}

17. Peso na $1^{\text {a }}$ consulta de Pré-natal:

18. Na gestação você teve:

18a - Infecção do trato urinário (ITU):

0 ( ) não

1 ( ) $\operatorname{sim}$

$\mathbf{1 8 b}$ - Teve ITU recorrente?

0 ( ) não

1 ( ) $\operatorname{sim}$

18c- Tratou:

0 ( ) não 
$1($ ) $\operatorname{sim}$

2 ( ) não se aplica

19. Durante a gestação você fez exercício perineal?

19a - Realizou exercícios perineais?

0 ( ) não

1 ( ) sim

19b - Realizou exercícios de Kegel?

0 ( ) não

1 ( ) $\operatorname{sim}$

19c - Consegue segurar o jato urinário?

0 ( ) não

1 ( ) $\operatorname{sim}$

19d - Outros sintomas?

0 ( ) não

1 ( ) $\operatorname{sim}$

Especificar:

\section{DADOS DO PUERPÉRIO}

20. Após o parto você teve:

20a -Teve infecção do trato urinário (ITU)?

0 ( ) não

1 ( ) $\operatorname{sim}$

20b -Teve ITU recorrente?

0 ( ) não

1 ( ) $\operatorname{sim}$

20c -Teve outros sintomas?

0 ( ) não

1 ( ) sim Especificar:

20d - Tratou?

0 ( ) não

1 ( ) $\operatorname{sim}$

2 ( ) não se aplica

21. Você fez exercício perineal após o parto?

21a - Realizou exercícios perineais?

0 ( ) não

1 ( ) $\operatorname{sim}$

21b - Realizou exercícios de Kegel?

0 ( ) não

1 ( ) $\operatorname{sim}$

21c - Consegue segurar o jato urinário?

0 ( ) não

1 ( ) $\operatorname{sim}$

21d - outro:

Especificar:

22. Atividade sexual:

22a - Idade da $1^{\text {a }}$. menstruação: anos.

22b - Idade da $1^{a}$. relação sexual:___ anos.

22c - Tempo de Atividade sexual ativa:___ anos.

22d - Retornou sua atividade sexual após o parto?

0 ( ) não Motivo? (ir para 26) 
$1($ ) $\operatorname{sim}$

22e - Tem dor durante a relação sexual?

0 ( ) não 2( ) não se aplica

1 ( ) $\operatorname{sim}$

23. Você faz uso de algum anticoncepcional?

0 ( ) não

1 ( ) $\operatorname{sim}$

23a - Uso: 2 ( ) esporadicamente 3 ( ) rotineiramente

Especificar qual:

\section{Consumo:}

24a - Você fuma?

0 ( ) não

1 ( ) $\operatorname{sim}$

2( ) todos os dias

$3($ ) às vezes

4( ) não se aplica

24b - Usa Drogas?

0 ( ) não

1 ( ) $\operatorname{sim}$

2( ) todos os dias

3( ) às vezes

4( ) não se aplica

$\mathbf{2 4 c}$ - Faz uso de álcool?

0 ( ) não

1 ( ) $\operatorname{sim}$

2( ) todos os dias

3( ) às vezes

4( ) não se aplica

25. Sintomas do trato gênito-urinário e anal:

25a - Tinha perda urinária antes da gestação?

0 ( ) não

$1($ ) $\operatorname{sim}$

25b - Teve perda de urina durante a gestação?

0 ( ) não

1 ( ) $\operatorname{sim}$

25c - Teve perda de urina logo após o parto?

0 ( ) não

1 ( ) $\operatorname{sim}$

25d - Você ainda perde urina involuntariamente?

0 ( ) não

1 ( ) $\operatorname{sim}$ (aplicar ICIQ-SF)

25e - Depois do parto você teve dificuldade para controlar a perda de gases?

0 ( ) não

1 ( ) $\operatorname{sim}$

Quando isso ocorre?

$\mathbf{2 5 f}$ - Ainda continua com essa perda?

0 ( ) não

1 ( ) $\operatorname{sim}$

Quando isso ocorre?

$\mathbf{2 5 g}$ - Depois do parto você teve dificuldade para controlar a perda de fezes? 
0 ( ) não

1 ( ) $\operatorname{sim}$

Quando isso ocorre?

25h - Ainda continua com essa perda?

0 ( ) não

1 ( ) $\operatorname{sim}$

Quando isso ocorre?

27. Exame físico

27a - Peso materno:

27b - Altura: g

27c - Índice de massa corpórea:

27d - Diferença de peso entre o início da gestação e o peso na internação: g

28. Perineometria (PE)

Mensuração da FMAP durante uma contração voluntária:

28a - $1^{\text {a }}$. Sessão: $\mathrm{cmH}_{2} \mathrm{O}$

28b - 2 $2^{\text {a }}$. Sessão: $\mathrm{cmH}_{2} \mathrm{O}$

$28 c$ - $3^{\text {a }}$. Sessão: $\mathrm{cmH}_{2} \mathrm{O}$

28d - Maior Valor da FMAP: $\mathrm{cmH}_{2} \mathrm{O}$

\section{ENTREVISTA APÓS O PARTO ETAPA 3}

Data Dias após o parto

29. Após a última consulta você teve:

29a - Infecção do trato urinário (ITU)?

0 ( ) não

1 ( ) $\operatorname{sim}$

29b -Teve ITU recorrente?

0 ( ) não

1 ( ) $\operatorname{sim}$

29c-Teve outros sintomas?

0 ( ) não

1 ( ) sim Especificar:

29d-Tratou?

0 ( ) não

1 ( ) $\operatorname{sim}$

2 ( ) não se aplica

30. Exercício perineal após a última consulta:

30a - Realizou exercícios perineais?

0 ( ) não

1 ( ) $\operatorname{sim}$

30b - Realizou exercícios de Kegel?

0 ( ) não

1 ( ) $\operatorname{sim}$

30c - Consegue segurar o jato urinário?

0 ( ) não

1 ( ) $\operatorname{sim}$

31. Atividade sexual

31a - Mantém atividade sexual após última consulta:

0 ( ) não Qual o motivo? \{ir para 26\}

1 ( ) $\operatorname{sim}$

31b - Tem dor durante a relação sexual?

0 ( ) não 
1 ( ) $\operatorname{sim}$

32. Você faz uso de algum anticoncepcional?

0 ( ) não

1 ( ) $\operatorname{sim}$

32a - Uso: 3 ( ) esporadicamente

4 ( ) rotineiramente

Especificar qual:

\section{Consumo:}

33a - Você fuma?

0 ( ) não

1 ( ) $\operatorname{sim}$

2( ) todos os dias

3 ( ) às vezes

4( ) não se aplica

33b - Usa Drogas:

0 ( ) não

1 ( ) $\operatorname{sim}$

33c-Faz uso de Álcool?

$1($ ) $\operatorname{sim}$

2( ) todos os dias

$3($ ) às vezes

4( ) não se aplica

34. Sintomas do trato gênito-urinário e anal:

34a - Você ainda perde urina involuntariamente?

0 ( ) não

1 ( ) $\operatorname{sim}$ (aplicar ICIQ-SF)

34b - Depois da última consulta você teve dificuldade para controlar a perda de gases?

0 ( ) não

$1($ ) $\operatorname{sim}$

Quando isso ocorre?

34c - Ainda continua com essa perda?

0 ( ) não

1 ( ) $\operatorname{sim}$

Quando isso ocorre?

34d - Depois da última consulta você teve dificuldade para controlar a perda de fezes:

0 ( ) não

1 ( ) $\operatorname{sim}$

Quando isso ocorre?

34e - Ainda continua com essa perda?

0 ( ) não

1 ( ) $\operatorname{sim}$

Quando isso ocorre?

\section{Exame físico}

35a- Peso materna:

35b - Altura: g

35c - Índice de massa corpórea:

35d - Diferença de peso entre etapa 2 e etapa 3:

37. Perineometria (PE)

Mensuração da FMAP durante uma contração voluntária:

36a - $1^{\mathrm{a}}$. Sessão: $\mathrm{cmH}_{2} \mathrm{O}$ 
36b - 2 $2^{\mathbf{a}}$. Sessão:

$\mathrm{cmH}_{2} \mathrm{O}$

36c - $3^{\text {a }}$. Sessão:

$\mathrm{cmH}_{2} \mathrm{O}$

36d - Maior Valor da FMAP: $\mathrm{cmH}_{2} \mathrm{O}$ 


\section{APÊNDICE 2 \\ TERMO DE CONSENTIMENTO LIVRE E ESCLARECIDO}

Eu, Sheyla Guimarães Oliveira, enfermeira obstétrica e estudante de mestrado da Escola de Enfermagem da Universidade de São Paulo, venho convidá-la a participar da pesquisa: "Força muscular do assoalho pélvico de primíparas segundo o tipo de parto: estudo de coorte". Estão sendo convidadas a participar desta pesquisa as mães que tiveram o primeiro filho na Maternidade Municipal Zoraide Eva das Dores/Itapecerica da Serra e que aceitarem a participar da pesquisa.

O motivo de realizar este estudo é porque a gravidez e o parto podem influenciar na função sexual das mulheres e na força dos músculos localizados na região da vagina que ajudam a sustentar a pelve e segurar urina e fezes. Para verificar a força desses músculos será utilizado um aparelho eletrônico que mede a contração dos músculos através de uma sonda introduzida na vagina. Esse procedimento não dói e não traz nenhum risco para sua saúde atual ou futura. Serão realizadas três medidas da força muscular em um único momento. Na presença de qualquer alteração você será encaminhada para assistência especializada, conforme o fluxo das Unidades Básica de Saúde do município.

Após entrevista (5 a 10 minutos) será realizado um exame físico para medir a força dos músculos, com duração de 25 a 30 minutos, em um consultório na UBS ou na maternidade onde ganhou bebê, garantindo sua privacidade.

Os resultados desta pesquisa serão utilizados em um estudo científico e apresentados em congressos, revistas da área da saúde, mantendo sigilo da sua identidade. Esta pesquisa não tem fins lucrativos ou qualquer conflito de interesse com os serviços de saúde que lhe prestam atendimento, garantindo a sua assistência sem quaisquer prejuízos, mesmo que você venha a desistir da pesquisa.

Você será esclarecida sobre a pesquisa em qualquer aspecto que desejar. Você é livre para recusar-se a participar, retirar seu consentimento ou interromper a participação a qualquer momento. A sua participação é voluntária e a recusa em participar não irá acarretar qualquer penalidade e perda de benefícios. Uma cópia deste termo de consentimento será arquivada pela pesquisadora e outra será fornecida a você. A participação no estudo não terá custo para você e não será oferecida nenhuma compensação financeira.

$\mathrm{Eu}$ , fui informada dos objetivos da pesquisa acima de maneira clara e detalhada e esclareci minhas dúvidas. Sei que em qualquer momento poderei solicitar novas informações e modificar minha decisão, se assim desejar. Em caso de dúvidas poderei chamar a pesquisadora Sheyla Guimarães Oliveira por telefone (011968176535) ou e-mail: (sheylaenf@hotmail.com) ou o Comitê de Ética e Pesquisa da Escola de Enfermagem da Universidade de São Paulo, à Av. Dr. Enéas de Carvalho Aguiar, 419, São Paulo, SP. Telefone: 11-30617548; e-mail: edipesq@usp.br.

Declaro que concordo em participar desse estudo. Recebi uma cópia deste termo de Consentimento Livre e Esclarecido e me foi dada a oportunidade de lê-lo e de esclarecer as minhas dúvidas.

Participante:

Assinatura:

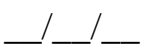

Pesquisadora: Sheyla Guimarães Oliveira

Assinatura:

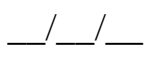




\section{APÊNDICE 3 \\ TERMO DE ASSENTIMENTO}

Olá, meu nome é Sheyla Guimarães Oliveira, enfermeira obstétrica e estudante de mestrado da Escola de Enfermagem da Universidade de São Paulo, venho convidá-la a participar da pesquisa: "Força muscular do assoalho pélvico de primíparas no puerpério segundo o tipo de parto: estudo de coorte". Estão sendo convidadas a participar desta pesquisa as mães que tiveram o primeiro filho na Maternidade Municipal Zoraide Eva das Dores/Itapecerica da Serra e que aceitarem a participar da pesquisa.

O motivo de realizar este estudo é porque a gravidez e o parto podem influenciar na função sexual das mulheres e na força dos músculos localizados na região da vagina que ajudam a sustentar a pelve e segurar urina e fezes. Para verificar a força desses músculos será utilizado um aparelho eletrônico que mede a contração dos músculos através de uma sonda introduzida na vagina. Esse procedimento não dói e não traz nenhum risco para sua saúde atual ou futura. Serão realizadas três medidas da força muscular em um único momento. Na presença de qualquer alteração você será encaminhada para assistência especializada, conforme o fluxo das Unidades Básica de Saúde do município.

Após entrevista (5 a 10 minutos) será realizado um exame físico para medir a força dos músculos, com duração de 25 a 30 minutos, em um consultório na UBS ou na maternidade onde ganhou bebê, garantindo sua privacidade.

Os resultados desta pesquisa serão utilizados em um estudo científico e apresentados em congressos, revistas da área da saúde, mantendo sigilo da sua identidade. Esta pesquisa não tem fins lucrativos ou qualquer conflito de interesse com os serviços de saúde que lhe prestam atendimento, garantindo a sua assistência sem qualquer prejuízo, mesmo que você venha a desistir da pesquisa.

Você será esclarecida sobre a pesquisa em qualquer aspecto que desejar. Você é livre para recusar-se a participar, retirar seu consentimento ou interromper a participação a qualquer momento. A sua participação é voluntária e a recusa em participar não irá acarretar qualquer penalidade e perda de benefícios. A participação no estudo não terá custo para você e não será oferecida nenhuma compensação financeira.

$\mathrm{Eu}$ , fui informada dos objetivos da pesquisa acima de maneira clara e detalhada e esclareci minhas dúvidas. Sei que em qualquer momento poderei solicitar novas informações e modificar minha decisão, se assim desejar. Em caso de dúvidas poderei chamar a pesquisadora Sheyla Guimarães Oliveira por telefone (011 968176535) ou e-mail: (sheylaenf@hotmail.com) ou o Comitê de Ética e Pesquisa da Escola de Enfermagem da Universidade de São Paulo, à Av. Dr. Enéas de Carvalho Aguiar, 419, São Paulo, SP. Telefone: 11-30617548; e-mail: edipesq@usp.br.

Declaro que concordo em participar desse estudo. Recebi uma cópia deste termo de Consentimento Livre e Esclarecido e me foi dada a oportunidade de lê-lo e de esclarecer as minhas dúvidas.

Participante:

Responsável pelo menor

Pesquisadora: Sheyla Guimarães Oliveira
Assinatura:

Assinatura:

Assinatura:

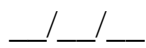
$1-1$

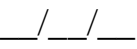


ANEXO 1

FOLHETO COM ORIENTAÇÕES DE EXERCÍCIOS PERINEAIS
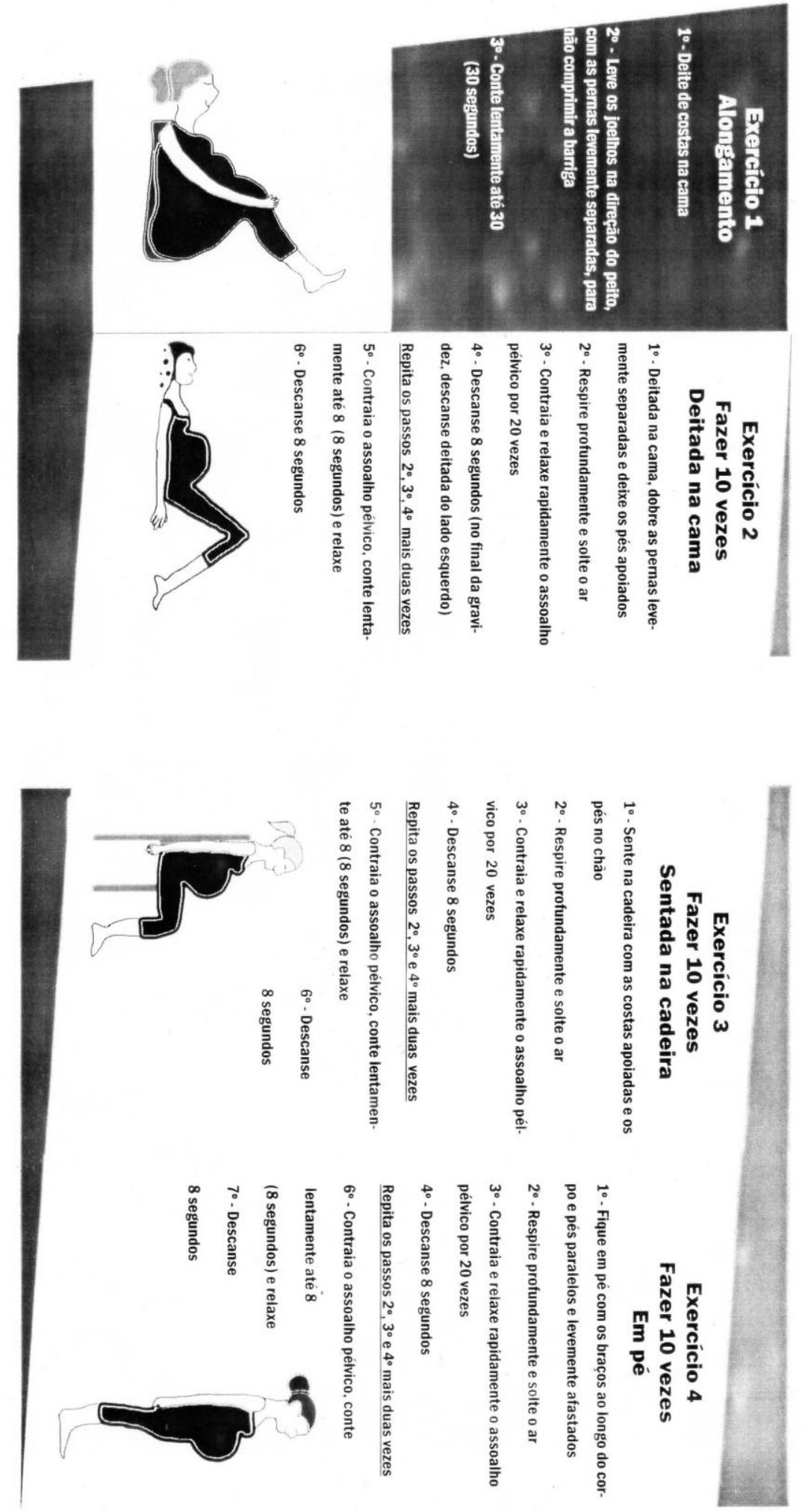


\section{ANEXO 2 \\ INTERNATIONAL CONSULTATION ON INCONTINENCE QUESTIONNAIRE - SHORT - FORM (ICIQ-SF)}

Nome do Paciente:

Data de Hoje:

Muitas pessoas perdem urina alguma vez. Estamos tentando descobrir quantas pessoas perdem urina e o quanto isso as aborrece. Ficaríamos agradecidos se você pudesse nos responder às seguintes perguntas, pensando em como você tem passado, em média nas ÚLTIMAS QUATRO SEMANAS.

1. Data de Nascimento:

2. Sexo: Feminino ( Dia / Mês / Ano )

3. Com que freqüêcia voce perde urina? (assinale uma resposta)

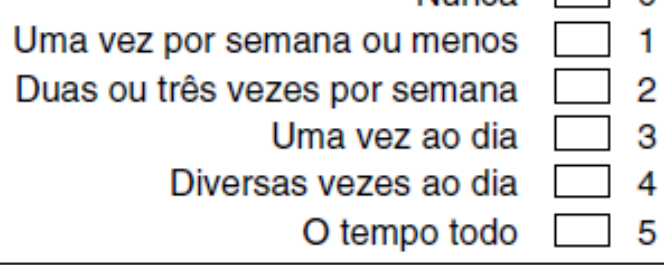

4. Gostaríamos de saber a quantidade de urina que você pensa que perde (assinale uma resposta)

Nenhuma $\square 0$
Uma pequena quantidade $\square 2$
Uma moderada quantidade $\square 4$
Uma grande quantidade $\square 6$

5. Em geral quanto que perder urina interfere em sua vida diária? Por favor, circule um número entre 0 (năo interfere) e 10 (interfere muito)

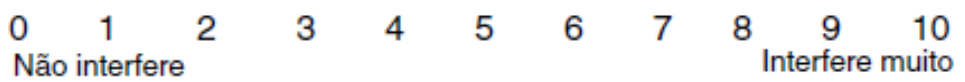

ICIQ Escore: soma dos resultados $3+4+5=$

6. Quando você perde urina?

(Por favor assinale todas as alternativas que se aplicam a você)

Nunca

Perco antes de chegar ao banheiro

Perco quando tusso ou espiro

Perco quando estou dormindo

Perco quando estou fazendo atividades físicas

Perco quando terminei de urinar e estou me vestindo

Perco sem razăo óbvia

Perco o tempo todo 


\section{ANEXO 3 \\ AUTORIZAÇÃO DO CONSELHO MUNICIPAL DE SAÚDE DA SECRETARIA MUNICIPAL DE SAÚDE DE ITAPECERICA DA SERRA}
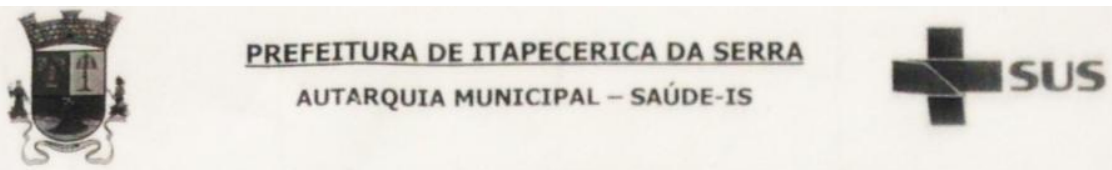

CONSELHO MUNICIPAL DE SAÚDE

REUNIÃO ORDINÁRIA -20 DE AGOSTO DE 2013

Em reunião ordinária do Conselho Municipal de Saúde de Itapecerica da Serra, nós, abaixo assinados, AUTORIZAMOS a realização do trabalho científico "Avaliação da força muscular perineal em primíparas pós-parto normal e cesariana" de Sonia Maria Junqueira Vasconcellos de Oliveira, Adriana de Souza Caroci da Costa, Maria Luiza Gonzáles Riesco e Edilaine de Paula Batista Mendes, alunas da Escola de Enfermagem da Universidade de São Paulo.

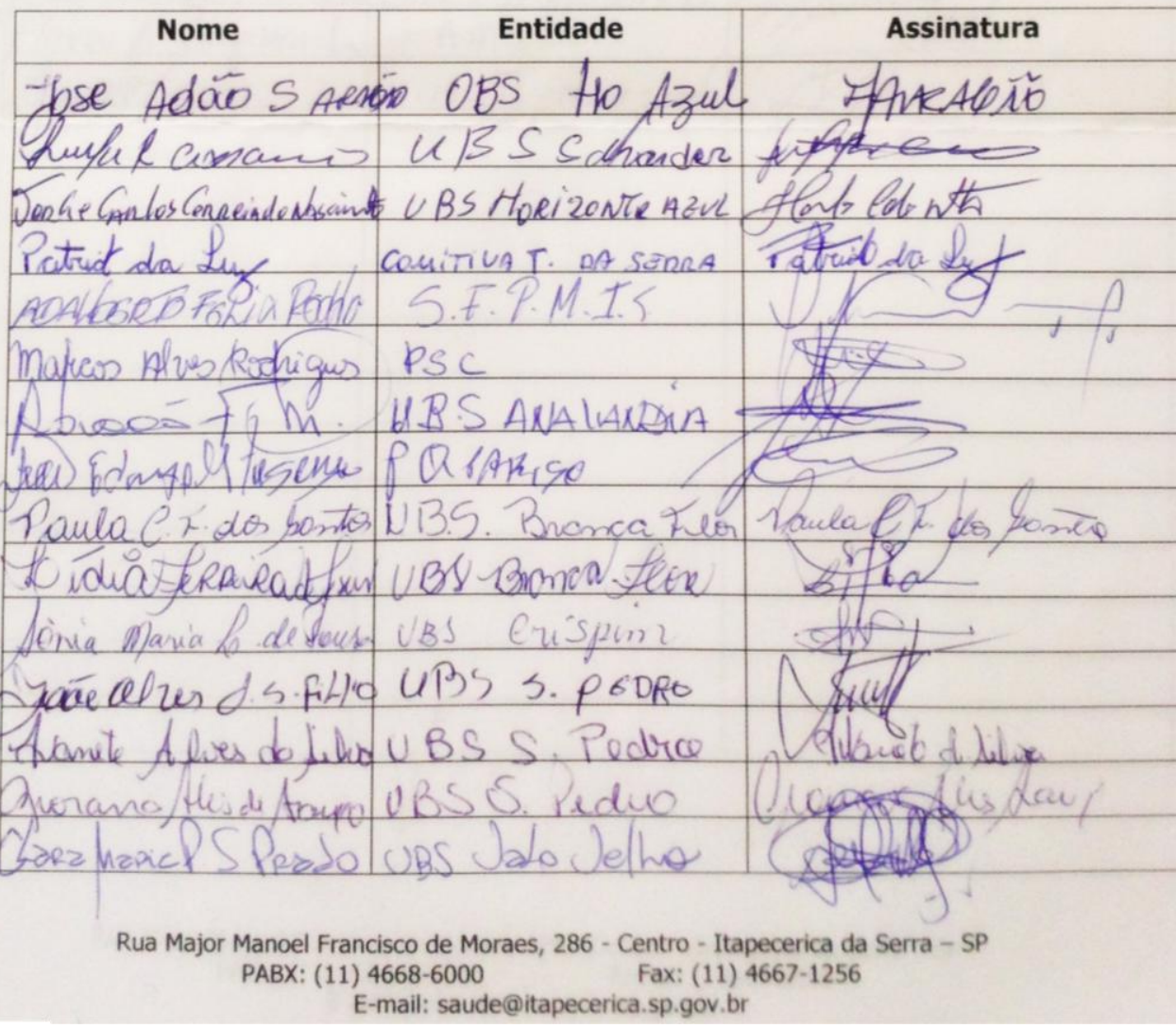




\title{
ANEXO 4 \\ PARECER COSUBSTANCIADO DO CEP
}

\author{
ESCOLA DE ENFERMAGEM DA \\ UNIVERSIDADE DE SÃO \\ PAULO - EEUSP
}

\section{PARECER CONSUBSTANCIADO DO CEP}

\section{DADOS DO PROJETO DE PESQUISA}

Título da Pesquisa: AVALIAÇÃo DA FORÇA MUSCULAR PERINEAL EM PRIMÍPARAS PÓS-PARTO NORMAL E CESARIANA

Pesquisador: Edilaine de Paula Batista Mendes

Área Temática:

Versão: 4

CAAE: 13545113.5 .0000 .5392

Instituição Proponente: Escola de Enfermagem da Universidade de São Paulo - EEUSP

Patrocinador Principal: Financiamento Próprio

\section{DADOS DO PARECER}

Número do Parecer: 527.273

Data da Relatoria: 11/02/2014

\section{Apresentação do Projeto:}

Trata-se de um estudo transversal para avaliar a força muscular perineal, com a finalidade de comparar a força muscular da região em dois grupos de mulheres por meio da perineometria e a partir dos dados, obter subsídios para a elaboração de programas para o fortalecimento da musculatura nas mulheres. A amostra será constituída por 99 puérperas e a coleta de dados se iniciará no momento da alta hospitalar com continuidade no momento de retorno à UBS para vacinação da criança.Critério de Inclusão: ter apenas um parto (normal ou cesariana); não ter tido gestação múltipla;não ter sido submetida à cirurgia abdominal ou urogenital prévia; estar entre 42 e 60 dias do pós-parto. Critério de Exclusão:ser portadora de doenças que podem interferir na FMP (prolapso de órgão pélvico, doenças neurológicas, diabetes, lesão pélvica ou da coluna vertebral); Oferecer resistência à inserção do perineômetro na vagina; ter dificuldade no entendimento do idioma português ou na comunicação, por diminuição da acuidade auditiva ou limitação da fala.

Objetivo da Pesquisa:

Objetivo Primário:

Avaliar a Força Muscular Perineal (FMP) em primíparas de acordo com o tipo de parto.

Objetivo Secundário:

Endereço: Av. Dr Enéas de Carvalho Aguiar, 419

Bairro: Cerqueira Cesar
UF: SP Município: SAO PAULO

Telefone: (11)3061-7548 Fax: (11)3061-7548 E-mail: edipesq@usp.br 


\section{ESCOLA DE ENFERMAGEM DA UNIVERSIDADE DE SÃO PAULO - EEUSP}

Continuaçăo do Parecer: 527.273

- Verificar a média da FMP em primíparas que tiveram parto normal e cesariana;

- Comparar a média da FMP no puerpério segundo tipo de parto,condições do períneo, peso do recémnascido, índice de massa corpórea, idade, cor e situação conjugal.

Avaliação dos Riscos e Benefícios:

De acordo com o pesquisador, a pesquisa não apresenta risco para os sujeitos. No entanto,descreve que se o sujeito apresentar desconforto será encaminhada para assistência especializada.

Benefícios: Fornecer dados para a construção do perfil da FMP em puérperas para elaboração de programas de treinamento para o fortalecimento do assoalho pélvico (AP), buscando contribuir com a prevenção, redução e cuidados de morbidades no trato genito-urinário.

Comentários e Considerações sobre a Pesquisa:

Projeto retorna ao CEP com emenda para alteração do tamanho amostral e mudança no momento de iniciar o recrutamento das puérperas (ocorrerá na alta hospitalar) para estabelecer

vínculo com as pacientes, garantir o $\mathrm{N}$ amostral e registrar os dados do parto com maior precisão. Por se tratar de primíparas, há a possibilidade de ter mulheres com idade menor que 18 anos, para tanto foi inserido o termo de Assentimento. $O$ retorno para a analise da Força muscular perineal, foi alterado para o período entre 50 e 70 dias, momento em que a mãe retorna a UBS para vacinar o bebê, portanto, não terão custos adicionais devido a pesquisa. Para melhor classificar as queixas urinarias, será utilizado um instrumento validado (ICIQ_SF), padronizando o tipo de perda urinaria das mulheres com queixas.

Considerações sobre os Termos de apresentação obrigatória:

Apresenta o TCLE e o Termo de assentimento para adolescentes gestantes.

Recomendações:

Não há.

Conclusões ou Pendências e Lista de Inadequações:

Mantém-se a aprovação do projeto.

Situação do Parecer:

Aprovado

Necessita Apreciação da CONEP:

Não

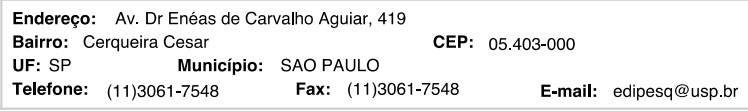

